\title{
Lava Lake Activity at the Summit of Kilauea Volcano in 2016
}

Scientific Investigations Report 2018-5008 
Cover. Photograph of the lava lake at Kilauea Volcano's summit, taken from the southeast rim of Halema'uma'u Crater. The view is towards the northwest, with the broad summit of Mauna Loa visible on the skyline. The lake is about 250 meters wide, across its longest axis. Matt Patrick, U.S. Geological Survey, September 28, 2016. 


\section{Lava Lake Activity at the Summit of Kïlauea Volcano in 2016}

By Matthew R. Patrick, Tim R. Orr, Donald A. Swanson, Tamar Elias, and Brian Shiro

Scientific Investigations Report 2018-5008 


\title{
U.S. Department of the Interior \\ RYAN K. ZINKE, Secretary
}

\section{U.S. Geological Survey \\ William H. Werkheiser, Deputy Director \\ exercising the authority of the Director}

\author{
U.S. Geological Survey, Reston, Virginia: 2018
}

For more information on the USGS-the Federal source for science about the Earth, its natural and living resources, natural hazards, and the environment-visit https://www.usgs.gov/ or call 1-888-ASK-USGS (1-888-275-8747).

For an overview of USGS information products, including maps, imagery, and publications, visit https://store.usgs.gov.

Any use of trade, firm, or product names is for descriptive purposes only and does not imply endorsement by the U.S. Government.

Although this information product, for the most part, is in the public domain, it also may contain copyrighted materials as noted in the text. Permission to reproduce copyrighted items must be secured from the copyright owner.

Suggested citation:

Patrick, M.R., Orr, T.R., Swanson, D.A., Elias, T., and Shiro, B., 2018, Lava lake activity at the summit of Kïlauea Volcano in 2016: U.S. Geological Survey Scientific Investigations Report 2018-5008, 58 p., https://doi.org/10.3133/ sir20185008.

ISSN 2328-0328 (online) 


\section{Contents}

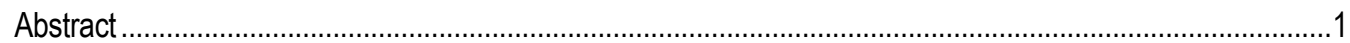

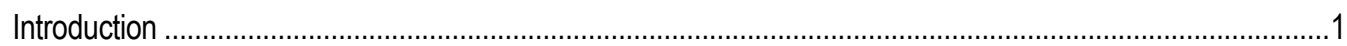

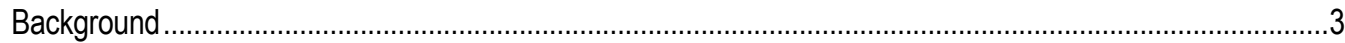

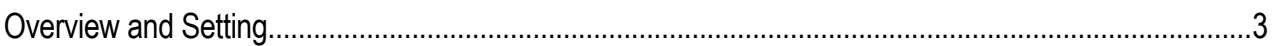

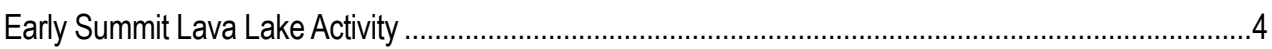

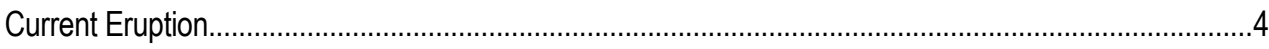

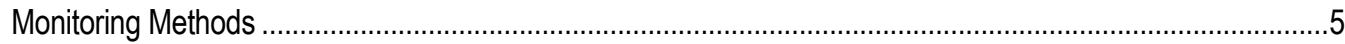

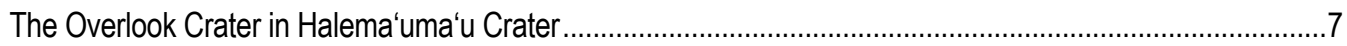

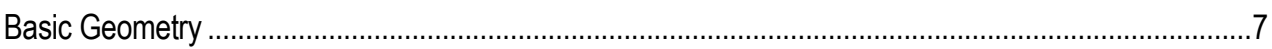

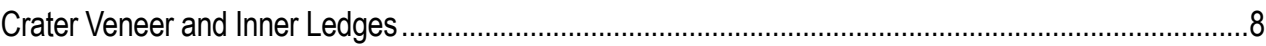

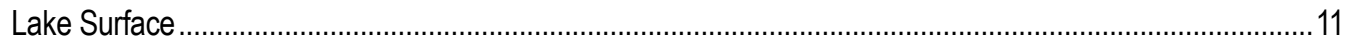

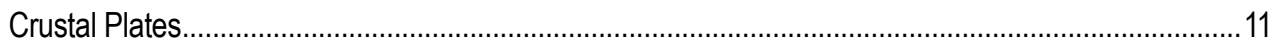

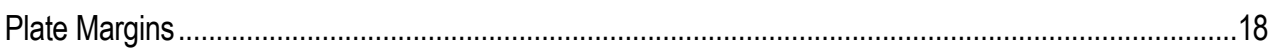

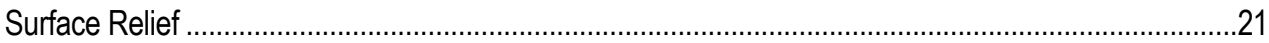

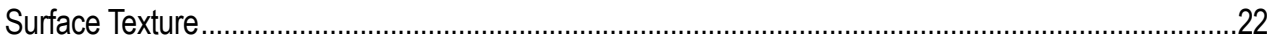

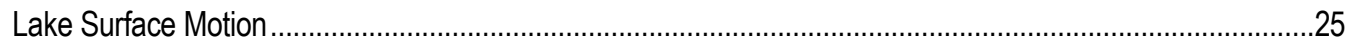

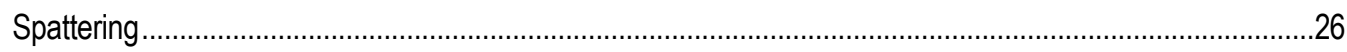

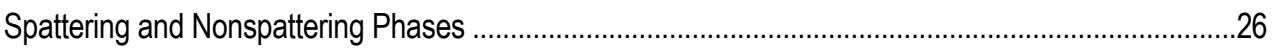

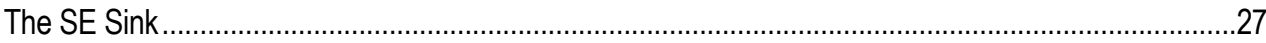

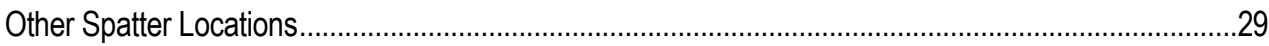

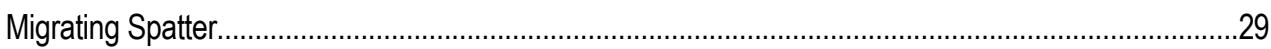

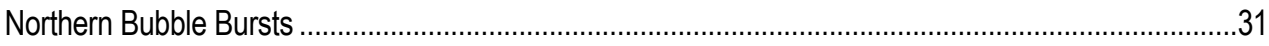

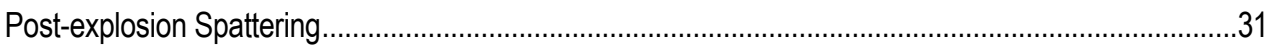

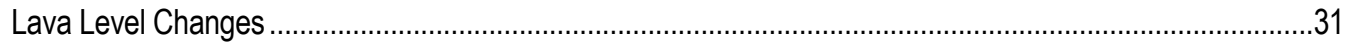

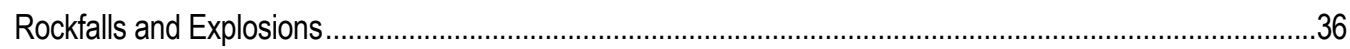

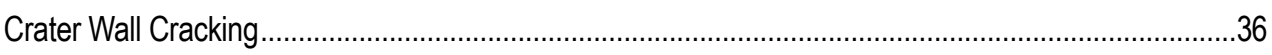

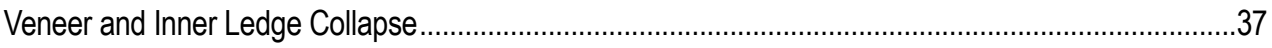

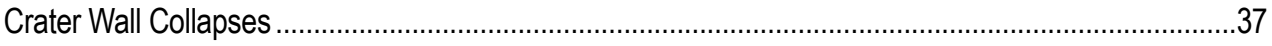

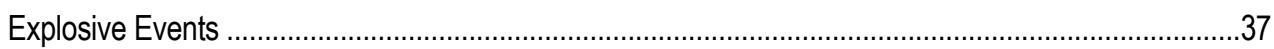

Tephra

Outgassing Plume

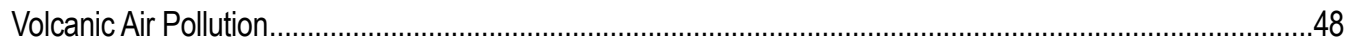

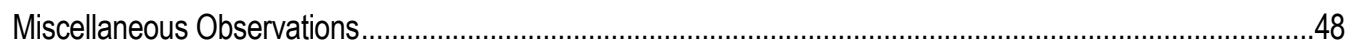

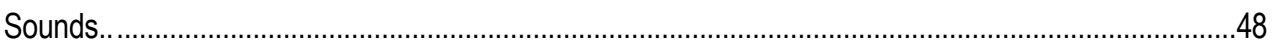

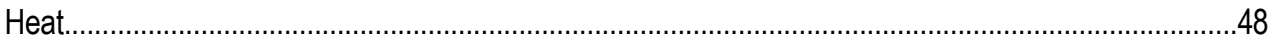

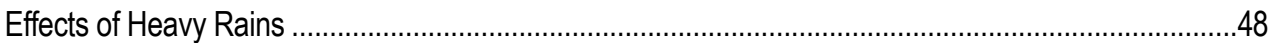

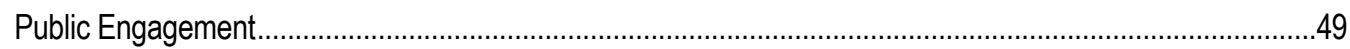

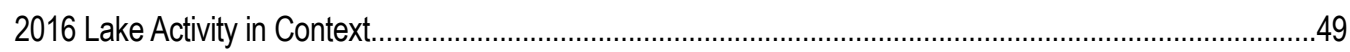

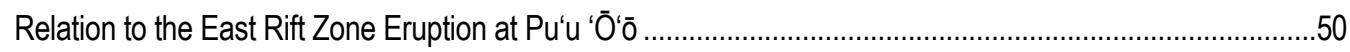

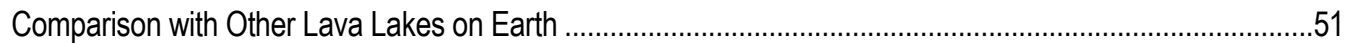

Conclusions

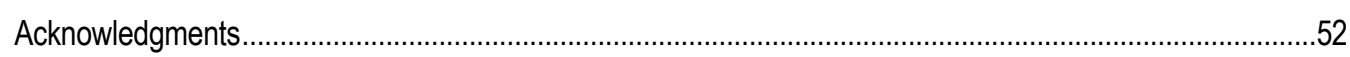

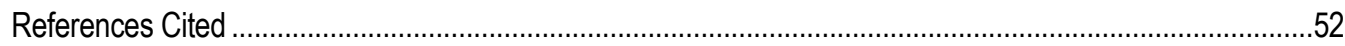

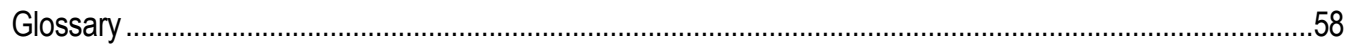




\section{Figures}

1. Map showing the location of Kîlauea Volcano and its summit vent .....................................................2

2. DigitalGlobe WorldView satellite image showing the Overlook crater in Halema'uma'u Crater...............3

3. Photographs showing measurements and observations at Halema'uma'u ...........................................6

4. Observations from the Hawaiian Volcano Observatory (HVO) ........................................................... 7

5. Photographs showing the webcams on the rim of Halema'uma'u Crater near the Overlook crater........7

6. Oblique aerial view of Halema'uma'u Crater, viewed from the east......................................................

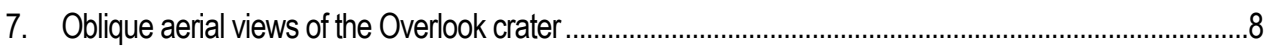

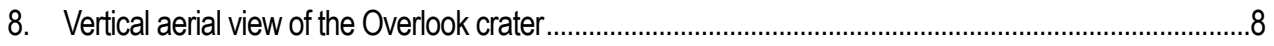

9. Photographs showing a cross section of the Overlook crater ................................................................

10. Photographs showing the lava veneer on the Overlook crater walls ..................................................9

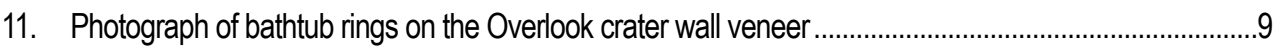

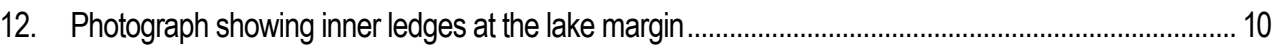

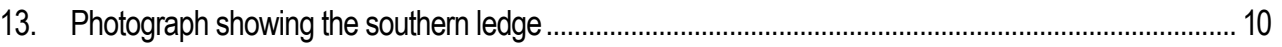

14. HTcam thermal image showing hot cracks developing on the southern ledge in the hours prior to

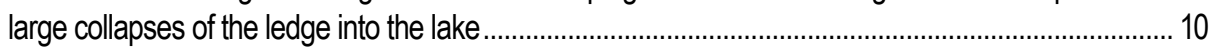

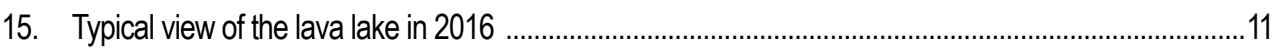

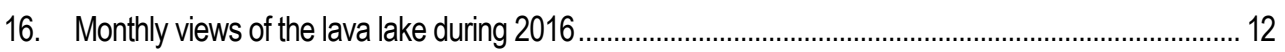

17. Satellite images of the lake in 2016 ....................................................................................... 13

18. Drawings of crustal plate outlines based on five high-resolution satellite images in 2016 .................. 14

19. Histograms of crustal plate measurements taken from WorldView images ........................................ 14

20. Image showing spreading zone replication and the formation of new plates...................................... 14

21. A sequence of HMcam images taken on December 18, 2016, showing new plates forming by

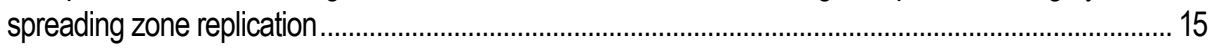

22. A sequence of HMcam images taken on December 18, 2016, showing new plates forming from

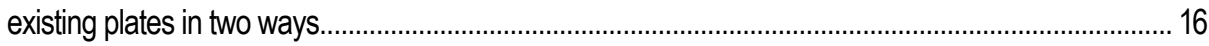

23. Images taken from HMcam and HTcam at roughly the same time showing the formation of a

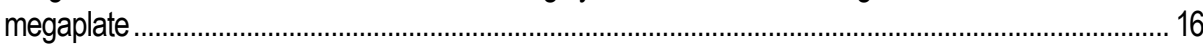

24. Sequence of HMcam images from December 21, 2016, showing a rockfall that triggered waves and sloshing of the lake surface and created many small plates ................................................................ 17

25. HMcam image from December 11, 2016, at 10:22 HST, showing a static plate at the lake margin ..... 17

26. Photographs showing the most common type of plate margin, simple spreading............................... 18

27. Photograph showing a pulled margin near the SE sink on December 12, 2016 ............................... 19

28. Photograph showing an example of strike-slip motion on a crustal plate margin, where only a minor amount of incandescent lava was exposed................................................................................ 19

29. Time-lapse images from December 12, 2016, at 17:11 HST, of a propagating crack in the crust........ 19

30. Time-lapse images showing crustal foundering, which normally occurred near the lake margins, particularly in the southern portion of the lake, as it is in this example from December 22, 2016........ 20

31. Photograph of quiescent downwelling at the lake margin, taken December 12, 2016, at 17:13 HST.. 20

32. Photograph showing small blisters on the lake surface ........................................................................ 21

33. Photographs showing small folds on the lake surface ....................................................................... 21

34. Photograph taken October 26, 2016, at 15:16 HST, showing the patchwork appearance of the lake

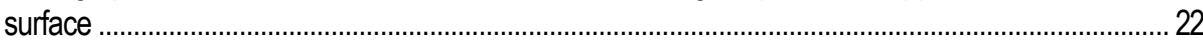

35. Photographs taken December 8, 2016, showing the provenance of crustal plate areas .................... 22

36. Photographs showing striations on the lake surface ....................................................................... 23

37. Photographs showing alternating bands of darkness parallel to the spreading zones......................... 23 
38. HMcam image from December 1, 2016, at 01:00 HST, showing pinholes on the lake surface............ 23

39. Sequence of images from December 22, 2016, showing proto-plates and their origin ........................ 24

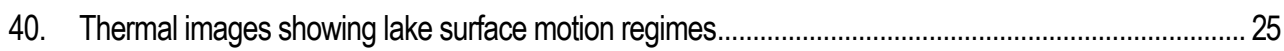

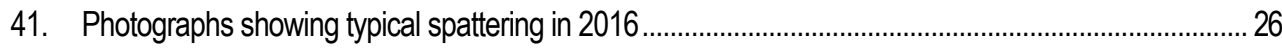

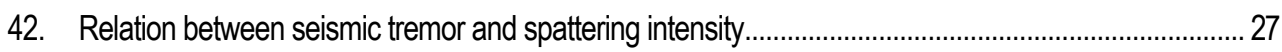

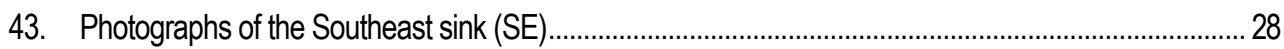

44. Photograph of a grotto surrounding the spattering in the SE sink.................................................. 28

45. Photograph of stalactites at the spatter grotto along the eastern lake margin on October $3,2016 \ldots . . .28$

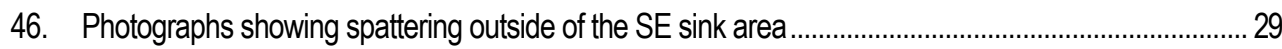

47. Sequence of images taken from the HMcam on December 20, 2016, showing spattering that appears along the northern lake margin split, with the eastern spatter site gradually migrating

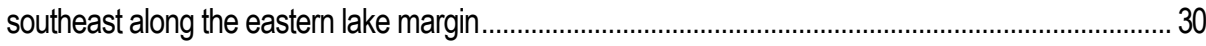

48. Photographs showing sporadic slug bursts in the upwelling zone.................................................... 31

49. Photographic sequence of a slug burst on December 22, 2016 .................................................. 32

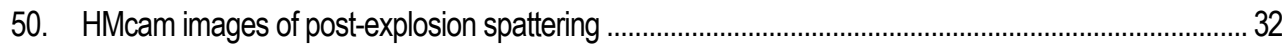

51. Thermal images from the HTcam showing the difference in lake level and appearance at the highest and lowest levels through the year ........................................................................................ 33

52. Plot of lava lake elevation, summit ground tilt, and seismicity ....................................................... 33

53. Monthly thermal camera images of the lava lake, showing level changes........................................ 34

54. Views of the lava lake from the Hawaiian Volcano Observatory .................................................... 35

55. Images from the HMcam show the differing lake level and appearance in September 2016.............. 35

56. K2cam webcam image showing a small overflow of lava onto the floor of Halema'uma'u Crater, taken on October 15, 2016, at 13:34 HST from the Hawailan Volcano Observatory tower .................. 35

57. Graphs showing increase in small earthquakes during periods of inflation and high lava level............ 36

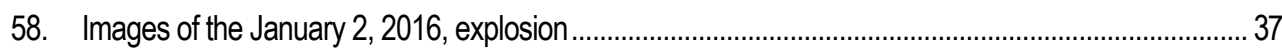

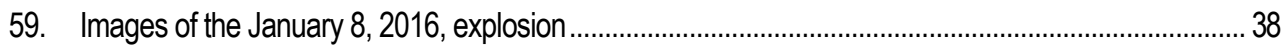

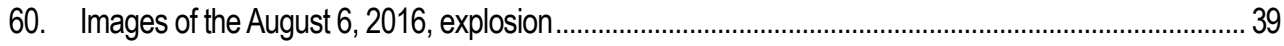

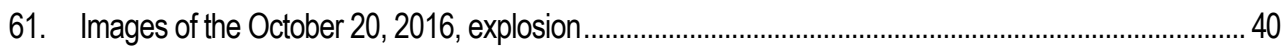

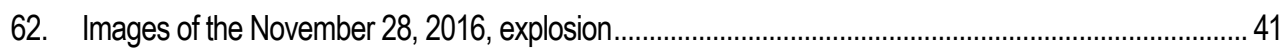

63. Composite seismic events associated with selected explosive events of 2016 .................................. 42

64. Photographs of tephra produced by continuous outgassing ............................................................ 42

65. Photograph of egg-shaped hollow glass spherule collected near the Halema'uma'u Overlook on

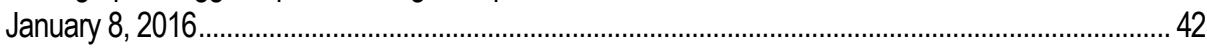

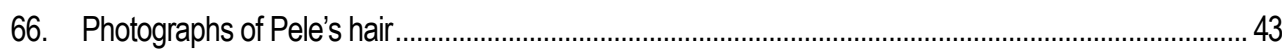

67. Photographs of carpet of Pele's hair downwind of lake ............................................................. 43

68. Photograph of a typical outgassing plume, taken from Uēkahuna Bluff, near the Hawaiian Volcano Observatory, March 20, 2016 ........................................................................................... 44

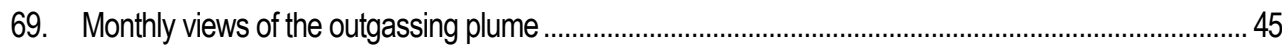

70. Photographs showing alternating trade wind and Kona wind effects on the plume.............................4 46

71. Photographs showing a vertical plume rise in slack winds............................................................. 46

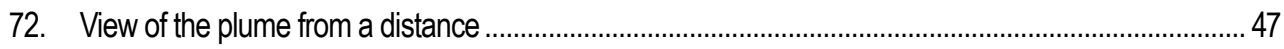

73. Photographs showing plume vigor changes in spattering and nonspattering phases.......................... 47

74. Photographs showing the robust portion of plume related to spattering.............................................. 47

75. Images of the lake surface immediately following unusually heavy rains............................................. 49

76. Photograph showing park visitors enjoying the view of the lake at the Jaggar Museum overlook,

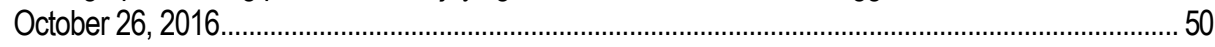

77. Photograph of the small lava lake in Pu'u 'Ō'ō crater, on Kilauea's East Rift Zone June 23, 2016 ...... 50 


\section{Table}

1. Summary of statistics for crustal plates in the lava lake at Overlook crater, Kîlauea Volcano, measured from high-resolution satellite data on five days in 2016 ... 


\title{
Lava Lake Activity at the Summit of Kîlauea Volcano in 2016
}

\author{
By Matthew R. Patrick, Tim R. Orr, Donald A. Swanson, Tamar Elias, and Brian Shiro
}

\section{Abstract}

The ongoing summit eruption at Kîlauea Volcano, Hawai' $i$, began in March 2008 with the formation of the Overlook crater, within Halema'uma'u Crater. As of late 2016, the Overlook crater contained a large, persistently active lava lake $(250 \times 190$ meters $)$. The accessibility of the lake allows frequent direct observations, and a robust geophysical monitoring network closely tracks subtle changes at the summit. These conditions present one of the best opportunities worldwide for understanding persistent lava lake behavior and the geophysical signals associated with open-vent basaltic eruptions. In this report, we provide a descriptive and visual summary of lava lake activity during 2016, a year consisting of continuous lava lake activity. The lake surface was composed of large black crustal plates separated by narrow incandescent spreading zones. The dominant motion of the surface was normally from north to south, but spattering produced transient disruptions to this steady motion. Spattering in the lake was common, consisting of one or more sites on the lake margin. The Overlook crater was continuously modified by the deposition of spatter (often as a thin veneer) on the crater walls, with frequent collapses of this adhered lava into the lake. Larger collapses, involving lithic material from the crater walls, triggered several small explosive events that deposited bombs and lapilli around the Halema'uma'u Crater rim, but these did not threaten public areas. The lava lake level varied over several tens of meters, controlled primarily by changes in summit magma reservoir pressure (in part driven by magma supply rates) and secondarily by fluctuations in spattering and gas release from the lake (commonly involving gas pistoning). The lake emitted a persistent gas plume, normally averaging $1,000-8,000$ metric tons per day $(\mathrm{t} / \mathrm{d})$ of sulfur dioxide $\left(\mathrm{SO}_{2}\right)$, as well as a constant fallout of small juvenile and lithic particles, including Pele's hair and tears. The gas emissions created volcanic air pollution (vog) that affected large areas of the Island of Hawai' $i$. The summit eruption has been a major attraction for visitors in Hawai' $i$ Volcanoes National Park. During 2016, the rising lake levels allowed the lake and its spattering to be more consistently visible from public viewing areas, enhancing the visitor experience. The U.S. Geological Survey's Hawaiian Volcano Observatory (HVO) closely monitors the summit eruption and keeps emergency managers and the public informed of activity.

\section{Introduction}

Lava lakes present a valuable opportunity for studying basaltic volcanism. The exposed lava surface provides a clear view of the uppermost magmatic system that, even at most open-vent volcanoes, is not normally available for direct observation. Lake activity may offer insights into the deeper magmatic system, providing important constraints on conduit dynamics, outgassing, and magmatic convection (Harris and others, 2005; Oppenheimer and others, 2009; Patrick and others, 2015). Despite the advantages of lava lakes as a research venue, relatively few long-term continuous observations exist in the modern record owing to the limited accessibility of most persistent lava lakes.

The first routine observations and measurements of lava lake activity anywhere on Earth were made at Kîlauea Volcano's summit, when a lava lake was present in Halema'uma'u Crater (fig. 1) during the early 1900s (Jaggar, 1947; Tilling and others, 2014). The Mauna Ulu eruption (1969-74) on Kīlauea's East Rift Zone provided another opportunity for detailed lava lake and lava pond observations, with descriptions of gas pistoning (Swanson and others, 1979) and the characterization of lake surface crust dynamics as an analogue to global plate tectonics (Duffield, 1972). More recently, studies performed in brief field campaigns have provided new details on activity at the Erta Ale (Ethiopia) and Nyiragongo (Democratic Republic of the Congo) lava lakes, aided by video, thermal camera imagery, and seismic data (Harris and others, 2005; Spampinato and others, 2008, 2013; Burgi and others, 2014; Lev and others, 2015). The emission rates and chemistry of gases emitted from lava lakes have also been studied in short field campaigns (Sawyer and others, 2008; Allard and others, 2016). Research performed on Erebus lava lake (Antarctica) has provided new insights into lake motion and pulsatory magma supply into the lake (Oppenheimer and others, 2009; Peters and others, 2014). Recent studies of lava ponds on Kîlauea's East Rift Zone have clarified the mechanism driving the gas pistoning process (Patrick and others, 2011b; Orr and Rea, 2012).

The ongoing summit eruption at Kîlauea Volcano, Hawai' $i$, began in 2008 and has evolved into a state of continuous lava lake activity (Patrick and others, 2013). The current lava lake in Halema 'uma'u Crater (figs. 1 and 2) is the most accessible lava lake on Earth, providing a venue for regular and detailed direct observations of lava lake 
Figure 1. Maps showing the location of Killauea Volcano and its summit vent. $A$, Kīlauea Volcano forms the southeast portion of the Island of Hawaili (see inset). Two rift zones extend down the flanks of the volcano. The Pu'u 'Ō'ō eruption, on the East Rift Zone, has been ongoing since 1983 and has produced a 144 square kilometer lava flow field (pink). The summit eruption, the focus of this report, is present in Kīlauea Caldera. White dotted line is the approximate boundary between Mauna Loa and Kilauea volcanoes. The basemap is derived from a 2005 digital elevation model. $B$, Map of Kîlauea Caldera. The summit lava lake is contained in Overlook crater, in Halema'uma'u Crater which is in the southwest portion of Kïlauea Caldera. Roads are marked by black lines, with the red line showing the portion of Crater Rim Drive closed to the public owing to the summit eruption. NPT is a broadband seismic station and UWE is an electronic tiltmeter. Many other instruments are present at the summit but are not shown because their data were not included in this report. HVO, Hawaiian Volcano Observatory; KMC, Kīlauea Military Camp.
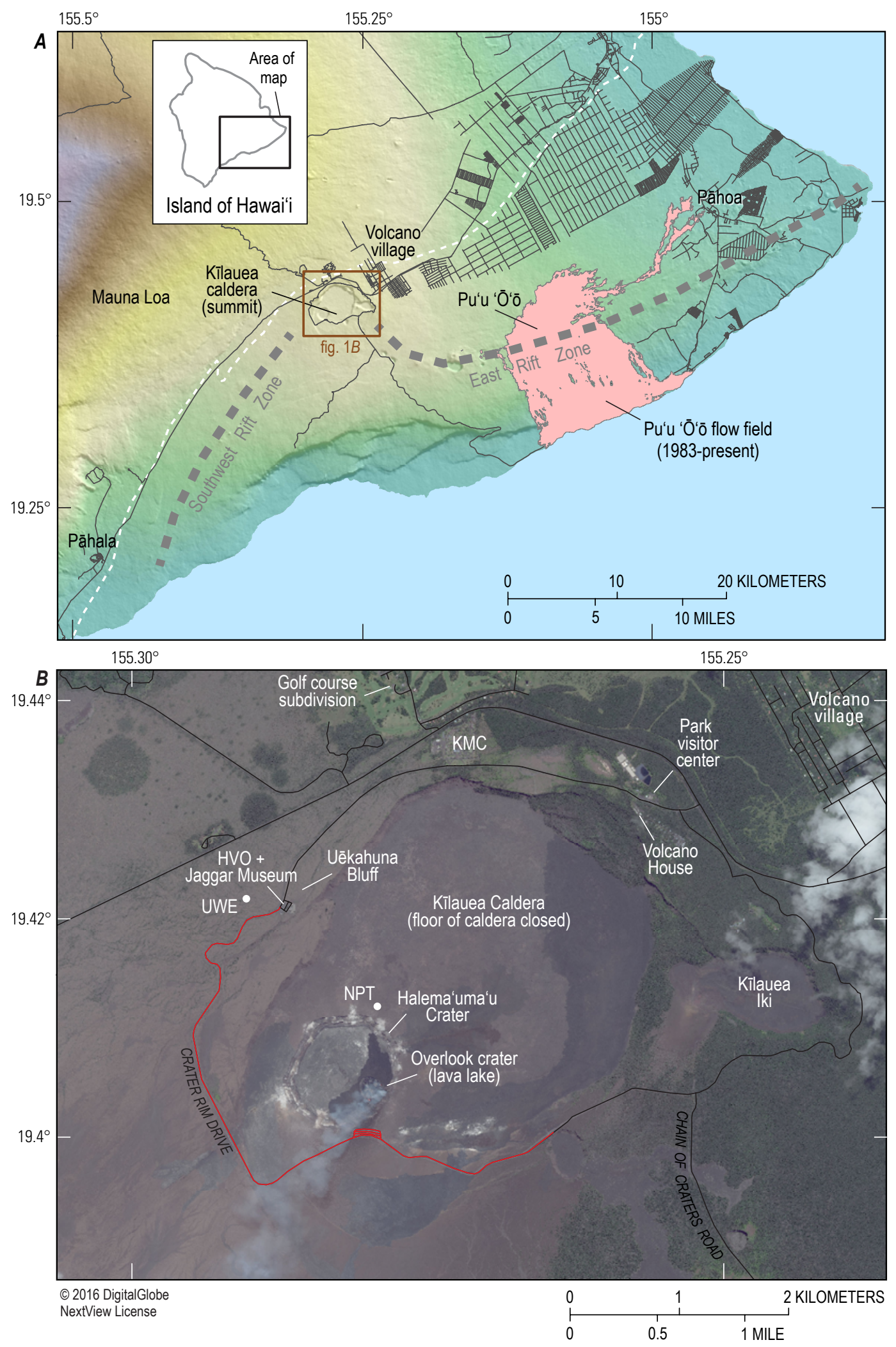

behavior over a prolonged time period (years) — and the first opportunity of this kind worldwide in recent years. The robust monitoring network already in place on the volcano has allowed for some of the most thorough monitoring of a lava lake anywhere in the world (Guffanti and others, 2010), providing a valuable opportunity to link direct observations with geophysical data, in order to both better understand the lava lake and interpret the myriad geophysical signals originating from open-vent basaltic eruptions. Beyond its role in research, the lake has been both a visitor attractionviewing the lake is a major draw in Hawai' $i$ Volcanoes National Park - and a public hazard, as the continuous 


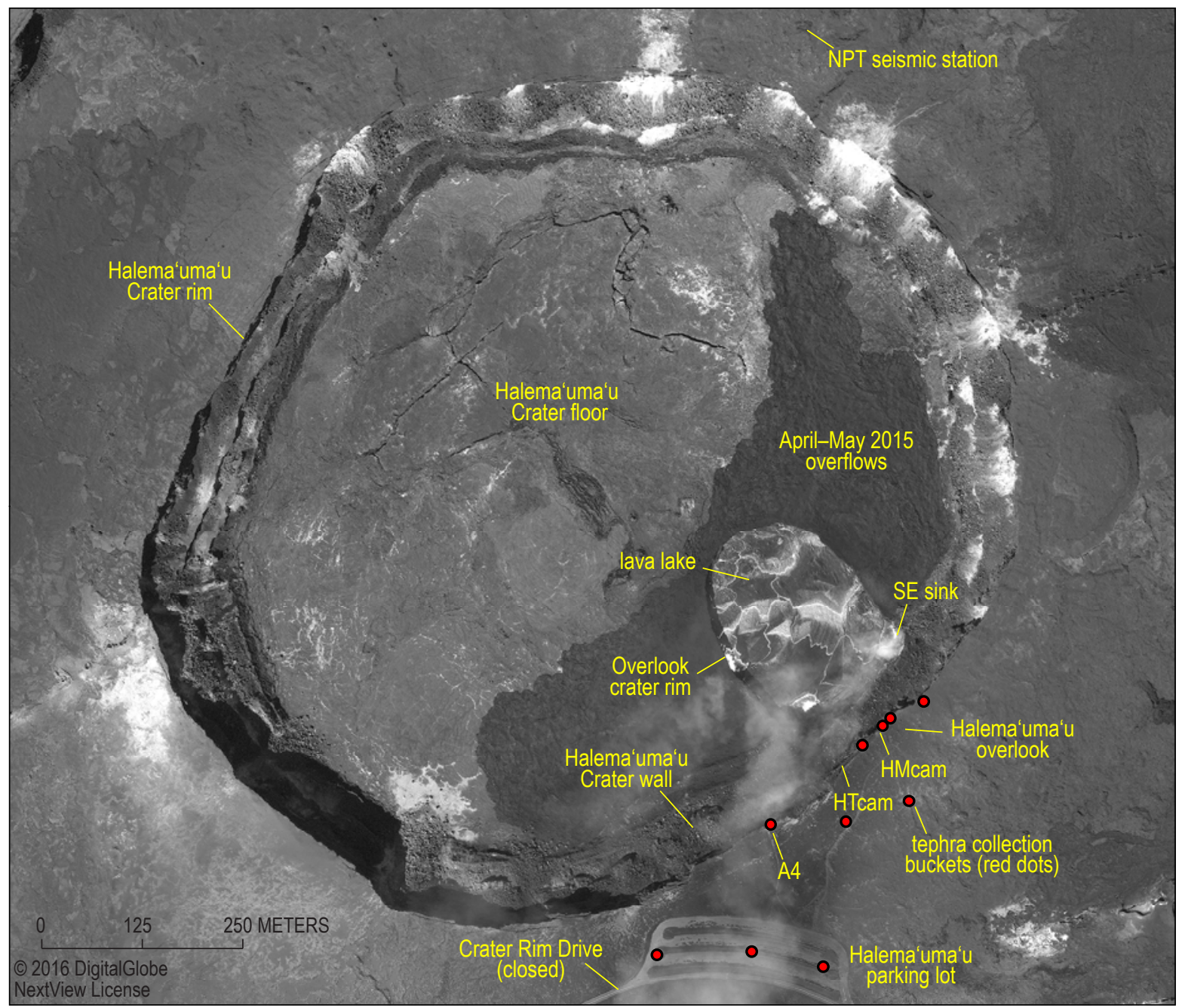

Figure 2. DigitalGlobe WorldView satellite image taken October 13, 2016, showing the Overlook crater in Halema'uma'u Crater. The lava lake was contained within the Overlook crater (about $250 \times 190$ meters) during 2016. Visual observations occurred primarily from the Halema'uma'u Overlook. Another common location for visual observations was station A4, which provided good views of the southeast (SE) sink (the SE sink was not normally visible from the Halema'uma'u Overlook as it was obscured by the Halema'uma'u Crater wall). A visual webcam (HMcam) and thermal camera (HTcam), on the rim of Halema'uma'u Crater, provided continuous observations of lake activity. In April-May 2015 the lava level rose to the Overlook crater rim and covered a portion (dark region) of the floor of Halema'uma'u Crater. The SE sink is an area of the lake where spattering is common, with vigorous downwelling. Red dots show the location of tephra collection buckets (Swanson and others, 2009).

outgassing creates widespread volcanic air pollution on the Island of Hawai' $i$. Detailed documentation of its recent activity is therefore essential both for fundamental research and assessing hazards.

This manuscript is intended to provide an overall summary of activity and context for more in-depth study. During 2016 the activity in the lava lake was relatively steady and this year presented a good opportunity to thematically describe the recent nature of lava lake activity at Kîlauea's summit. In this paper, we use the term "lithic" to refer to material erupted prior to the current summit eruption, and the term "juvenile" to refer to material erupted during the current summit eruption.

\section{Background}

\section{Overview and Setting}

Kîlauea Volcano forms the southeast portion of the Island of Hawai'i (fig. 1). Eruptions at Kîlauea normally occur either at the summit, where Kîlauea Caldera is situated, or along one of two rift zones (the East Rift Zone and Southwest Rift Zone). The East Rift Zone eruption at $\mathrm{Pu}^{`} \mathrm{u}$ ' $\overline{\mathrm{O}}^{`} \mathrm{o}$ began in 1983 and continues at the time of writing (late 2017). This eruption has consisted of lava flows, primarily tube-fed pāhoehoe, that have 
formed a flow field covering 144 square kilometers $\left(\mathrm{km}^{2)}\right.$ as of 2017 (Orr and others, 2015; Hawaiian Volcano Observatory, written commun., 2016). The ongoing summit eruption began in March 2008 and has been concurrent with the East Rift Zone eruption. These two ongoing eruptions at Kīlauea mark the first time in more than 200 years that long-lived ( $>1$ year) concurrent eruptions have occurred at the summit and along a rift zone. The summit eruption consists of a large lava lake contained within the Overlook crater, which formed at the onset of the eruption (Patrick and others, 2013). The Overlook crater is within Halema 'uma' $\mathrm{u}$, a 1-km-diameter crater that resides in the southwest portion of Killauea Caldera. The caldera floor is contained entirely within Hawai'i i Volcanoes National Park, which is managed by the U.S. National Park Service. The U.S. Geological Survey's Hawaiian Volcano Observatory (HVO) is situated on the north rim of Killauea Caldera, $1.9 \mathrm{~km}$ from the Overlook crater, and is charged with monitoring and hazard assessment of the eruption (Tilling and others, 2014).

\section{Early Summit Lava Lake Activity}

Lava lakes were observed in Kỉlauea's summit caldera in the first written record of Kīlauea's activity in 1823, when missionary William Ellis and his companions travelled over the volcano during a tour of the Island of Hawai' $i$ (Ellis, 1825). Lava lake activity was present for much of the next 100 years (Macdonald and others, 1983). Much of this lake activity was focused in the southwestern portion of Killauea Caldera, in Halema 'uma' $u$ Crater, and the persistent lava lake was a primary impetus for the establishment of the Hawaiian Volcano Observatory in 1912 (Apple, 1987; Tilling and others, 2014; Dvorak, 2011, 2016). The year before, in 1911, Frank Perret arrived in Hawai' $i$ and began regular, detailed observations of lava lake activity at Halema'uma'u (Perret, 1913a,b,c). Regular lava lake observations consisted of monitoring seismic activity and ground tilt, lava level measurements, and basic visual observations (Jaggar, 1947; Tilling and others, 2014). Continuous lava lake activity ceased in early 1924 with withdrawal of the magma column during an intrusion on the lower East Rift Zone, triggering a series of collapses and phreatic explosions in Halema'uma'u during May of that year (Jaggar and Finch, 1924). Sporadic, and generally brief, eruptive activity occurred at the summit through the rest of the 1900s, with the longest eruption consisting of nine months of lava lake activity in Halema'uma'u during 1967-68 (Kinoshita and others, 1969). The most recent summit eruption before the current one was in 1982, and consisted of a brief fissure eruption on the floor of the caldera (Macdonald and others, 1983).

\section{Current Eruption}

In late 2007, seismic tremor and sulfur dioxide $\left(\mathrm{SO}_{2}\right)$ emissions began escalating well above normal background levels (Wilson and others, 2008; Johnson and Poland, 2013; Patrick and others, 2013). The increasing tremor and $\mathrm{SO}_{2}$ emissions continued into early 2008 despite ongoing deflation, providing conflicting indicators of eruption potential considering that previous summit eruptions were consistently preceded by significant inflation. By late February 2008, $\mathrm{SO}_{2}$ emissions were sufficiently high that visitor health was impacted and Hawai' $i$ Volcanoes National Park closed the western portion of Crater Rim Drive to the public (fig. 1B). On March 12, a fumarolic area was observed on the south wall of Halema'uma'u Crater, directly beneath the closed Halema'uma'u Overlook (fig. 2), producing a robust outgassing plume. In the early morning hours of March 19, a collapse of the fumarolic area was associated with several small earthquakes and a small explosive event which ejected lithic blocks around the Halema 'uma' u Overlook (Wilson and others, 2008; Houghton and others, 2011). The collapse formed a new crater, informally called the "Overlook crater", which was initially 35 -meters (m) wide. The new crater continued to produce an outgassing plume that persists to this day. Several crater collapses occurred over the next few months, enlarging the Overlook crater and triggering small explosive events that deposited a mixture of juvenile and lithic ejecta around the Halema'uma'u Overlook (Wooten and others, 2009; Houghton and others, 2013; Carey and others, 2015).

Lava was not visible in the new crater until September 2008, when a roiling lava lake was observed by helicopter. The lake was gas pistoning and was visible during a brief phase of inflation associated with a deflation-inflation cycle (Patrick and others, 2008), suggesting that the level may have risen into view with the inflation. The lake was only sporadically visible over the next eight months, and views were obscured by thick fumes. A handheld thermal camera provided improved views into the crater, and revealed that the lava lake was not continuously present in the crater. During summit inflation the lake would often rise to cover the bottom of the crater, but at other times (particularly deflation phases) lava drained out of sight below the deep floor of the Overlook crater, exposing a surface covered by rubble and (or) small outgassing vents. A month of continuous lava lake activity in June 2009 was the most persistent phase of activity until that time (Patrick and others, 2011a), and light detection and ranging (lidar) determined that the lake surface was $205 \mathrm{~m}$ below the rim of the Overlook crater at that time (T. Ericksen, University of Hawai'i Mānoa, personal commun., 2009). Sporadic lava lake activity, deep in the Overlook crater, continued into early 2010 and alternated with periods of spattering at vents on the Overlook crater floor. In general, inflation phases corresponded with the lake rising and covering the floor of the Overlook crater, while during deflation phases the lava lake would drain to leave the rubbly crater floor visible.

In February 2010, deflation associated with a collapse of the floor of the Overlook crater was followed by inflation associated with the lava lake rising and subsequently establishing a more continuous presence. The lake level generally rose through 2010 , and experienced frequent gas pistoning; it reached its highest levels (at that time) in February and March 2011, when the lake level was $60 \mathrm{~m}$ below the Overlook crater rim (Orr and others, 2015). During this period, rock cracking sounds were common and several explosive events occurred, triggered by large collapses of the Overlook crater wall into the lava lake (Orr and others, 
2013). The March 2011 Kamoamoa eruption, near $\mathrm{Pu}^{‘} \mathrm{u}{ }^{‘} \overline{\mathrm{O}}^{‘} \overline{\mathrm{o}}$ on Kilauea's East Rift Zone, caused the summit lake to drain out of view over the course of a day, dropping roughly $140 \mathrm{~m}$ (Orr and others, 2015; Carbone and others, 2013; Patrick and others, 2015). The lake reappeared about a week later and gradually rose to its previous level, but dropped again when new vents opened on $\mathrm{Pu}^{\mathrm{u}} \mathrm{u}$ 'Ō'o in August 2011. The lake level recovered again in late 2011, and slowly rose to even higher levels over the next year (Patrick and others, 2015).

Inflation during October 2012 was associated with the lake rising to about $20 \mathrm{~m}$ below the Overlook crater rim, but the lake dropped several tens of meters with a small intrusion in the summit region near the end of that month. Lake levels were generally high in 2013 and 2014, normally 30-60 m below the Overlook crater rim, but fluctuated on a daily basis with frequent deflation-inflation (DI) events (Anderson and others, 2015; Patrick and others, 2015). Sharp inflation in April 2015 drove rapid lava level rise for several weeks, culminating in the lake spilling onto the floor of Halema' uma' $u$ Crater for the first time during this eruption (fig. 2). These overflows occurred several times over the next two weeks, covering about a quarter of the floor of Halema'uma'u Crater with shelly pāhoehoe (a type of pāhoehoe described in Swanson [1973]), and building up the rim of the Overlook crater by about $8 \mathrm{~m}$. A small intrusion in the summit region triggered a drop in the lake to its more typical levels, which persisted through the remainder of 2015.

\section{Monitoring Methods}

The accessibility of the summit lava lake allowed daily direct observations of lake behavior from the Halema'uma' $u$ Overlook (figs. 2 and $3 A$ ). These visits often corresponded with daily tephra collection and (or) lava level measurements described below. HVO scientists normally stood at the Halema'uma'u Overlook for 10-20 minutes, noting the location and intensity of spattering, grotto development, general lava level, surface flow direction, sounds, and other observations. Although webcams were stationed at the same spot, the direct observations were valuable for identifying several things that the cameras did not always register clearly. This includes rockfalls that were too small to be clearly identified in the webcam images but could be sufficiently large to trigger spattering. Rock popping and cracking sounds were also best recorded through direct observations. High-quality photographs taken by HVO scientists tended to have better resolution and clarity than webcam images.

Observations from HVO and the Jaggar Museum overlook were also useful. The HVO observation tower was built to provide commanding views of Kīlauea Caldera, including Halema'uma'u (fig. 4). When lake levels were high there were good views of the lake surface and spattering from the tower. Rock cracking and popping sounds were often audible from the Jaggar Museum overlook, particularly on slack wind days.

Tephra, which normally included Pele's hair and tears as well as small lithic particles, was normally collected each workday from a network of 10 buckets distributed downwind of the Overlook crater (Swanson and others, 2009; figs. 2, 3C). Total tephra accumulation rates were inferred from the distribution across the network, and the proportion of juvenile and lithic material in the tephra assemblage was also tracked (Swanson and others, 2009). Geochemical analysis of tephra has included spatter samples from sporadic explosive events as well as Pele's tears and hair collected daily during normal activity (Rowe and others, 2015; Thornber and others, 2015).

Starting in 2013, measurements of lava lake level were generally made once per day using a handheld laser rangefinder from the Halema' uma'u Overlook (fig. 3B). One of two laser rangefinder models was used: a Safran Vectronix Vector23 or a TruPulse 360R. The TruPulse has a stated accuracy of $<1 \mathrm{~m}$. The Vector 23 only states its accuracy $( \pm 5 \mathrm{~m})$ over long distances (500$12,000 \mathrm{~m}$ ), however, our line of sight distances were $<200 \mathrm{~m}$ and we found that the Vector 23 consistently agreed with the TruPulse within 1 meter when measuring the lake level. We also performed a test over a distance of $160 \mathrm{~m}$, and compared the results with a tape measure, and both rangefinders agreed with the measured distance to within 1 meter. Therefore, we infer that both the Vector23 and TruPulse had an accuracy of $\pm 1 \mathrm{~m}$ for our measurements. Real-time estimates of lake level were made using an automated analysis of thermal camera images (Patrick and others, 2016b) but this method was not useful when the lake rose above the top of the thermal image field of view in mid-2015 and late 2016.

Cameras provided a means of observing the lake activity on a continuous basis. Two visible-wavelength cameras were in the HVO observation tower (fig. $4 B$ ), with one providing a wide view of Halema' uma' $u$ at a rate of one image every two minutes, and a second camera providing a close-up view of the Overlook crater at a higher rate (several frames per second). The Halema'uma'u Overlook webcam (HMcam) provided a closer view of the lake activity (figs. 2 and $5 B$ ). The camera recorded continuously on a near-infrared (IR) setting, which allowed improved views through the fume compared to views in visible wavelengths. This camera acquired images at a rate of one frame per second in 2016, and observations of the lake improved when the live stream from this camera became accessible on a large-screen monitor in the HVO lobby during 2016. The live stream allowed HVO scientists to see more activity and identify patterns, as well as to react rapidly to events like collapses. A thermal camera (HTcam) roughly $80 \mathrm{~m}$ southwest of the Halema'uma' $u$ Overlook has been in operation since late 2010, and acquires an image every five seconds (figs. 2 and $5 A$ ) (Patrick and others, 2014). The thermal camera can "see" through the thick fume that commonly obscures views in the Overlook crater, providing a nearly continuous record of lake activity. An automated routine at HVO uses the thermal images to track the lake surface speed and flow direction, as well as the abundance of spattering, on a near-real-time basis (Patrick and Orr, 2018). In addition to the real-time webcams and thermal camera, we also deployed two time-lapse cameras on the rim of Halema'uma'u. These systems used high-quality digital single lens reflex (DSLR) cameras, which were an improvement over the models described in Orr and Hoblitt (2008). 
Figure 3. Photographs showing measurements and observations at Halema'uma'u. A, Making visual observations of the lake from A4 on May 16, 2016. B, Using a laser rangefinder to make a daily measurement of lake level on December 19, 2016. The HMcam is in the foreground. C, Daily tephra collection from a network of buckets provides estimates of tephra output on December 21, 2016. D, Collecting Pele's hair for geochemical analysis in the Halema'uma'u parking lot on November 9, 2016. E, Hawaiian Volcano Observatory geologist at the margin of the 2015 overflows on the floor of Halema'uma'u Crater on November 29, 2016.
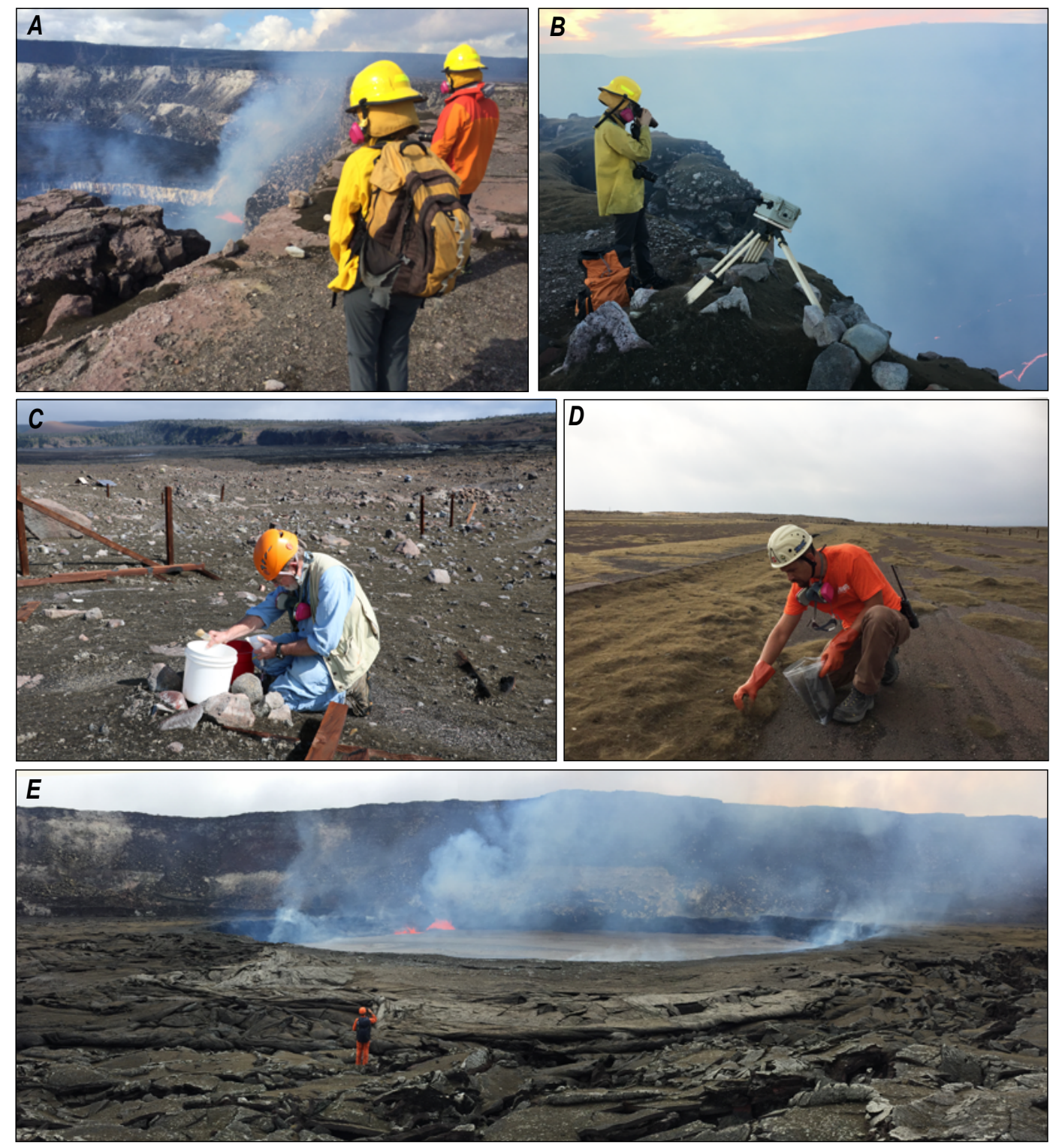

A robust geophysical monitoring network has been in place at the summit of Kîlauea for decades (Guffanti and others, 2010). Seismic monitoring includes a broadband network within Kîlauea Caldera (Dawson and others, 1998; Okubo and others, 2014), as well as several short-period and strong motion stations on the volcano. For summit activity, we commonly analyzed data from broadband station NPT, on the rim of Halema'uma' $u$ Crater (fig. 1B). Deformation monitoring includes a network of borehole tiltmeters (Cervelli and Miklius, 2003) as well as global positioning system (GPS) stations (Miklius and others, 2005). Data from these ground-based deformation instruments are analyzed along with interferometric synthetic aperture radar imagery collected by spaceborne instruments (for example, Poland and others, 2012). Tiltmeter station UWE, located near the Hawaiian Volcano Observatory on the north rim of Kîlauea Caldera, was a common station used to monitor the summit eruption (fig. $1 B$ ).
Routine gas monitoring has occurred for decades at the summit of Kīlauea, consisting primarily of $\mathrm{SO}_{2}$ emission rates estimated using a correlation spectrometer (COSPEC) and other ultraviolet spectrometers (Sutton and others, 2003; Elias and Sutton, 2012; Sutton and Elias, 2014). This traditional method for $\mathrm{SO}_{2}$ emission rate estimation is performed in brief field visits, generally no more than once per day. Other techniques have been developed for estimating $\mathrm{SO}_{2}$ emission rate on a more continuous basis, although they are still limited to daylight hours (Sutton and others, 2013). These techniques include (1) an array of upward-looking ultraviolet spectrometers downwind of the Overlook crater that can estimate $\mathrm{SO}_{2}$ emissions every 10 seconds during normal trade wind conditions (Horton and others, 2012; Elias and others, 2016); and (2) an ultraviolet camera (Kern and others, 2015) that also provides high-rate estimates of $\mathrm{SO}_{2}$ emission. In addition to $\mathrm{SO}_{2}$ emission rates, gas chemistry is measured 

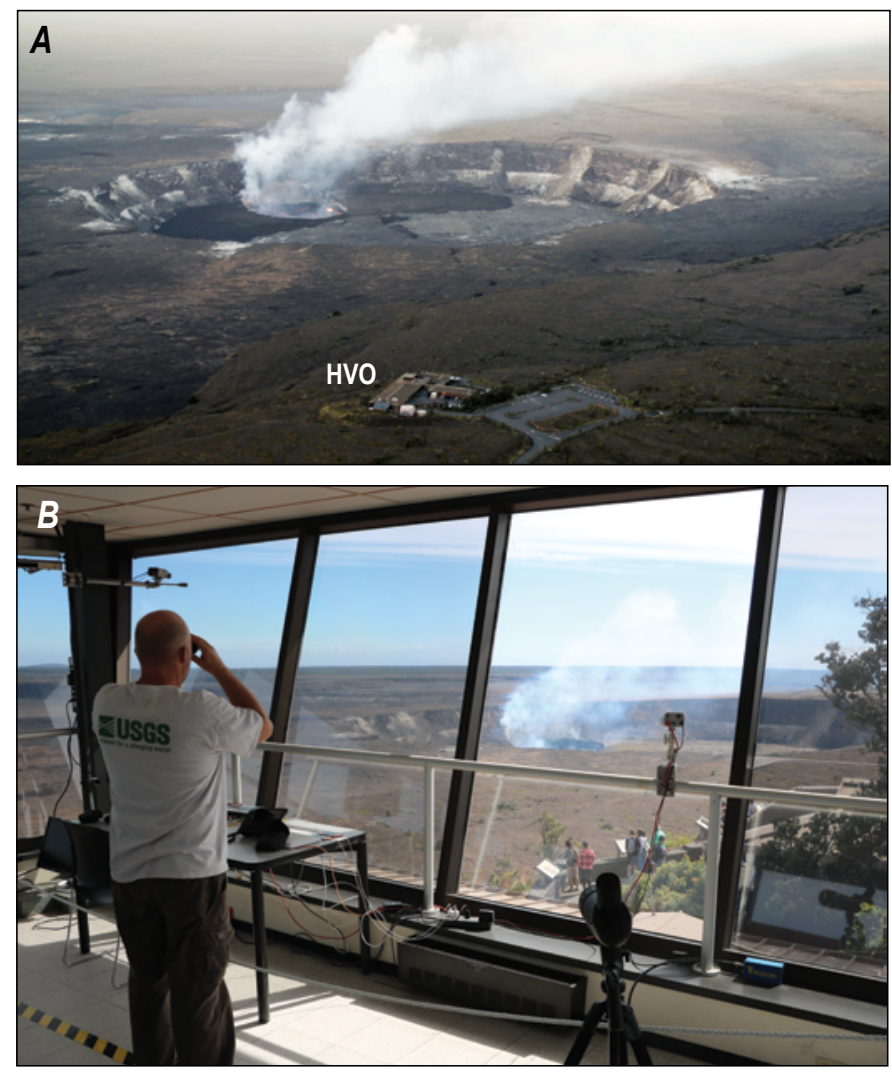

Figure 4. Observations from the Hawaiian Volcano Observatory (HVO). A, Aerial view, looking south, showing the Hawaiian Volcano Observatory and Jaggar Museum (foreground) with Halema'uma'u Crater and the lava lake in the distance. HVO and the museum are 1.9 kilometers from the lava lake. Photograph taken July 27, 2016. B, Making observations of the lava lake from the HVO observation tower on December 20, 2016.

with a Fourier Transform Infrared spectrometer (FTIR) during sporadic field campaigns (Sutton and others, 2013). Ground level $\mathrm{SO}_{2}$ concentrations downwind of Halema'uma' $u$ were measured continuously at three stations in 2016, at varying distances from the vent.

\section{The Overlook Crater in Halema'uma'u Crater}

\section{Basic Geometry}

The lava lake was contained within the Overlook crater ( $\sim 250 \mathrm{~m}$ diameter), which was itself contained within the larger Halema'uma'u Crater ( $\sim 1 \mathrm{~km}$ diameter) (figs. 2 and 6$)$. The northern portion of the Overlook crater rim coincided with the floor of Halema'uma' $u$ Crater, and the southern portion of the rim ran along the south wall of Halema'uma'u (figs. 6 and 7). The wall consisted of a talus slope at the base of near-vertical walls,
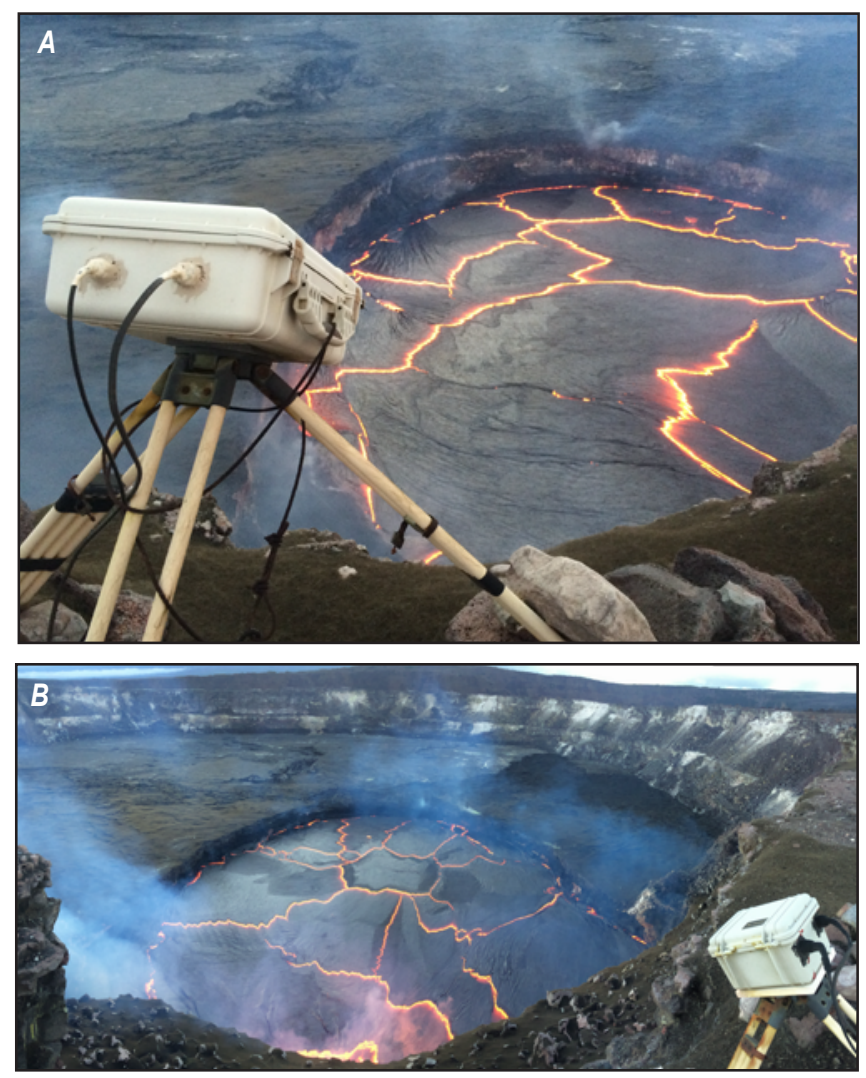

Figure 5. Photographs showing the webcams on the rim of Halema'uma'u Crater near the Overlook crater (see fig. 2 for locations). $A$, The HTcam thermal camera on July 29, 2016. B, The HMcam near-infrared camera on September 9, 2016.

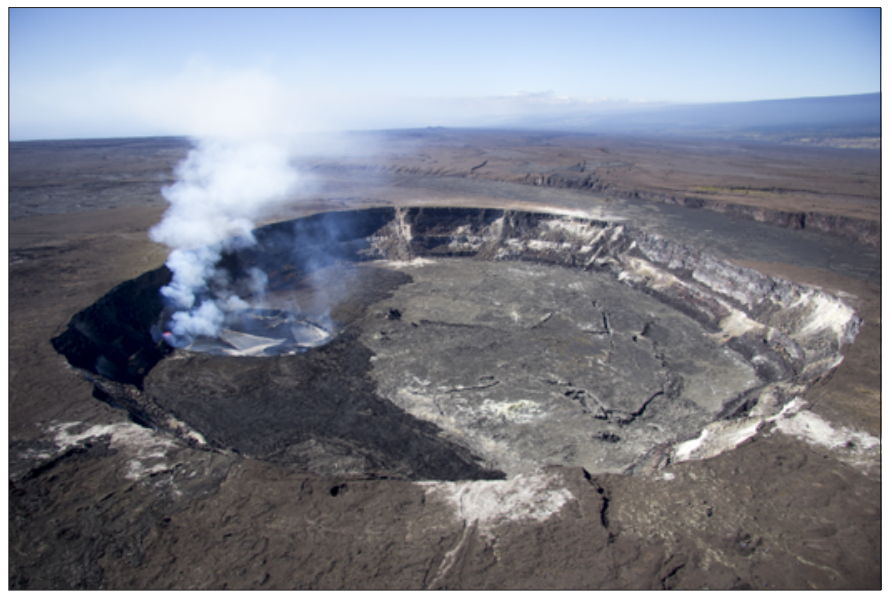

Figure 6. Oblique aerial view of Halema'uma'u Crater, viewed from the east. The Overlook crater and lava lake are located to the south (left). The dark portion of the Halema'uma'u Crater floor represents overflows from the lava lake in mid-2015. Photograph taken November 3, 2016. 
with extensive chemical alteration of the Halema'uma' $u$ Crater wall (fig. 7). The Overlook crater was elliptical in map view, with dimensions of $250 \mathrm{~m}$ (northwest-southeast) $\times 190 \mathrm{~m}$ (southwestnortheast) in November 2016 (fig. 8). In 2016, the Overlook crater rim was roughly $77 \mathrm{~m}$ below the Halema'uma'u Overlook.
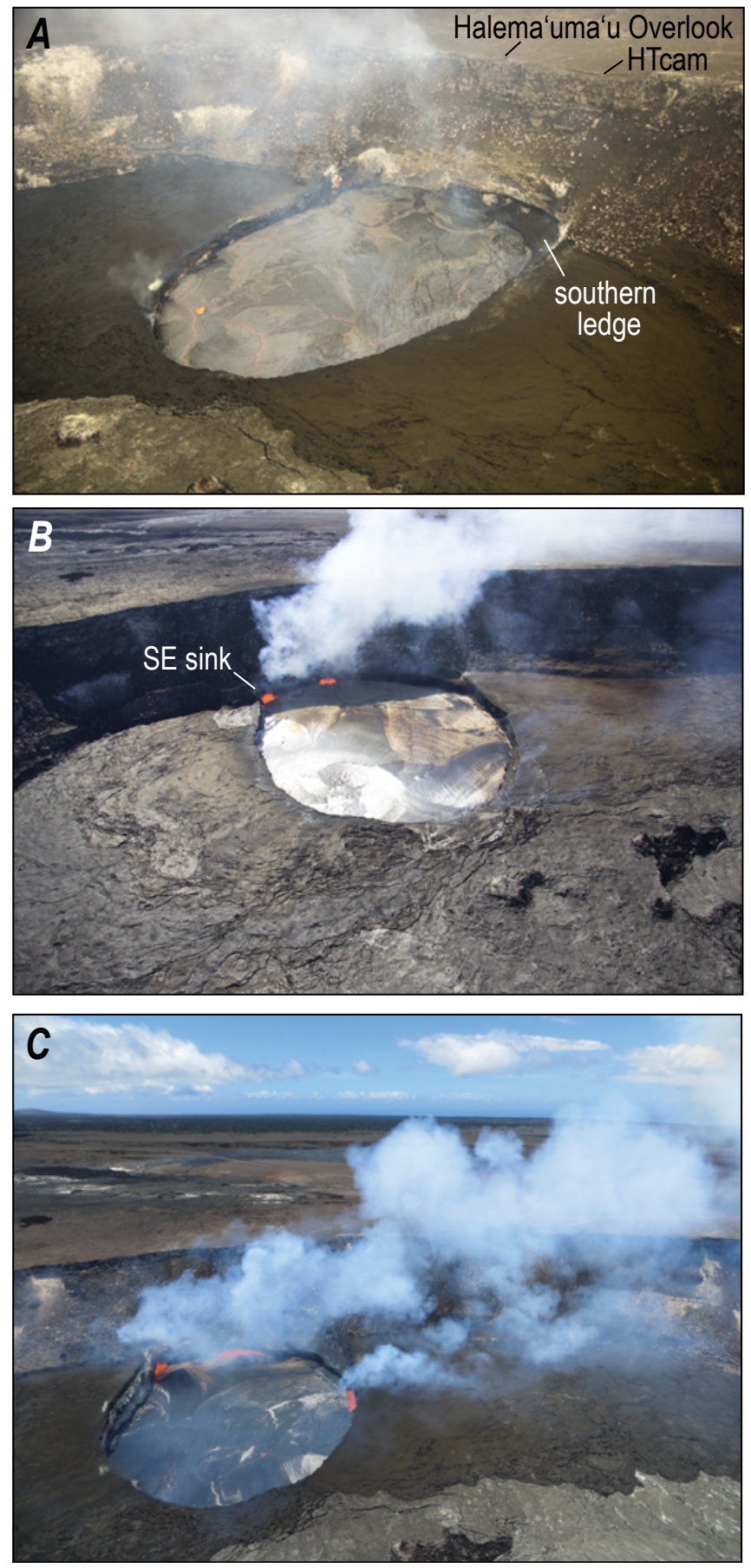

Figure 7. Oblique aerial views of the Overlook crater. $A$, The lava lake on September 12, 2016, during a nonspattering phase. Note the lack of a robust gas plume. $B$, The lake on November 3, 2016. Note the robust portion of the plume that originates directly from spattering along the southeastern margin of the lake. C, The lake on July 29, 2016. The robust portions of the plume originate from spattering along the southeastern and western margins of the lake.
The planimetric area of the Overlook crater enlarged during 2016 owing to collapses of lithic rock that forms the Overlook crater walls. Based on high-resolution WorldView satellite images, the area of the Overlook crater on December 18, 2015, was about $37,000 \mathrm{~m}^{2}$. On November 16, 2016, the area was roughly $43,500 \mathrm{~m}^{2}$, which represents roughly an 18 percent increase.

The Overlook crater walls normally consisted of several morphologic zones (fig. 9). The lowest point on the wall, where the lake surface contacted the crater wall, sometimes had a small ledge built of solidified lava. Above this, extending upwards a variable distance, was a deposit of juvenile veneer left attached to the wall during higher stands of the lake. Above and behind the veneer, the wall of the Overlook crater exposed a cross section of the 1974 and the 1967-68 solidified lava fill of Halema'uma' $u$. In 2016, the upper $8 \mathrm{~m}$ of the wall exposed overflows of lava that occurred in 2015. Overflows during 2016 were minor and added slightly to the existing overflow thickness only along some portions of the Overlook crater rim.

\section{Crater Veneer and Inner Ledges}

When the lava lake level dropped, a thin veneer of lava (probably less than a meter or two thick) would often remain attached to the Overlook crater walls, extending up to the high stand of the lake (fig. 10). The veneer often had numerous horizontal ribs, which were "bathtub rings" that presumably represented incremental lake level changes (and possibly gas piston events) (fig. 11). The veneer was an ephemeral feature in the crater, often collapsing piecemeal — as large slabs or sheets - when the lake surface dropped during summit deflation. These collapses would impact the lake surface and often trigger spattering; this process is described in more detail in the rockfall section of this manuscript.

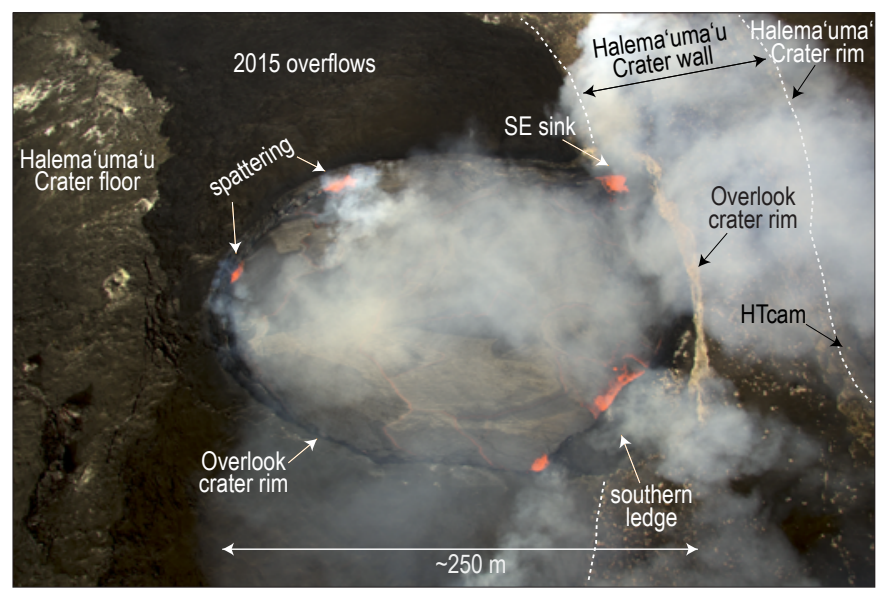

Figure 8. Vertical aerial view of the Overlook crater. Photograph was taken on November 29,2016, and at this time spattering was present in several locations, including the SE sink. 

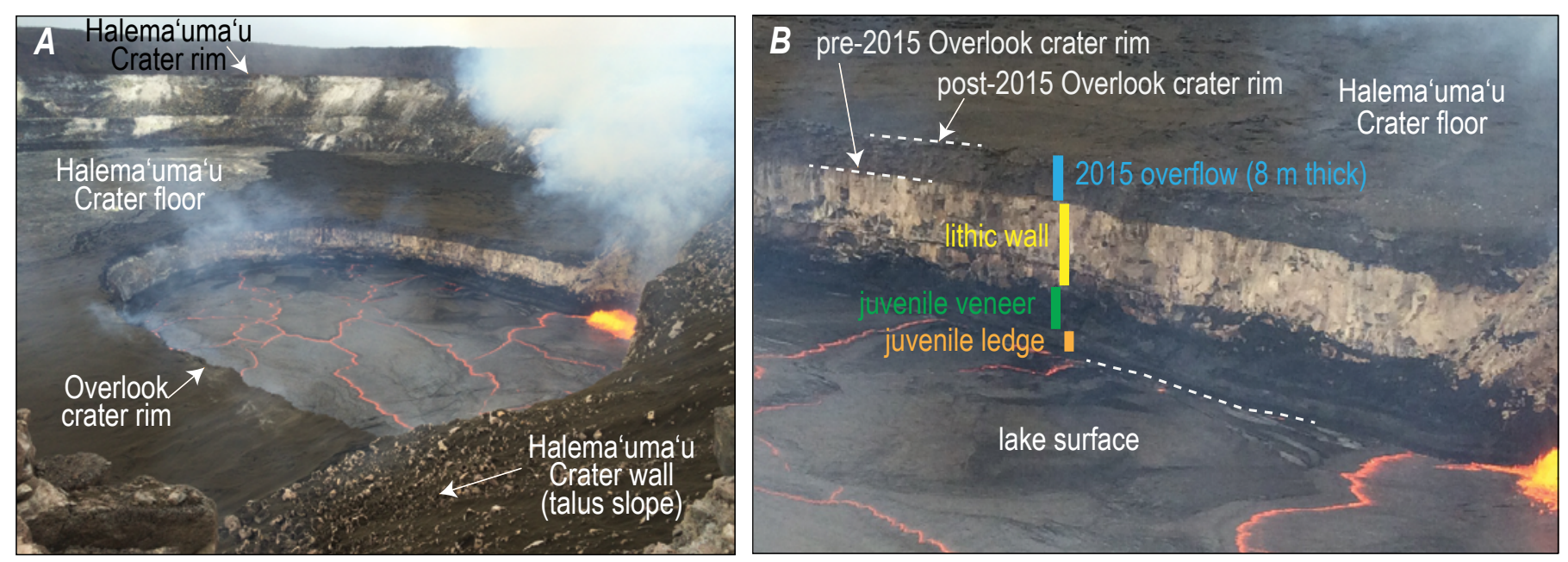

Figure 9. Photographs showing a cross section of the Overlook crater. $A$, Wide view of the Overlook crater from station $\mathrm{A} 4$ on the rim of Halema'uma'u Crater (see fig. 2 for location). Spattering is active in the typical SE sink. Photograph taken March 19, 2016. B. Close-up of same photograph, showing detailed structure of the Overlook crater wall on a typical day. From bottom to top, the wall consisted of several zones: (1) a ledge of solidified juvenile lava, extending out from the wall by as much as a few meters, (2) an unstable veneer of juvenile lava deposited by the lake during higher lake levels, (3) the exposed lithic wall of the crater, formed by lava erupted prior to 2008 on the floor of Halema'uma'u Crater, and (4) a layer of juvenile lava, roughly 8 meters ( $\mathrm{m}$ ) thick, formed by successive overflows during April and May of 2015. The base of this 8-m-thick layer marks the rim of the Overlook crater prior to mid-2015.
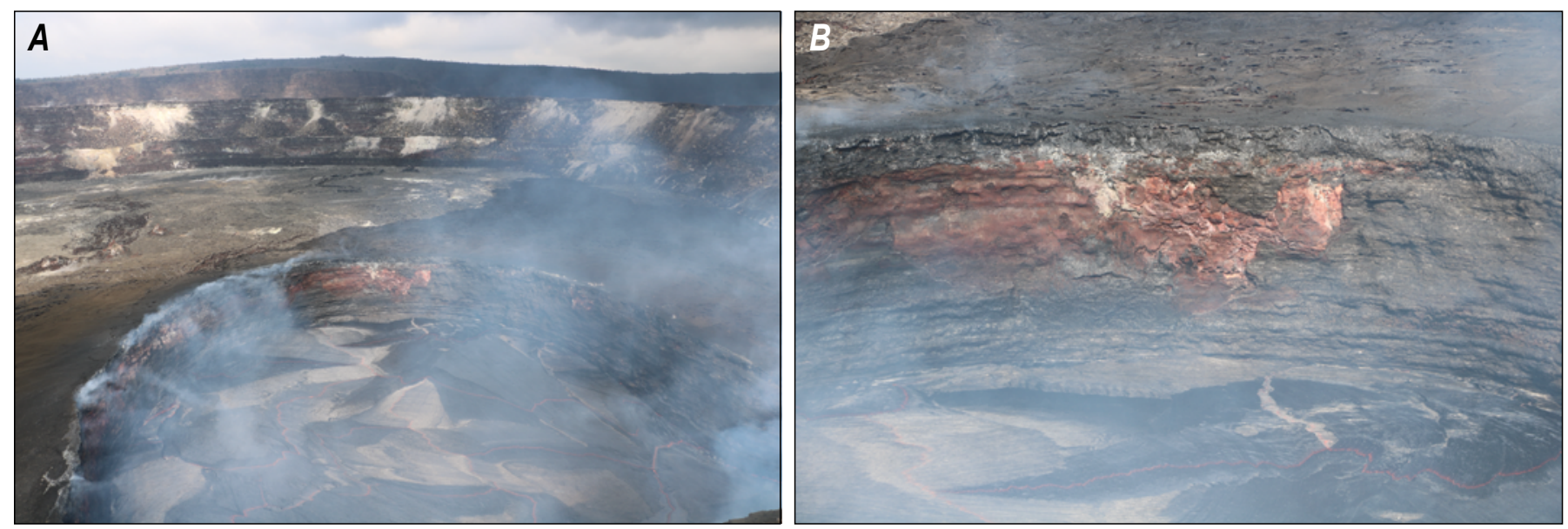

Figure 10. Photographs showing the lava veneer on the Overlook crater walls. A, View of the northern Overlook crater wall from the HTcam site. The far wall has a light-colored red patch that indicates a recently collapsed portion of the lava veneer. The skyline marks the rim of Kilauea Caldera, with the Hawaiian Volcano Observatory and Jaggar Museum visible as a small bump on the crest. Photograph taken December 13, 2016. B, Close-up of the northern Overlook crater wall on the same day. The black veneer extends from the lake surface to the Overlook crater rim, but the red area shows where a large patch of the veneer has fallen away. The lake surface was roughly 30 meters below the rim at this time.

Figure 11. Photograph of bathtub rings on the Overlook crater wall veneer. The lava veneer, which often extended the entire height of the Overlook crater wall, as it does here, sometimes had a ribbed appearance that presumably represents lava deposition associated with incremental changes in lake level. Photograph is taken from station A4 on December 4, 2016, with the SE sink on the right side of the photo (see fig. 2 for locations). For scale, the lake surface is 30 meters below the Overlook crater rim (the crater rim is marked by the horizontal line of fume near the top of the image).

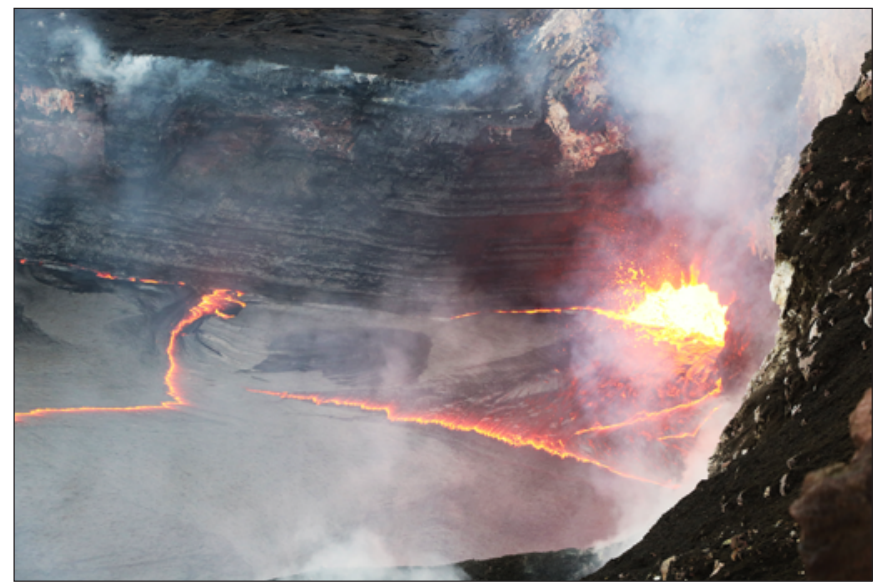


If the lake level remained steady, a small inner ledge would be built out from the wall by as much as a few meters (fig. 12). These small inner ledges were often built from solidified spatter deposits and, like the veneer, were ephemeral and prone to collapse with drops in the lake level during summit deflation. The collapses of the small inner ledges would often trigger brief spattering at the point of impact into the lake.

A large inner ledge of solidified lava formed in the southern corner of the crater and was present through 2016, changing in size and shape with lake level changes (figs. 8 and 13). We call this the "southern ledge". It was triangular in plan view (triangular because it filled the southern corner of the Overlook crater) with dimensions of roughly $80 \mathrm{~m}$ by $20 \mathrm{~m}$ (area about $1,600 \mathrm{~m}^{2}$ ) in October 2016, based on high-resolution satellite imagery. During high lava stands the lake would spill onto this ledge and add additional layers of lava (appearing to be shelly pāhoehoe), building it higher. Collapses of the highly altered Halema'uma'u Crater wall above the ledge often deposited large, white lithic blocks on the ledge. These lithic blocks were subsequently inundated by juvenile overflows when the lake level rose above the level of the ledge. When the lake level dropped during summit deflation, the front of the ledge would often slough off in a piecemeal fashion, reducing the size of the ledge. The collapses were presumably triggered by the removal of lateral support as the lake level dropped. They were sometimes preceded by hours or days of enlargement of hot cracks near the front of the ledge, as observed by the HTcam (fig. 14). Collapses of the southern ledge allowed the lake to fill a larger volume, increasing the lake's surface area.

On September 16-17, 2016, much of the north face of the ledge collapsed into the lake in several episodes, leaving a

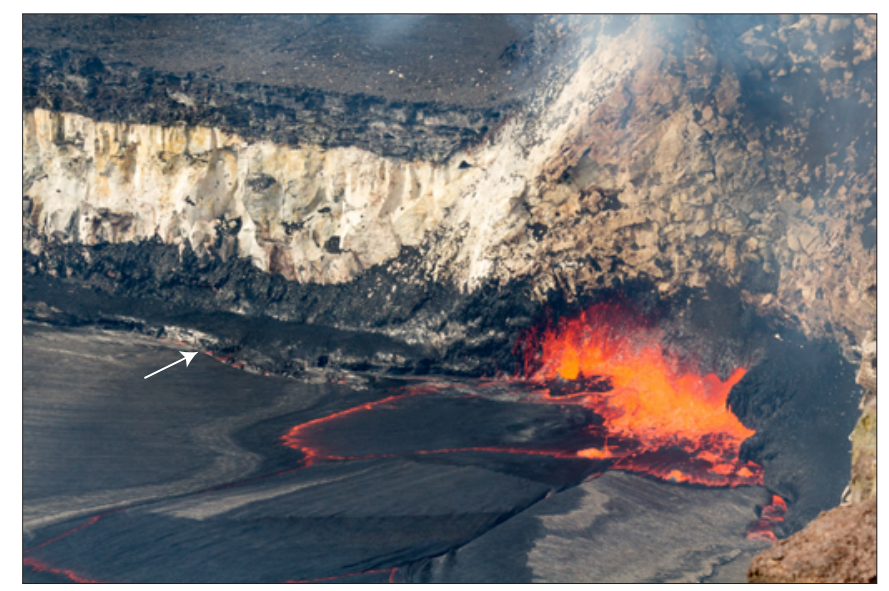

Figure 12. Photograph showing inner ledges at the lake margin. Small ledges (example marked by arrow) developed where the lake margin contacted the Overlook crater wall, extending as much as a few meters towards the lake center and modifying the shape of the lake margin. Spattering in the SE sink is visible at the right side of the photo. The lightcolored areas consist of altered lava originating from flows from the 1960s and 1970s that filled Halema'uma'u Crater. Photo by Kirsten Stephens, U.S. Geological Survey, May 16, 2016.

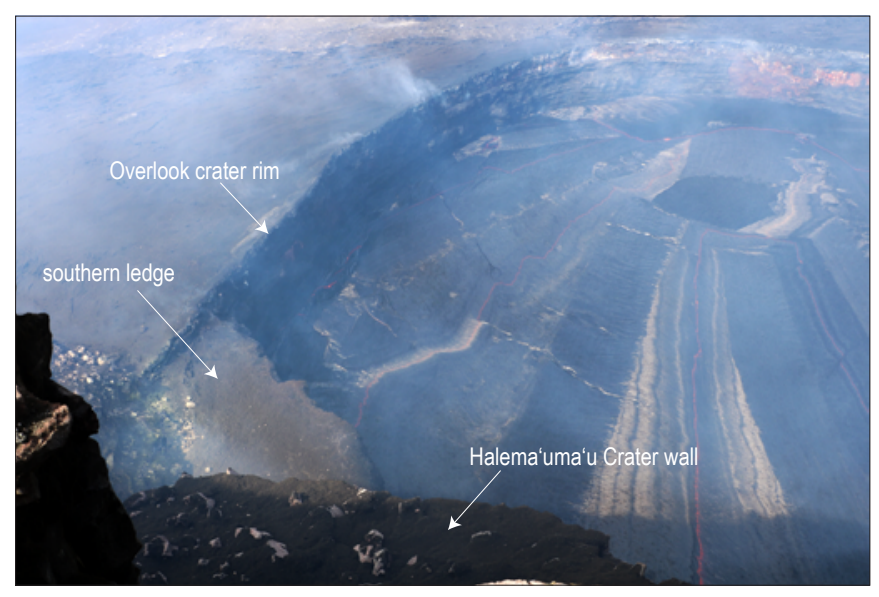

Figure 13. Photograph showing the southern ledge. Lava deposited by the lake along the southern margin of the Overlook crater developed a ledge that was triangular in plan view and about 80 meters long. Several large, white lithic blocks have collapsed from the Halema'uma'u Crater wall onto the ledge - a common phenomenon. At the time of this photograph (December $22,2016)$ the southern ledge was roughly 5 meters below the rim of the Overlook crater. The southern ledge was built upwards by overflows during high lava lake levels, but would often collapse into the lake when the lake level dropped a significant distance (tens of meters).

fresh, near-vertical north-facing scarp perched above the lake surface. Shortly after one of the collapses on September 16, HVO scientists at the Halema'uma'u Overlook observed that incandescent rubbly material (resembling clinker on an active ' $a$ ' $\bar{a}$ flow) was occasionally sloughing from the face of the north scarp, suggesting that the interior of the southern ledge was "mushy" and semifluid owing to incomplete cooling. Jaggar (1917) noted

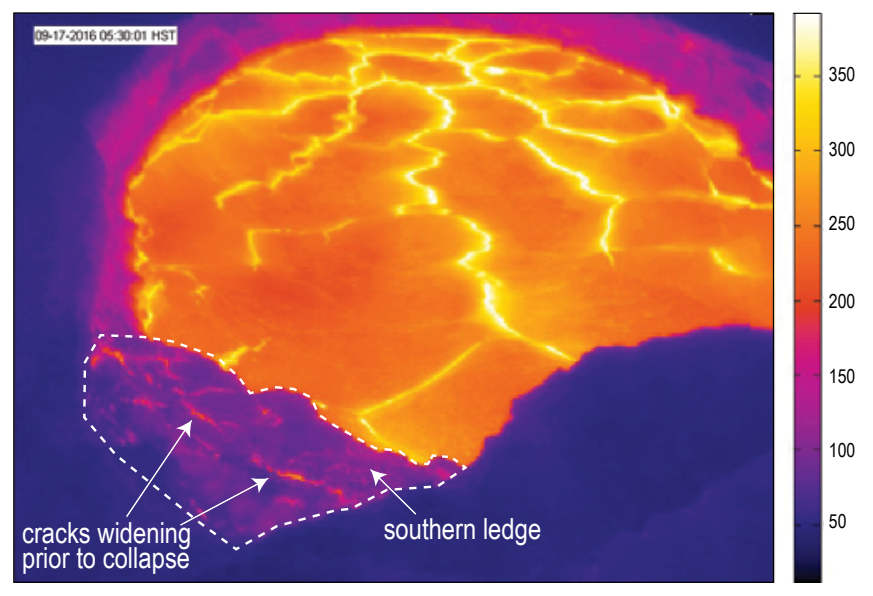

Figure 14. HTcam thermal image showing hot cracks developing on the southern ledge in the hours prior to large collapses of the ledge into the lake. Image taken September 17, 2016. Scale is in degrees Celsius. 
similar observations during collapses of inner ledges in the early Halema'uma'u lava lake, describing "an outflow which also is like crumbled cheese, and incandescent, but starting out like a liquid and falling like gravel or sand. It trickles out from fresh vertical breaks in falling benches."

\section{Lake Surface}

The lava lake was present continuously throughout 2016, and most of the surface was easily visible from the Halema'uma' $u$ Overlook. The lava lake measured roughly $250 \mathrm{~m}$ (northwestsoutheast) $\times 190 \mathrm{~m}$ (southwest-northeast) in November 2016, with a surface area of approximately $39,000 \mathrm{~m}^{2}$. This is comparable to, if not exceeding, the surface area of the lava lake in Nyiragongo (Spampinato and others, 2013; Burgi and others, 2014; Patrick and others, 2016c), and indicates that the Halema'uma'u lava lake was one of the two largest lava lakes on Earth (if not the largest) during 2016. The lake dimensions on January 25, 2016, were $240 \mathrm{~m}$ (northwest-southeast) $\times 175 \mathrm{~m}$ (southwest-northeast), with an area of roughly $35,000 \mathrm{~m}^{2}$. Therefore, during 2016 , the lake surface area increased by roughly 10 percent. The lake was bound on all sides by the steep walls of the Overlook crater, and the lake area enlargement was a result of the widening of the Overlook crater through collapses of the crater walls.

\section{Crustal Plates}

The lake surface consisted of numerous large crustal plates separated by narrow incandescent spreading zones (fig. 15). Depending on the surface texture and solar illumination, the plate appearance could range from dull black to lustrous silver. The overall appearance of the lake was roughly similar to the descriptions of lava lake activity at Mauna Ulu in 1971 by Duffield (1972). This basic geometry was maintained throughout 2016 (see section below on crustal plate dimensions), despite changes in lake level and spattering activity (fig. 16).

The crustal plates appeared to be thin and flexible. Where crust was consumed at spattering sites, the crust was often violently ripped and torn - sometimes thrown a few meters in the air-revealing that the black crustal plates formed a thin (probably no more than several centimeters thick) flexible skin over the underlying incandescent lava. As described below, approximate surface velocities on the lake were $0.1-0.2 \mathrm{~m} / \mathrm{s}$. Over a distance of $250 \mathrm{~m}$ (see below), this implies that the crust was generally less than 20-40 minutes old. At this age, according to equation 1 in Hon and others (1994), the uppermost crust would be 4-7 centimeters $(\mathrm{cm})$ thick. Based on direct observations, Jaggar (1917) states that the surface crust was normally $8-10 \mathrm{~cm}$ thick for the Halema'uma'u lava lake in the early 1900s. This meager thickness presumably contributes to the flexibility of the crust, which was evident when it would momentarily bend, without cracking, as small waves emanated from spatter sites. Small folds, described below, also indicate a flexible nature to the crust. Brittle behavior was exhibited at the limits of the crust's

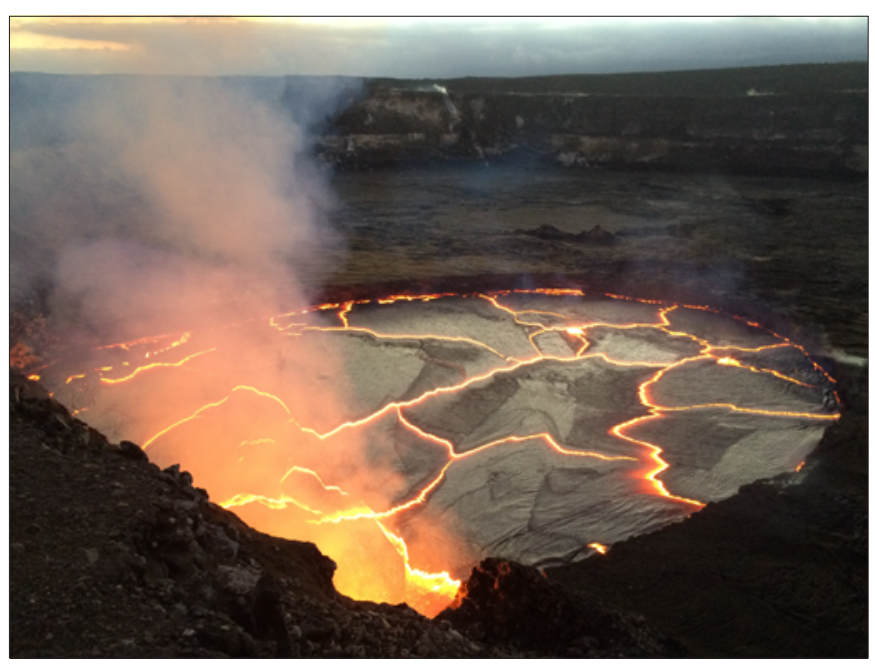

Figure 15. Typical view of the lava lake in 2016. Photograph taken from the rim of Halema'uma'u Crater, about 100 meters east of the Halema'uma'u Overlook on September 7. The lake surface consists of large (tens of meters across) black crustal plates separated by narrow incandescent spreading zones. The robust portion of the gas plume originates from spattering in the SE sink, which is just out of view on the near margin of the lake.

tensile strength, when tension ripped the surface and produced tears that propagated through the black crust.

Crustal plates were irregular in size, ranging from small (a few meters wide) to large plates that could span most of the lake surface (in other words, nearly $200 \mathrm{~m}$ across). We analyzed five high-resolution WorldView satellite images during 2016 that provided clear views of the lake surface during typical activity, and made measurements of a total of 96 crustal plates (table 1, figs. 17-19). At a given time the lake surface consisted of 16-22 plates (mean=19). The plates had an average longest dimension of $64 \mathrm{~m}$ (standard deviation of $35 \mathrm{~m}$ ), with a maximum of $182 \mathrm{~m}$. The average area of the individual plates was $1,949 \mathrm{~m}^{2}$ (table 1, fig. 17). The plate boundaries were often angular and jagged, but could also be arcuate (fig. 18).

The geometry of the plates was constantly changing during the course of plate migration from the upwelling zone in the north towards the south. Plate geometry changed as a result of (1) spreading zone migration from lake margins, (2) spreading zone replication, (3) plate splitting by way of crack propagation across a plate, and (4) plate fusing by way of spreading zone cessation. New plates formed near the upwelling area in the northern section of the lake in one of two ways. First, a plate might grow from the lake margin as a spreading zone migrated from the lake margin toward the lake center. Second, a plate might grow from a spot away from the lake margin (for example, in the upwelling zone in the north part of the lake) when a spreading zone replicated, forming two parallel spreading zones, with the new plate forming in the intervening gap as the two spreading zones migrated apart (figs. 20 and 21). New plates also formed from existing plates in two ways. First, a new plate might form as a result of a crack propagating across a plate, splitting it into two plates as 


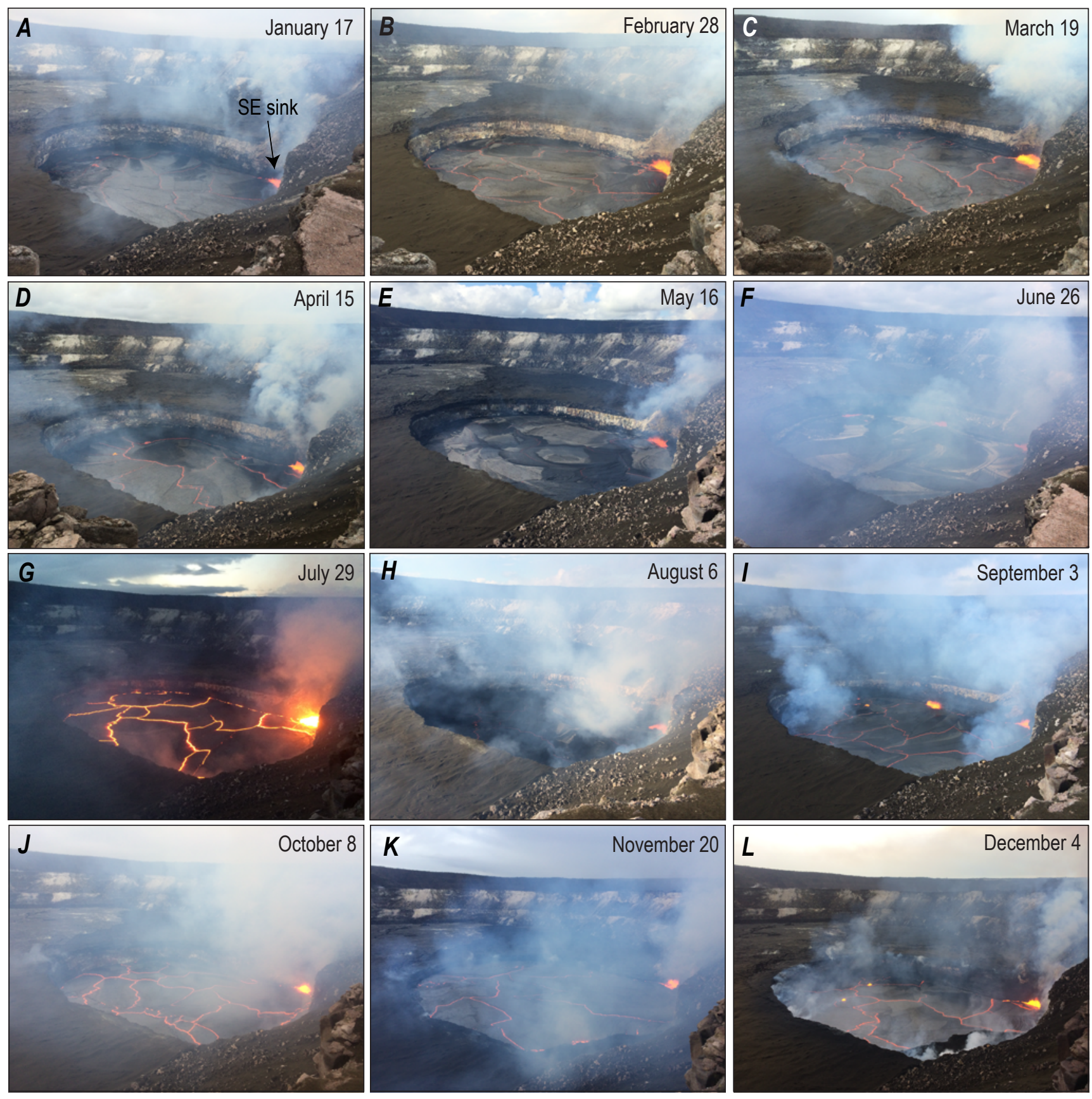

Figure 16. Monthly views of the lava lake during 2016. The shifting plume results in varying views of the lake. Lake activity was relatively steady throughout the year, but minor changes occurred. Lake level varied over several tens of meters (evident in this montage). Spattering was highly variable, but most commonly present in the SE sink. All 12 images in this figure show active spattering in the SE sink, but this does not imply that spattering was always present-in fact, spattering in the SE sink sometimes ceased for several hours at a time. 
Table 1. Summary of statistics for crustal plates in the lava lake at Overlook crater, Kïlauea Volcano, measured from high-resolution satellite data on five days in 2016.

[m, meters; Std Dev, standard deviation]

\begin{tabular}{|c|c|c|c|c|c|c|}
\hline Date & January 25 & June 25 & August 1 & October 13 & November 16 & Total \\
\hline Total lake surface area, $\mathrm{m}^{2}$ & 34,860 & 35,759 & 38,092 & 39,610 & 38,809 & \\
\hline Number of plates & 20 & 22 & 18 & 20 & 16 & 96 \\
\hline \multicolumn{7}{|c|}{ Area, $\mathrm{m}^{2}$} \\
\hline Minimum & 10 & 223 & 48 & 31 & 14 & 10 \\
\hline Maximum & 5,740 & 4,582 & 9,831 & 8,017 & 5,906 & 9,831 \\
\hline Mean & 1,743 & 1,625 & 2,116 & 1,981 & 2,426 & 1,949 \\
\hline \multicolumn{7}{|c|}{ Longest dimension, $\mathrm{m}$} \\
\hline Minimum & 5 & 25 & 14 & 11 & 6 & 5 \\
\hline Maximum & 118 & 104 & 182 & 151 & 150 & 182 \\
\hline Mean & 60 & 63 & 63 & 63 & 74 & 64 \\
\hline Maximum & 359 & 331 & 526 & 480 & 425 & 526 \\
\hline Mean & 176 & 174 & 181 & 182 & 214 & 184 \\
\hline Median & 139 & 169 & 125 & 176 & 213 & 164 \\
\hline Std Dev & 108 & 71 & 145 & 112 & 115 & 109 \\
\hline
\end{tabular}

January 25, 2016

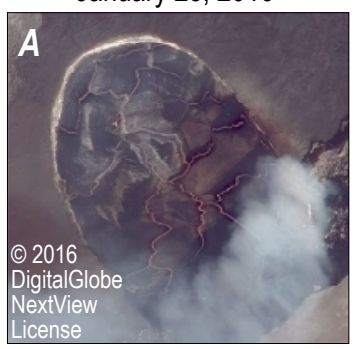

$\boldsymbol{F}$

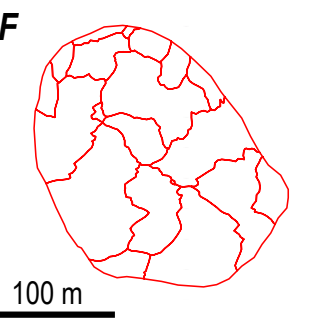

June 25,2016
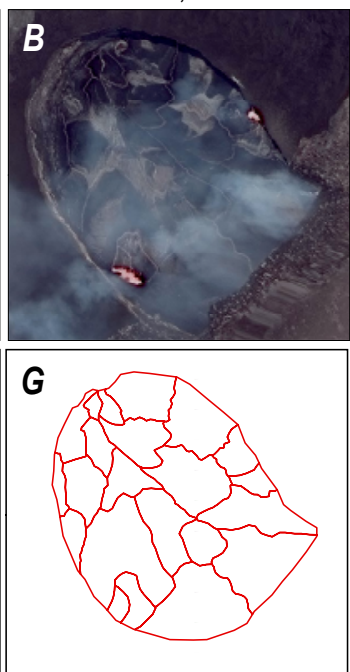

August 1, 2016
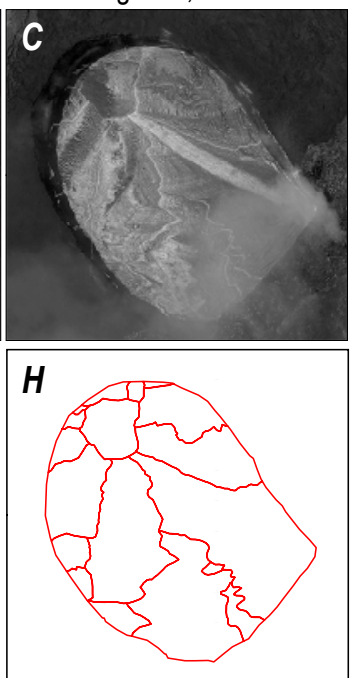

October 13, 2016
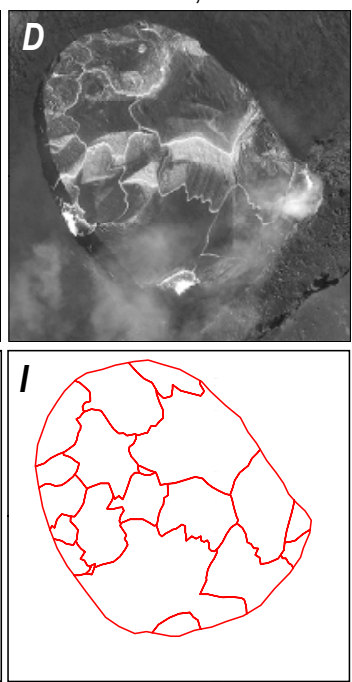

November 16, 2016

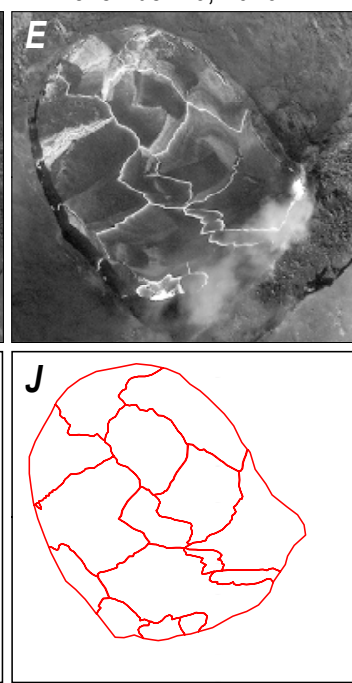

Figure 17. Satellite images of the lake in 2016. A-E, High-resolution WorldView satellite images of the lake through the year. F-J, Manually outlined drawings of crustal plates based on the satellite images. When the boundaries were not clear in the satellite images we used HTcam and HMcam images from the same time as the satellite acquisition to help identify plate boundaries. 
A.

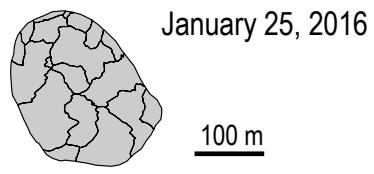

B.

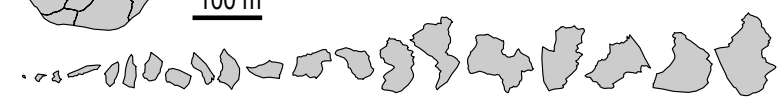

C.

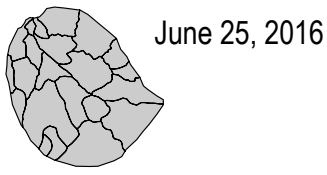

D.

E.

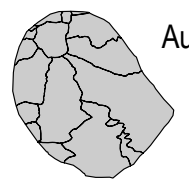

$F$

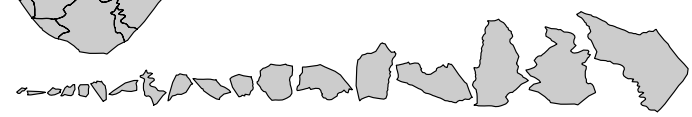

G.

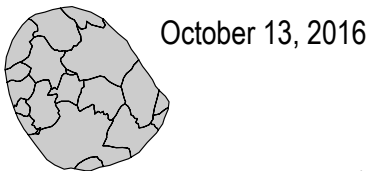

H.

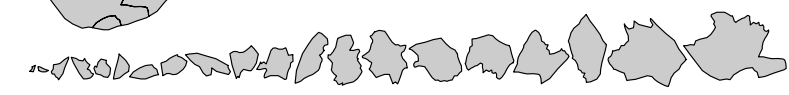

I.

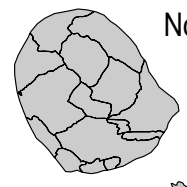

November 16, 2016

$J$.

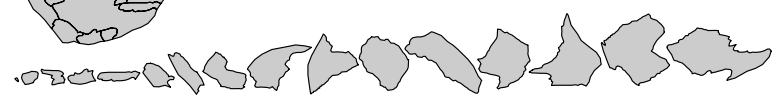

Figure 18. Drawings of crustal plate outlines based on five highresolution satellite images in 2016 (fig. 17). The crustal plates at each time are arranged by size to illustrate their varying geometries.

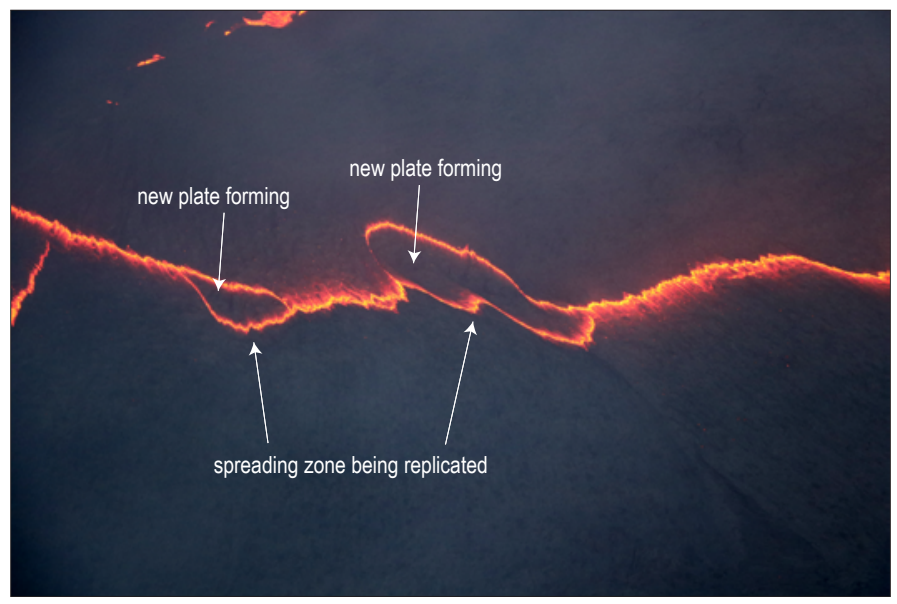

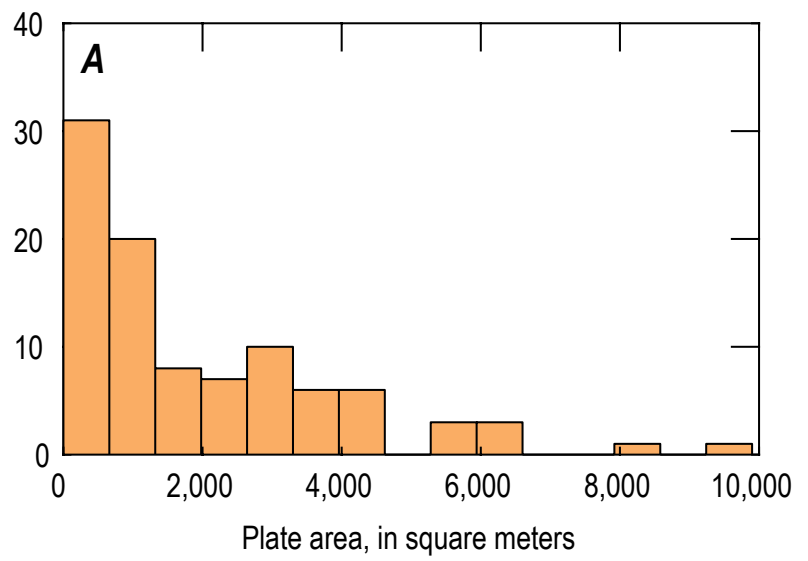
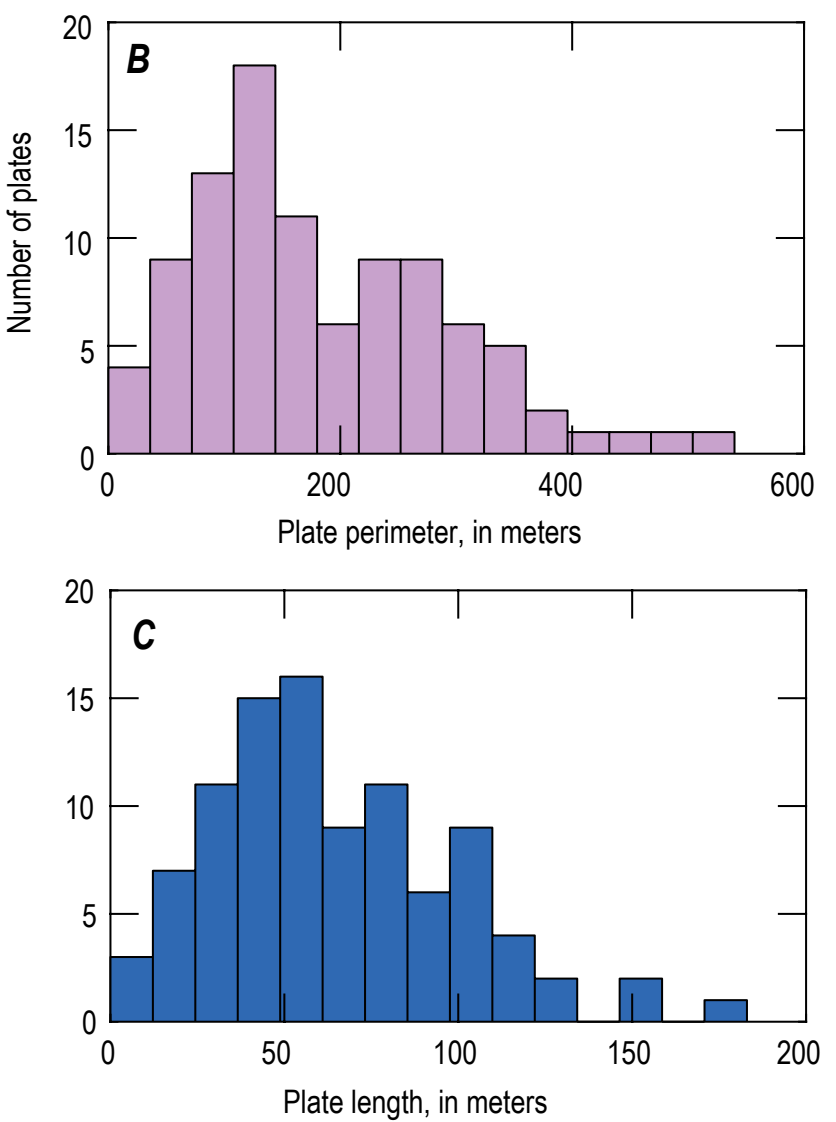

Figure 19. Histograms of crustal plate measurements taken from WorldView images (see figs. 17 and 18).

Figure 20. Image showing spreading zone replication and the formation of new plates. A spreading zone could replicate, forming two parallel spreading zones and a new, growing crustal plate in the intervening space. Photograph taken December 15, 2016. 

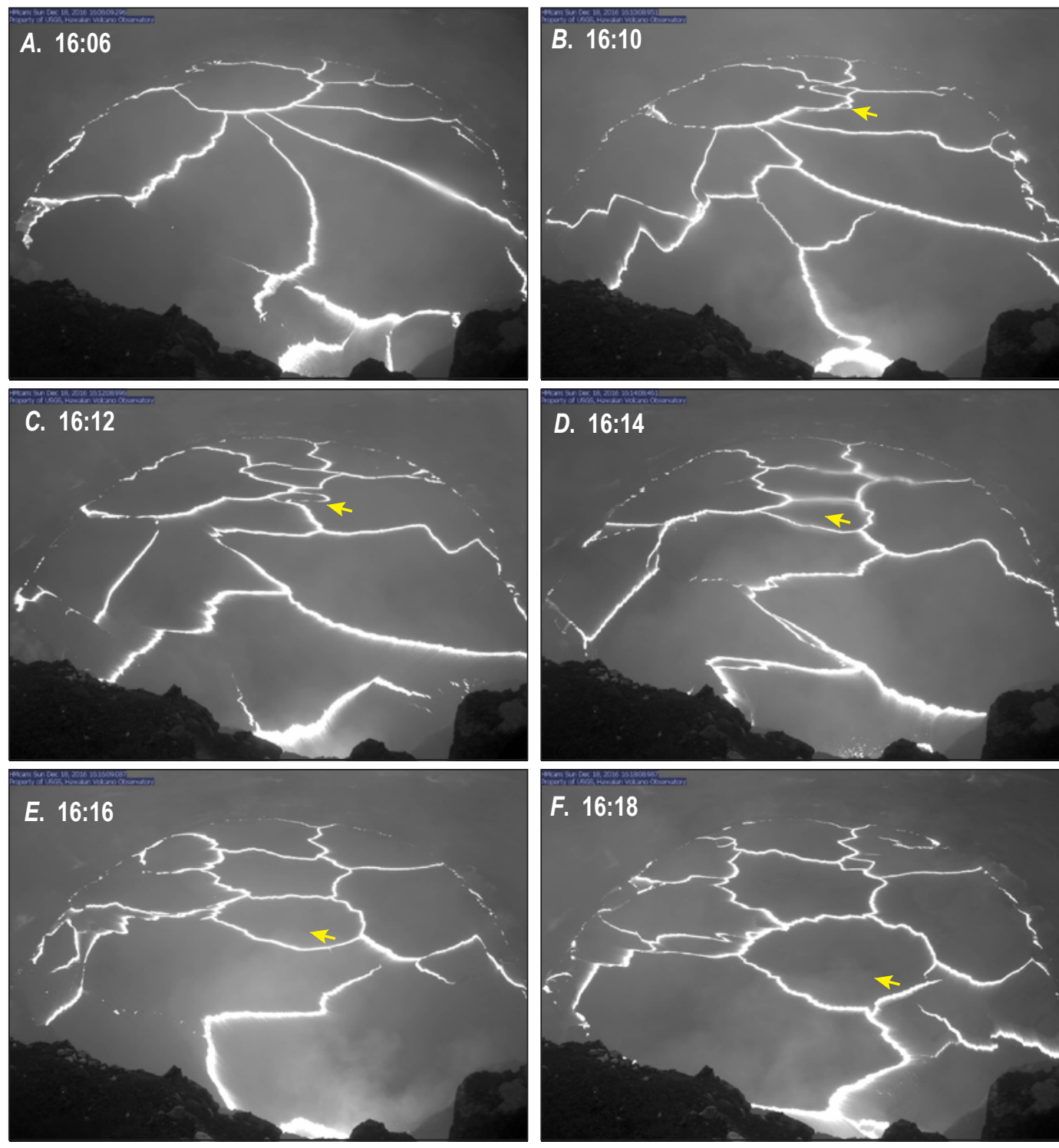

Figure 21. A sequence of HMcam images taken on December 18, 2016 (times are HH:MM HST), showing new plates forming by spreading zone replication. The yellow arrow tracks the formation and growth of a new plate, formed where a single spreading zone split into two parallel spreading zones, with the plate forming in the intervening gap. The plate is formed in the upwelling zone (north portion of lake) and grows steadily in area as it migrates south (towards bottom of image). a spreading zone developed along the crack (fig. 22). Second, spreading zones sometimes became inactive, allowing adjacent plates to fuse together into a composite plate (fig. 22).

Unusually large plates, sometimes covering nearly the entire visible lake surface as viewed from the HTcam, occasionally formed (fig. 23). These "megaplates" grew from fusing of individual plates as the lake surface velocity dropped substantially, which was normally associated with spattering in the northern margin of the lake that initiated a flow reversal towards the north (Patrick and others, 2016c). Further work has shown that the average plate size across the lake at a given time is inversely related to the overall surface velocity (and therefore plate number scales with surface velocity). In other words, a rapid surface flow produced smaller plates, of a greater number, while a slowed surface flow produced larger plates, of lesser number.
Occasional large rockfalls impacting the lake surface triggered sloshing across the entire lake that abruptly pulled and split plates into smaller units, creating many small plates. This process created a greater number of plates than was usual at any one time, and was a conspicuous indicator of a recent collapse (fig. 24). Once the waves on the lake surface subsided, within several minutes small plates fused into larger ones and the lake surface returned to having a typical number of plates.

In some cases a static plate formed near the northern margin and remained attached to the crater wall, providing a cap on the upwelling zone (fig. 25). When this occurred long crustal plates radiated out from the margins of the static plate, extending into and migrating towards the southern portion of the lake. Sometimes portions of the static plate would detach from the leading edge and be shed into the current while the rest of the static plate remained attached to the crater wall. 

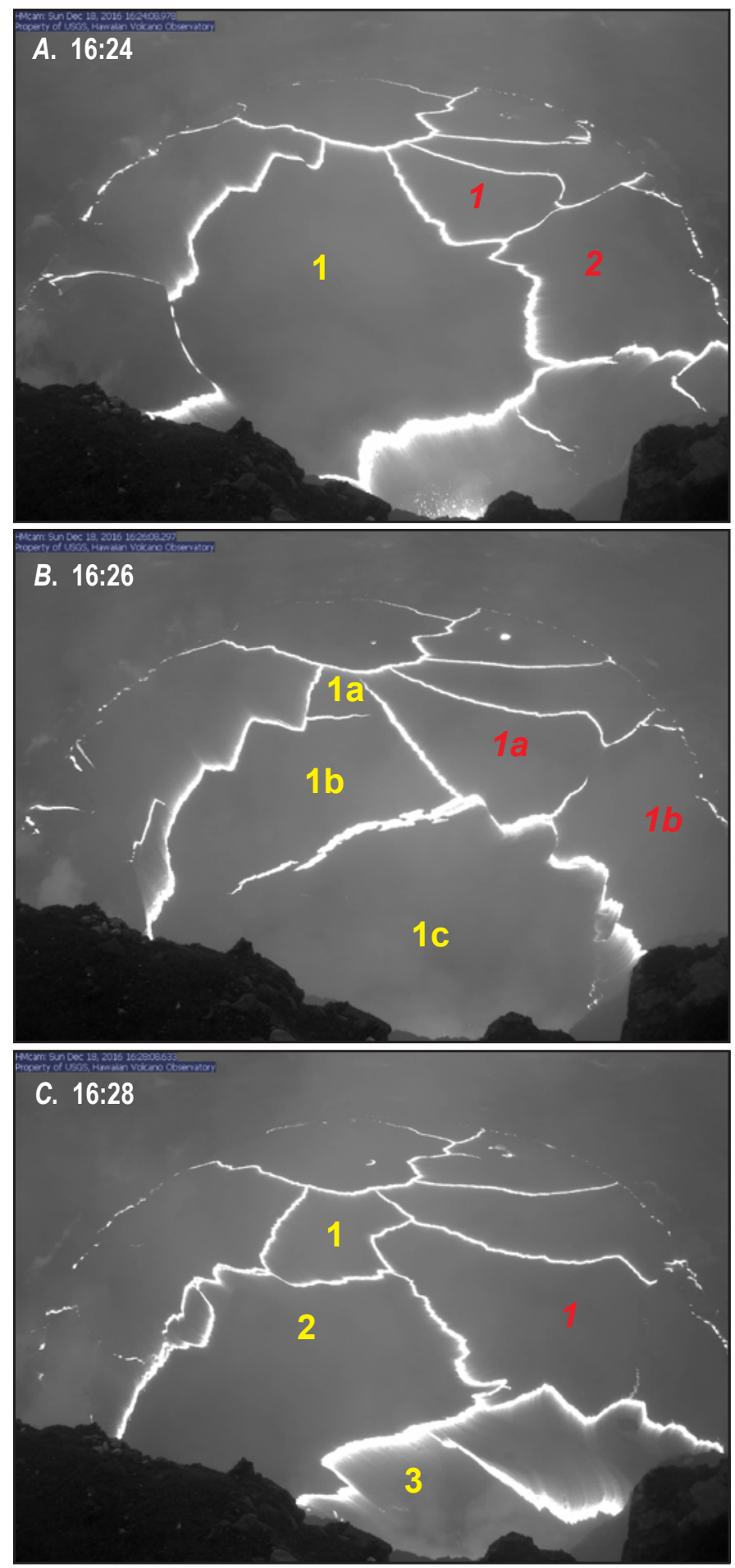

Figure 22. A sequence of HMcam images taken on December 18, 2016 (times are HH:MM HST), showing new plates forming from existing plates in two ways, First, as marked by the yellow labels, a single plate could develop a propagating spreading zone that split the plate into two or more new plates. In this example, one plate (1) is split into three plates $(1 a, b, c)$. Second, as marked by the red labels $(1 a, b)$, multiple plates could fuse together to form a composite plate (1). In this example, the spreading zone separating two plates gradually becomes inactive, solidifying and fusing the two plates into one.
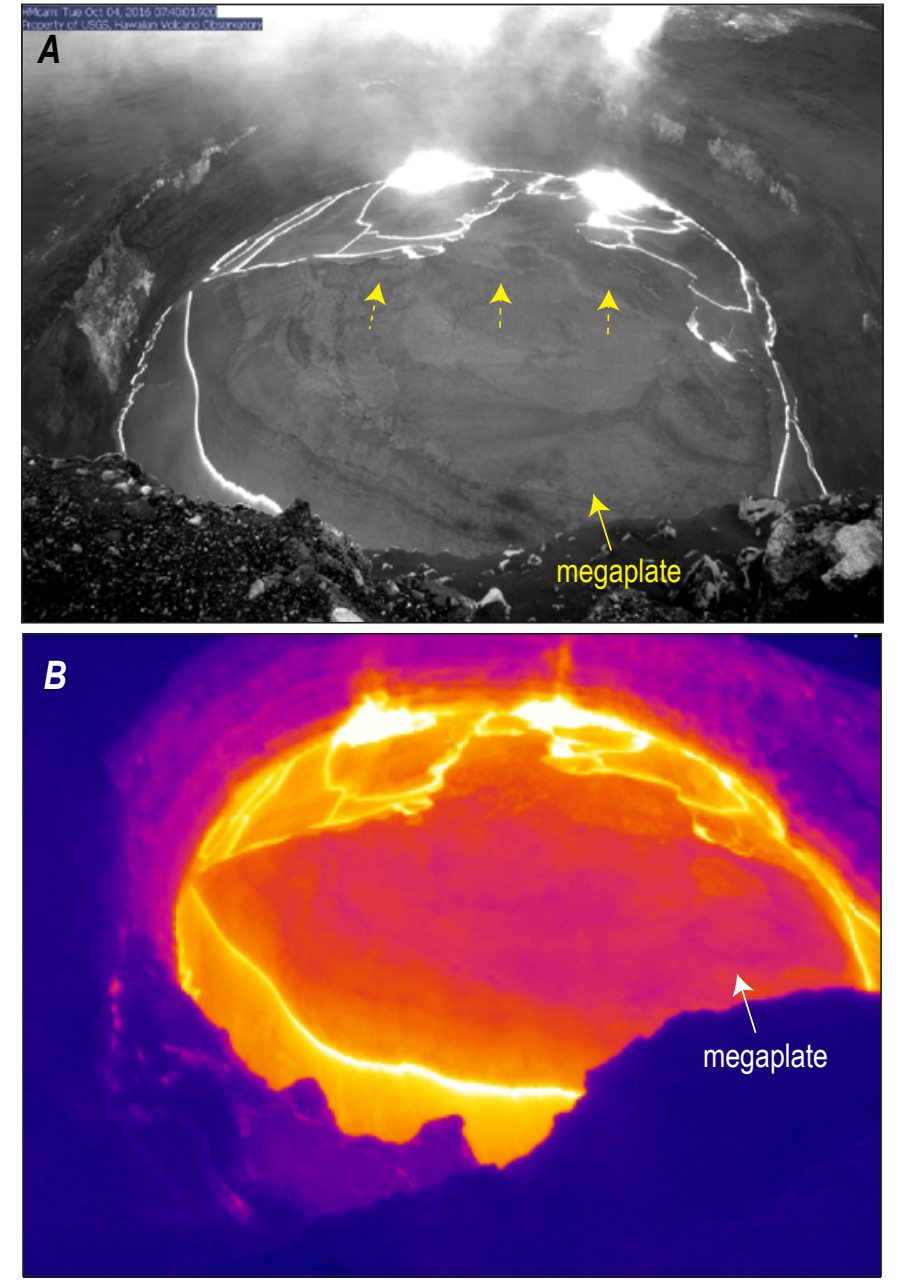

Figure 23. Images taken from HMcam $(A)$ and $\mathrm{HTcam}(B)$ at roughly the same time (October 4, 2016 at 07:40 HST) showing the formation of a megaplate. When the lake surface velocity dropped to very low levels, often associated with spattering in the northern part of the lake which would trigger a reversal of the typical southward flow, adjacent plates could fuse together as spreading zones became inactive, forming a megaplate that covered the majority of the lake surface (Patrick and others 2016c). The yellow arrows in $\boldsymbol{A}$ give a sense of the general motion of the megaplate at this time, which was towards the two spatter sites at the northern lake margin. 

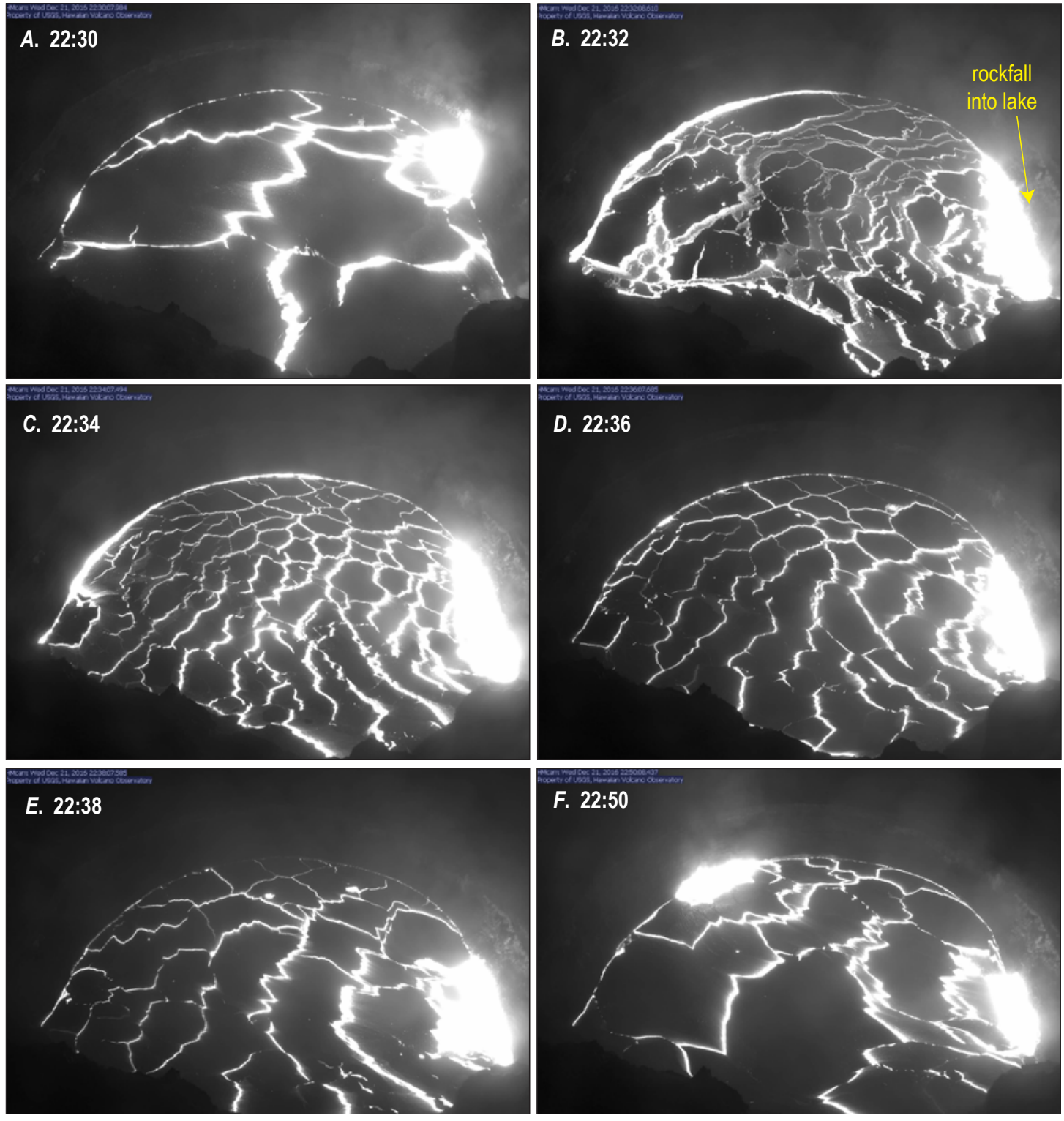

Figure 24. Sequence of HMcam images from December 21, 2016, showing a rockfall (occurs around 22:32 HST) that triggered waves and sloshing of the lake surface and created many small plates. Plate size returned to normal within about 20 minutes. Times are shown as $\mathrm{HH}: \mathrm{MM}$ HST.

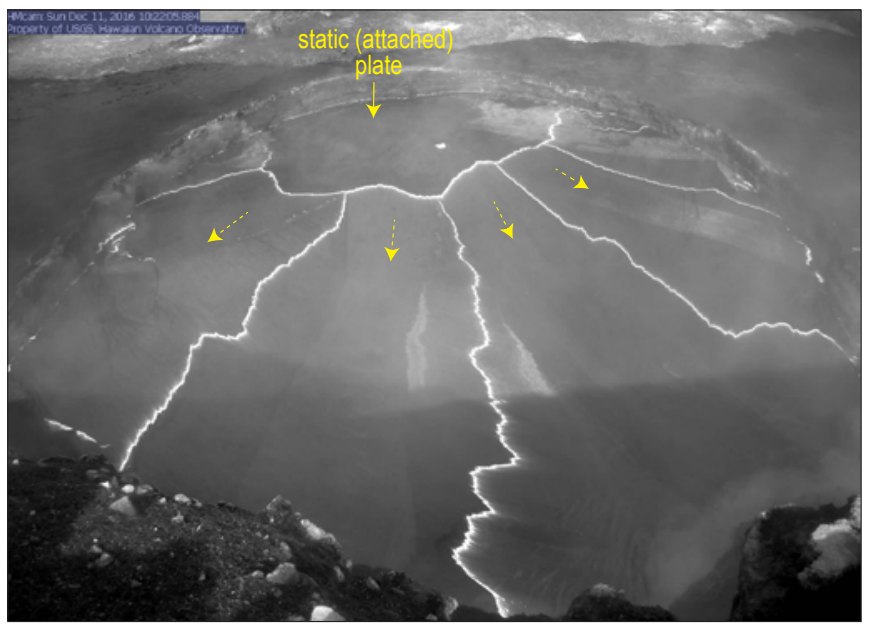

Figure 25. HMcam image from December 11, 2016, at 10:22 HST, showing a static plate at the lake margin. At times, a plate could remain attached to the northern lake margin, providing a cap over the upwelling zone. When this happened, long crustal plates radiated out from the static plate, spanning the majority of the length of the lake surface. The yellow arrows show the general motion of these radiating plates. 


\section{Plate Margins}

We describe a number of different types of plate margins, including (1) simple spreading (both symmetric and asymmetric), (2) pulled, (3) transform, (4) unzipping, and (5) foundering. In the sections below we discuss the relative motion of adjacent plates, but it is important to note that, in most circumstances, the plates and margins were together migrating with the overall southward lake motion.

The most common type of margin was simple spreading, which could range from symmetric to asymmetric (fig. 26). Spreading margins consisted of a narrow $(<1 \mathrm{~m}$ wide) linear zone of incandescent lava where crust was formed and slowly moved away from the spreading zone. Often the narrow incandescent zone formed a jagged, zig-zag line. In other places the spreading zone was offset in steps with transform (strike-slip) margins in between Symmetric spreading zones consisted of a bright incandescent centerline that transitioned evenly on both sides to dull incandescence, and then black crust, suggesting similar spreading rates on either side of the margin. In asymmetric spreading zones, new crust formed only on one side of the incandescent zone. In this case the incandescent zone had an abrupt boundary with welldeveloped black crust on one side, with the other side having the gradual transition into dull incandescence and then black crust. In asymmetric spreading zones, incandescent lava flowed out from underneath the more slowly moving black crust of the parent plate.

Pulled margins were zones of enhanced spreading owing to proximity to a spatter site, where surrounding crust is pulled more rapidly than it would move passively elsewhere in the lake (fig. 27). The crust was "pulled" downward into the volume evacuated by gas escaping from the lava. The pulled margins produced larger zones of fresh, incandescent lava, which tended to have enhanced bursting of small (decimeter size) bubbles, perhaps as a result of the larger span of fluid, uncrusted lava.

Transform margins consisted of strike-slip motion between plates, and sometimes exposed little to no incandescent lava (fig. 28). Instead, the margins had small transpressional folds resulting from slight compression, and the folds on each side of the margin were in contact, or nearly so, masking any incandescence between the plates. Transform margins often occurred in steps between offset zones of spreading.

Often an intact plate would be pulled apart, creating a rapidly propagating incandescent crack in the black crust, sometimes consisting of small, discontinuous en echelon cracks at the leading edge (fig. 29). As the crack tip propagated, the crack behind the tip would spread open, creating a triangular wedge of incandescent lava cutting through the plate. We call this an unzipping margin. As fluid lava in the wedge cooled slightly, towards the dullest level of incandescence, it would develop a classic zig-zag incandescent spreading line. The propagating crack tip would eventually intersect another spreading zone (sometimes at right angles) over the course of tens of seconds, and the unzipping margin would transition to a simple spreading zone.

Crustal foundering was a process whereby slabs of crust would detach, slide, and sink into the lake, exposing patches of fluid incandescent lava that often experienced minor bubbling. Slabs from both sides of the margin were often dragged down together. Foundering rarely happened near the center of the lake and was much more common around the lake margins and in the very southern portion of the lake near the southern ledge (fig. 30). One exception was during times of megaplates, described above, in which a single large plate covered much of the lake surface. At these times, the megaplate was susceptible to foundering that could occur near the center of the lake. Crustal foundering is common in static lava lakes, such as Kīlauea Iki in 1959 (Stovall and others, 2009); the nearly constant movement within the Overlook crater lava lake probably inhibited the conditions required for foundering.

At the lake margins the downwelling process often involved a narrow zone of foundering, extending out from the crater walls by a few meters (fig. 31). In other cases, the lava simply subducted against the crater wall at the immediate lake margin without any foundering.
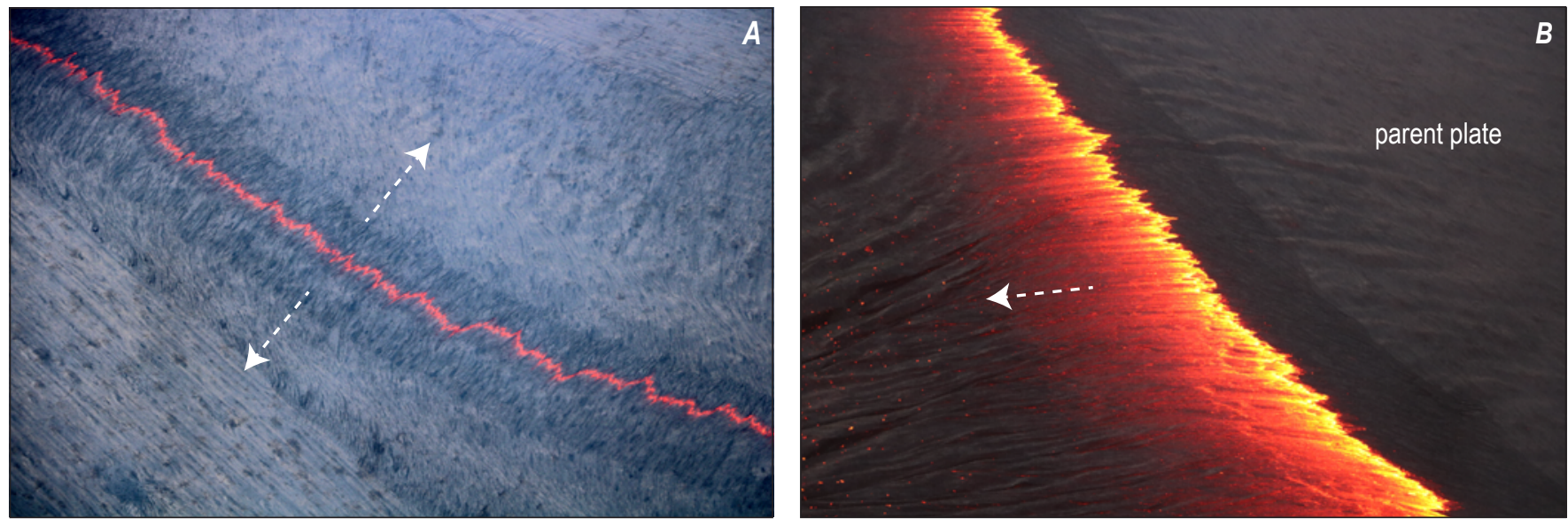

Figure 26. Photographs showing the most common type of plate margin, simple spreading. $A$, Symmetric spreading involves adjacent plates moving at roughly the same rate. Photograph taken December 8,2016 . B, Asymmetric spreading involves one plate moving more rapidly away from a more slowly moving plate. In this case, fresh lava had the appearance of flowing out from under a parent plate. For scale, the image spans roughly 25 meters from left to right. Photograph taken November 26, 2016. Dashed white arrows indicate general direction of plate movement. 


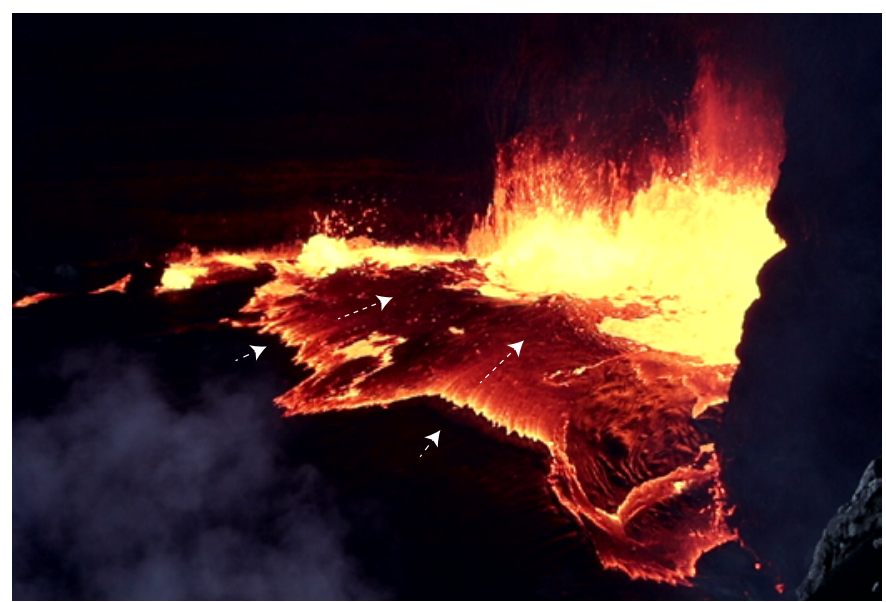

Figure 27. Photograph showing a pulled margin near the SE sink on December 12, 2016. White arrows show the approximate motion of the lake surface. Crustal plates near spattering sites are "pulled" towards the spattering at a higher velocity than they would normally experience on the lake. When these plates rapidly migrate towards the spatter, a detachment zone forms, which we call a pulled margin. At this margin, a broader area of incandescent lava was exposed compared to normal spreading zones. Often, enhanced bubbling was present in this incandescent zone.
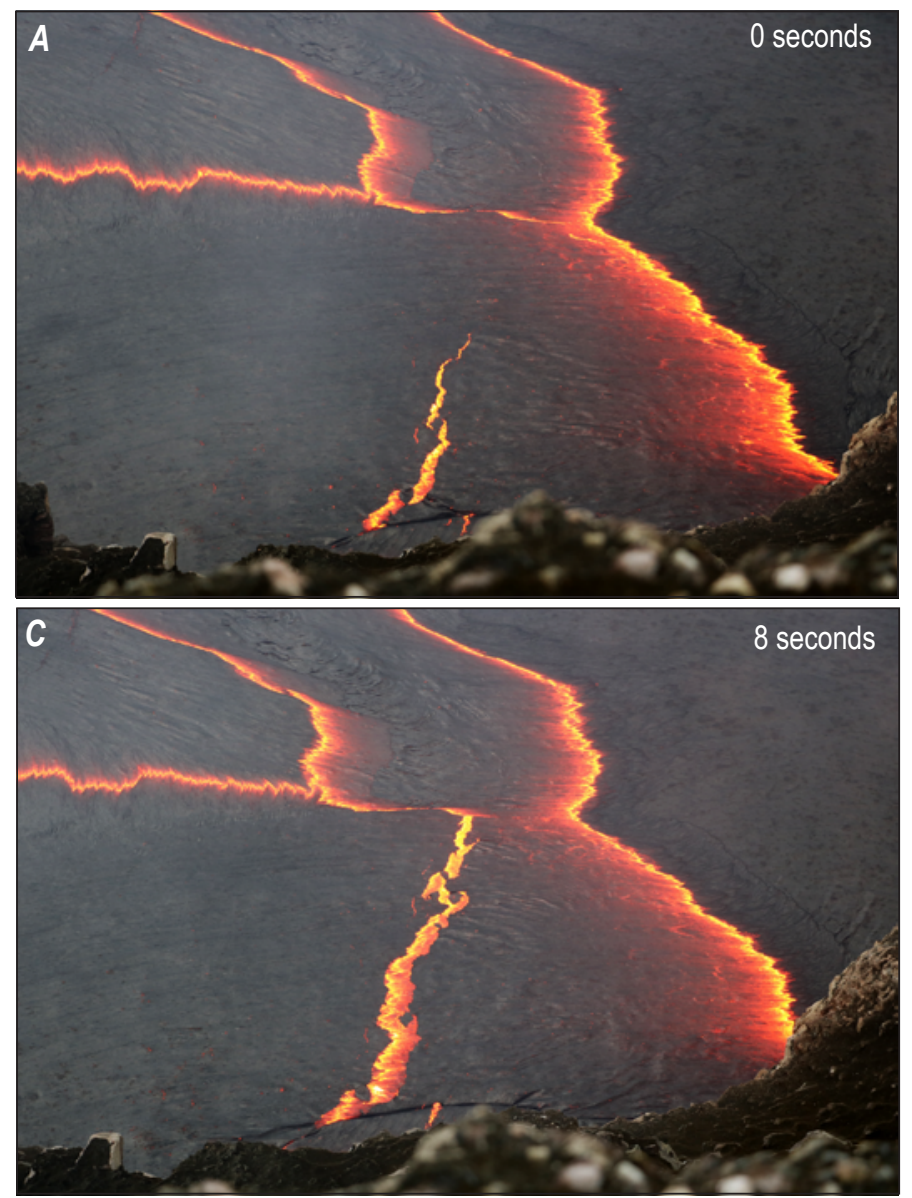

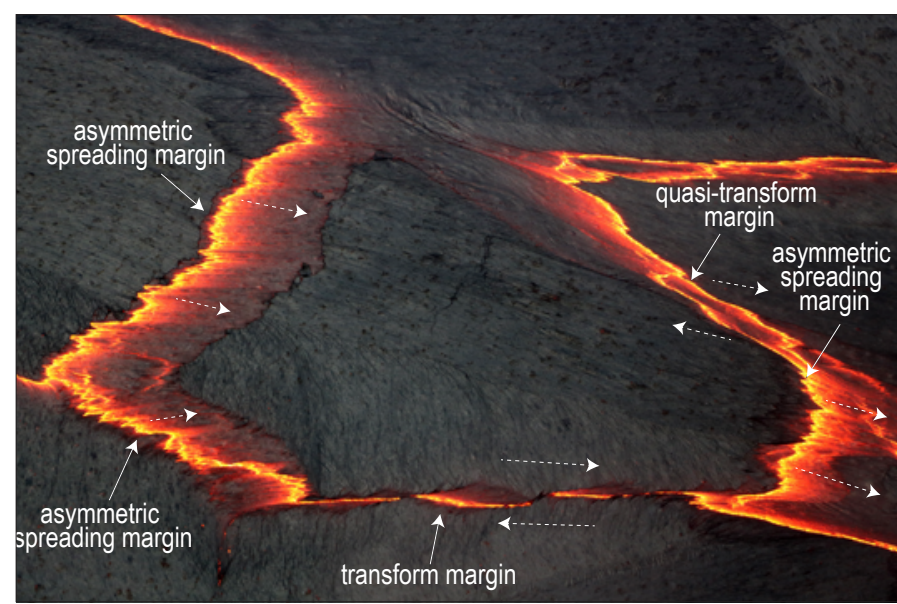

Figure 28. Photograph showing an example of strike-slip motion on a crustal plate margin, where only a minor amount of incandescent lava was exposed (bottom of photograph). Quasi-transform margins, where the spreading direction was highly oblique to the trend of the plate margin, could also occur (upper right area of photo). Photograph taken December 12,2016
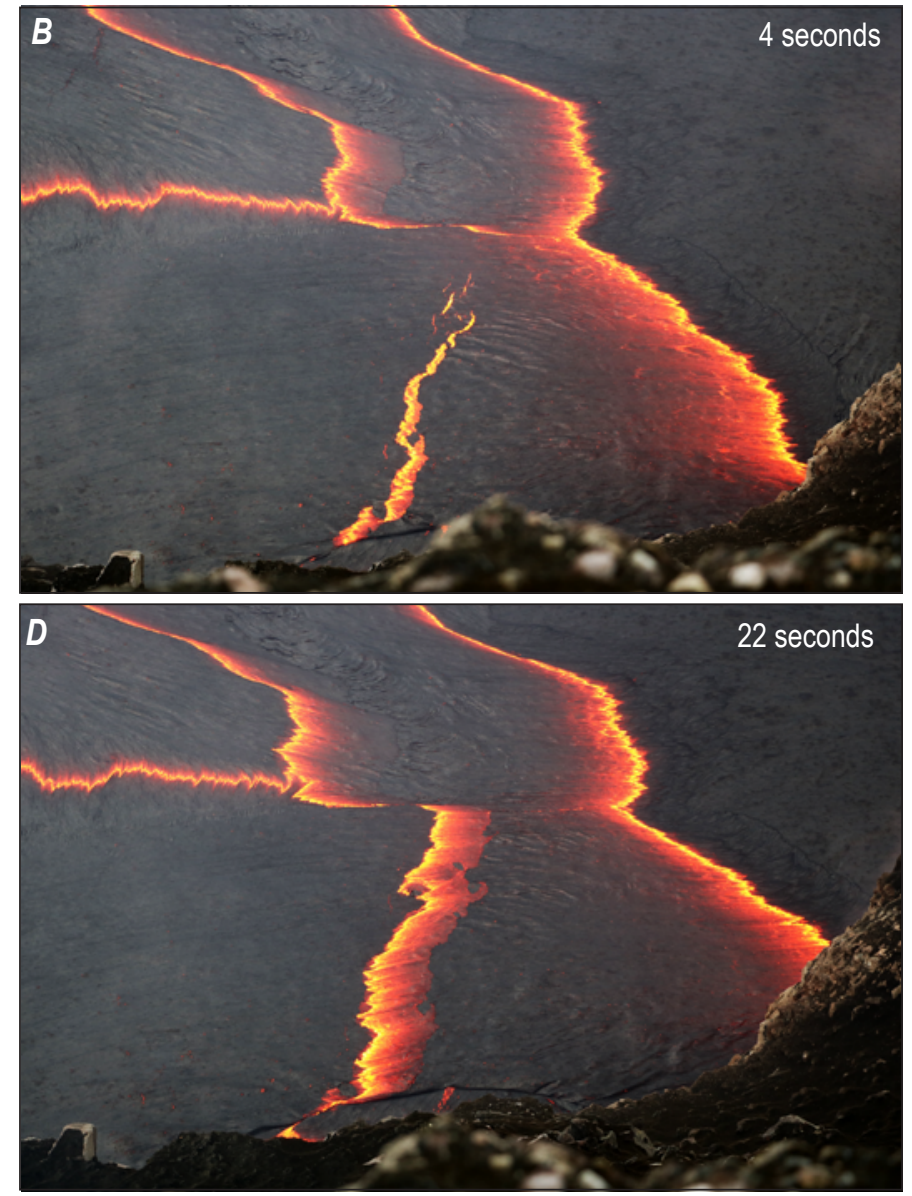

Figure 29. Time-lapse images from December 12, 2016, at 17:11 HST, of a propagating crack in the crust. New spreading zones could appear when a plate "unzipped", with the propagating, discontinuous crack and spreading zone migrating across the plate, and intersecting another spreading zone. In this example, the crack traverses approximately 9 meters, about half the plate span, in roughly 8 seconds. 

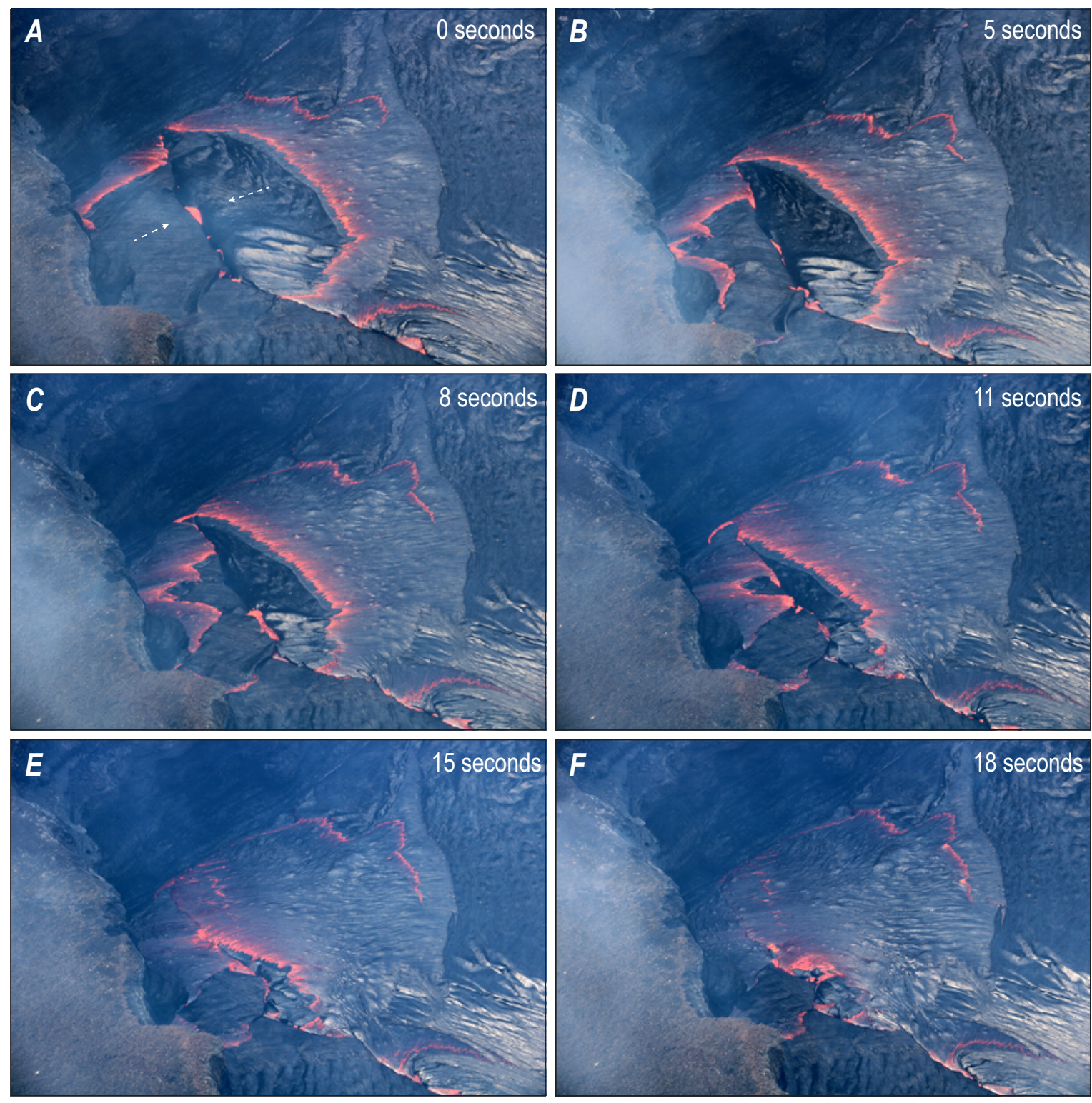

Figure 30. Time-lapse images showing crustal foundering, which normally occurred near the lake margins, particularly in the southern portion of the lake, as it is in this example from December 22, 2016 (at 12:17 HST). In A, the arrows show the convergent motion of the two plates, which eventually subduct against one another and disappear into the lake. The southern ledge is visible at the left side of the images.

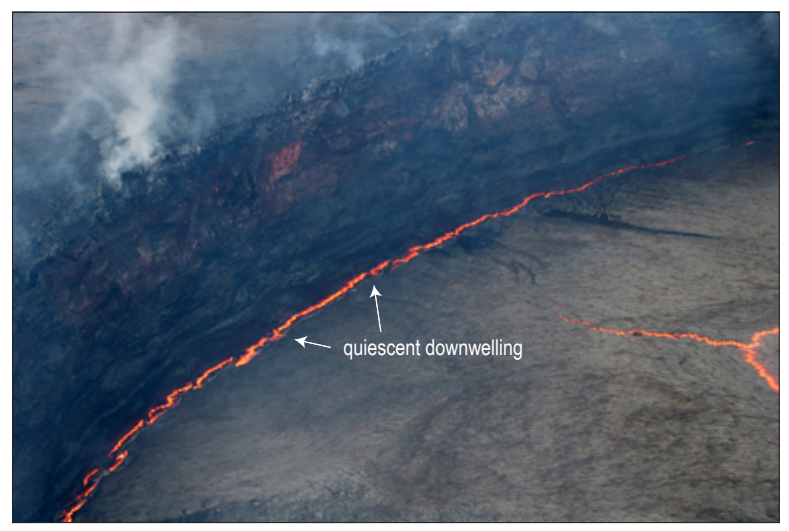

Figure 31. Photograph of quiescent downwelling at the lake margin, taken December 12, 2016, at 17:13 HST. The majority of the lake margin had lava quietly downwelling against the crater wall, in a zone of foundering that extended out from the crater wall by a meter or two. 


\section{Surface Relief}

The crustal plates were commonly covered by scattered small (1-2 $\mathrm{m}$ diameter) domes that resembled blisters (fig. 32). The formation of these blisters has been observed clearly by the naked eye and video, and consisted of a thin, semi-flexible surface crust abruptly doming up within a second or two - suggesting that a bubble of gas rose and was trapped beneath the crust. Occasionally these blisters would burst as they formed, and eject a small bit of spatter, reinforcing the interpretation that the blisters are discrete bubbles rising to the surface that fail to break the crust.

Although most of the lake surface was relatively smooth, folds did occur (fig. 33). Small folds, with wavelengths less than a meter, could occur anywhere on the lake and were associated with localized compression of the thin semi-flexible crustal plates, particularly near spreading zones. Larger folds, with wavelengths of several meters, tended to occur near the lake margins where lava was downwelling. Large folds were particularly common in the southern portion of the lake near the southern ledge, perhaps because the crust was thicker in the section of the lake farthest from the upwelling area.
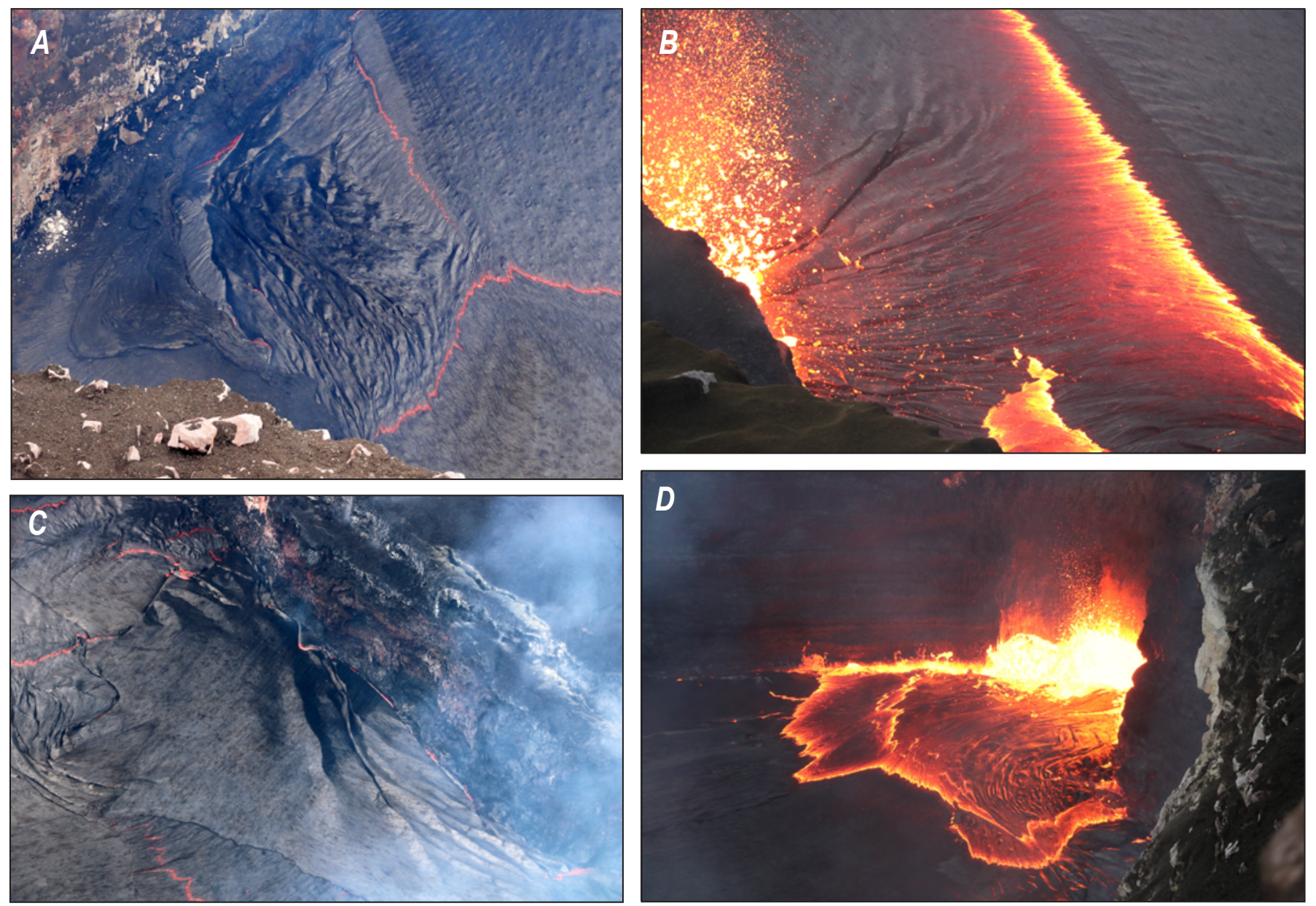

Figure 33. Photographs showing small folds on the lake surface. Small folds, attesting to the thin and semi-flexible nature of the surface crust, were common near the lake margins where lava downwelled. Most folds appeared to have amplitudes less than 1-2 meters. A, A series of folds along the southern lake margin on January 12, 2016. B, Folds in front of a spattering site, along the southern lake margin on November 26, 2016. C, Larger folds along the eastern lake margin on December 8, 2016. D, Small folds made visible by the incandescence from spattering in the SE sink, on December 12, 2016. 
Small waves were another surface relief feature but were limited strictly to the immediate area surrounding a spatter site. The waves appeared to have an amplitude of 1-2 $\mathrm{m}$, and extended roughly 5-10 m out from the spatter site. The black crust rolled atop the waves as they passed, without being torn or broken, consistent with a thin and flexible crust.

No lidar data were collected during 2016, so we do not have precise information on the variations in surface elevation across the lake. Data from 2013 indicated that the upwelling zone was $0.6 \mathrm{~m}$ higher than the southern part of the lake (Anderson and others, 2014).

\section{Surface Texture}

Crustal plates often had a variety of surface textures (fig. 34). Surface texture could be used for tracking the provenance of different portions of a given plate, sometimes allowing us to link a given area of the plate to the particular spreading zone where it formed (fig. 35). The surface textures across the lake were best observed at dawn or dusk when oblique sunlight highlighted the surface relief.

A uniformly rough texture, on the scale of centimeters, was commonly observed and was associated with symmetric spreading zones (fig. 26). Striations were a common feature on the crustal plates (Duffield, 1972), often extending the entire length of plates, and were associated with asymmetric spreading zones. Close-up photographs showed that the striations corresponded with small jagged points along the front of the asymmetric spreading zone where the striated crust formed (fig. 36). The lava extruding from the embayments between the jagged points seemed to form narrow ridges, whereas the lava extruding out from the tips of the jagged points formed subtle valleys. This small-scale relief appears to correspond to the striations. Striations were oriented parallel to the direction of spreading and thus indicated the direction of flow as the crust moved away from the spreading zone where it formed, which was useful in determining plate provenance (fig. 35).

At times, alternating bands of light and dark crust developed parallel to the spreading zones, and probably represented variations in the surface texture highlighted by the sun angle (fig. 37). These surface texture differences presumably were produced by changes at the spreading zone, perhaps in the spreading rate, but we do not know for sure.

The crustal plates commonly had many small, centimetersized scattered holes that exposed incandescent lava beneath the crust. These holes were easily visible at night, and resembled stars in the night sky (fig. 38). The holes seemed to be produced at spreading zones when small bubbles burst through the nascent, solidifying crust, with the hole preserved as the crust migrated away from the spreading zone. The holes were more abundant in certain zones of a given plate, suggesting that they were more likely to be formed at some spreading zones than others.

When plates were split apart by unzipping margins, new spreading zones appeared and supplied fresh lava to the surface. The newer lava commonly had a different surface texture than the original plate that was split apart, and the original "proto-plate"

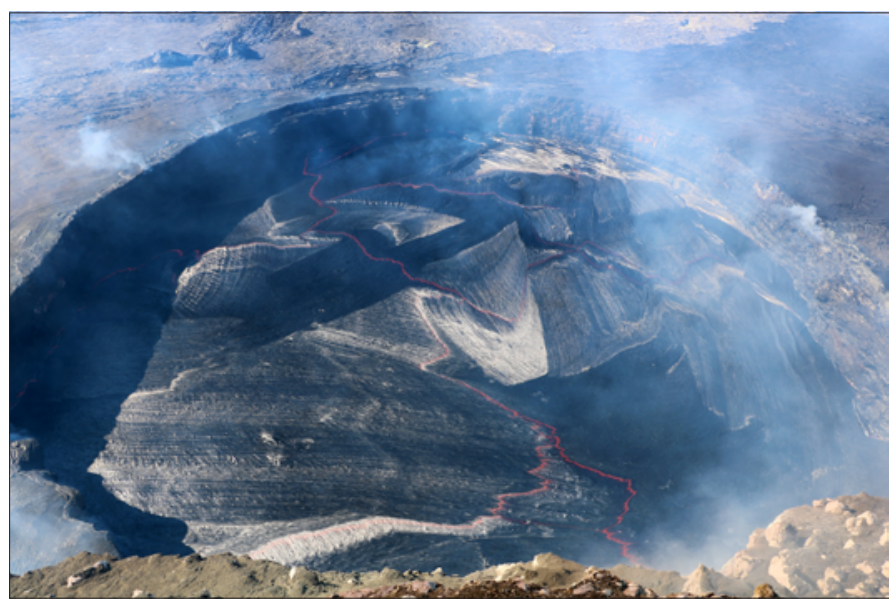

Figure 34. Photograph taken October 26, 2016, at 15:16 HST, showing the patchwork appearance of the lake surface. A given plate could have several areas of differing textures, including striations oriented at different angles (Duffield, 1972). At low sun angles, these texture differences produced strong differences in the brightness of the lake surface.
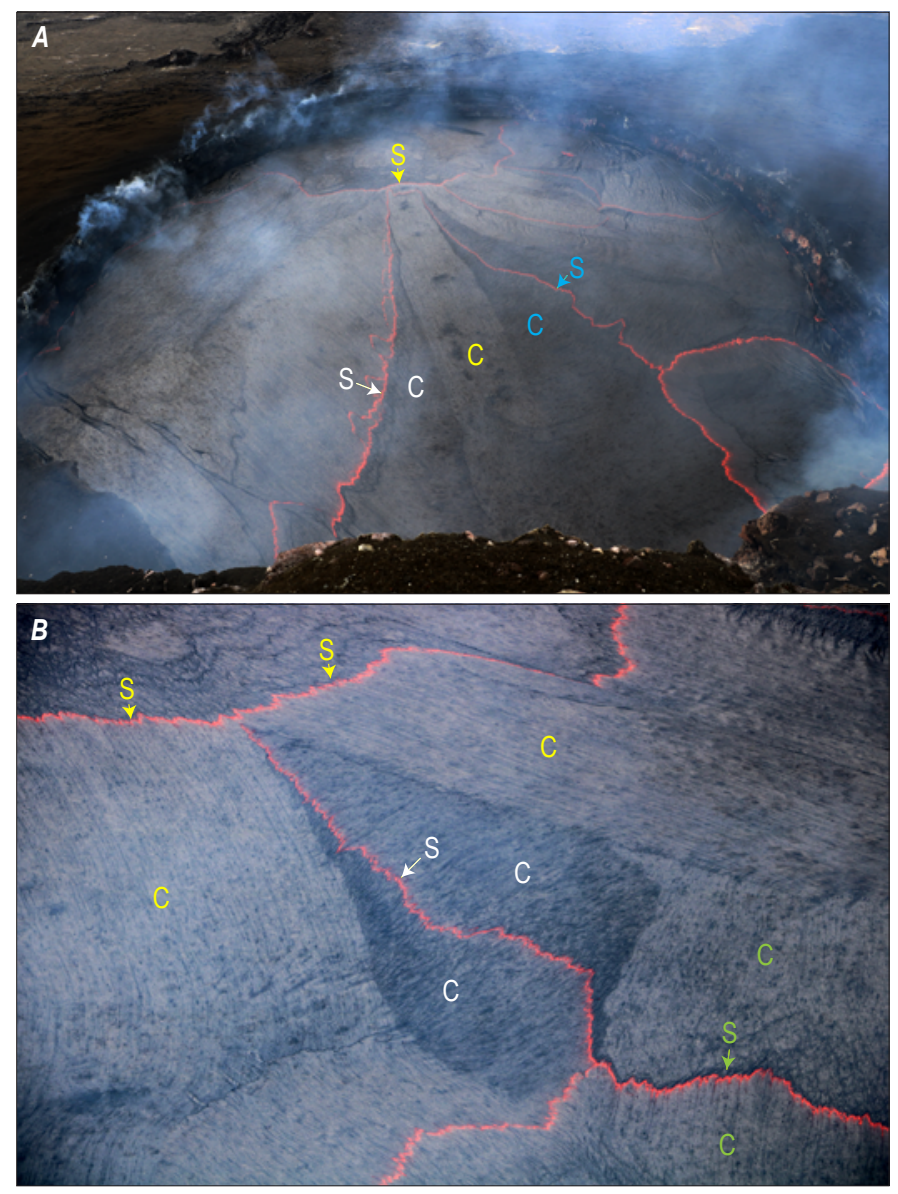

Figure 35. Photographs taken December 8, 2016, showing the provenance of crustal plate areas. In many cases the surface texture could be used to link a given portion of a crustal plate to the spreading zone where the crust formed. In these examples, the area of crust (labeled " $\mathrm{C}$ ") can be linked to its parent spreading zone ("S" of the same color). 

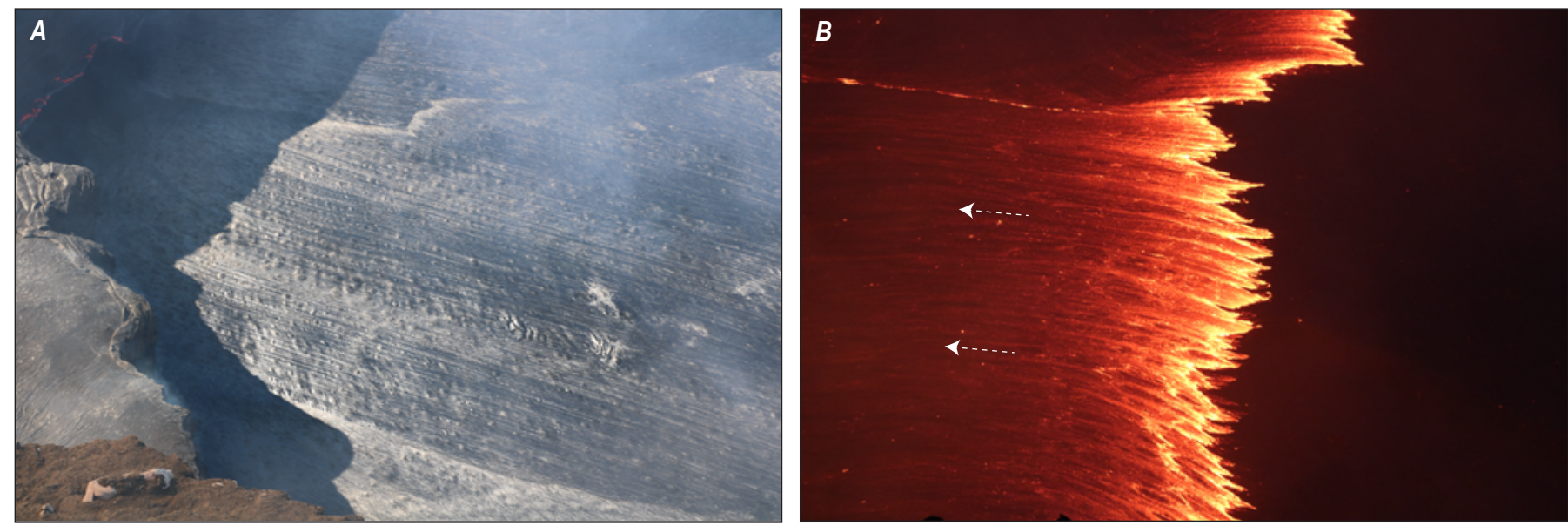

Figure 36. Photographs showing striations on the lake surface. $A$, Long parallel striations on the lake surface were common, and best visible in low-angle sunlight. Image taken October 26,2016 , at $15: 15$ HST. B, These striations appeared to represent small ridges and valleys formed by jagged boundaries of the parent plate at asymmetric spreading zones. Image taken December 10, 2016, at 17:53 HST.
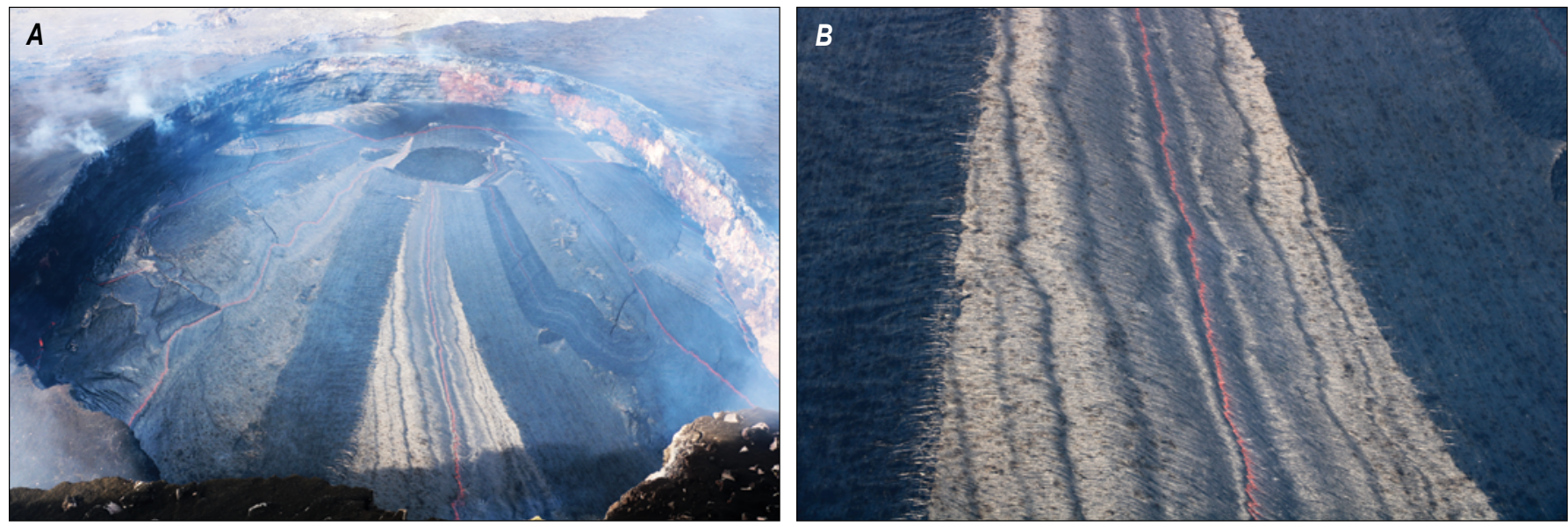

Figure 37. Photographs showing alternating bands of darkness parallel to the spreading zones. The bands probably relate to variations in surface texture, and presumably reflect changes in the spreading zone. Photographs taken December 22, 2016.

Figure 38. HMcam image from December 1, 2016, at 01:00 HST, showing pinholes on the lake surface. Small (centimeter size) holes were common in crustal plates, resulting in tiny spots of incandescence scattered across the plate surface. The holes appeared to form from tiny bubble bursts in the region of fluid (or semi-fluid) lava at spreading zones, with the hole preserved as the crust solidified.

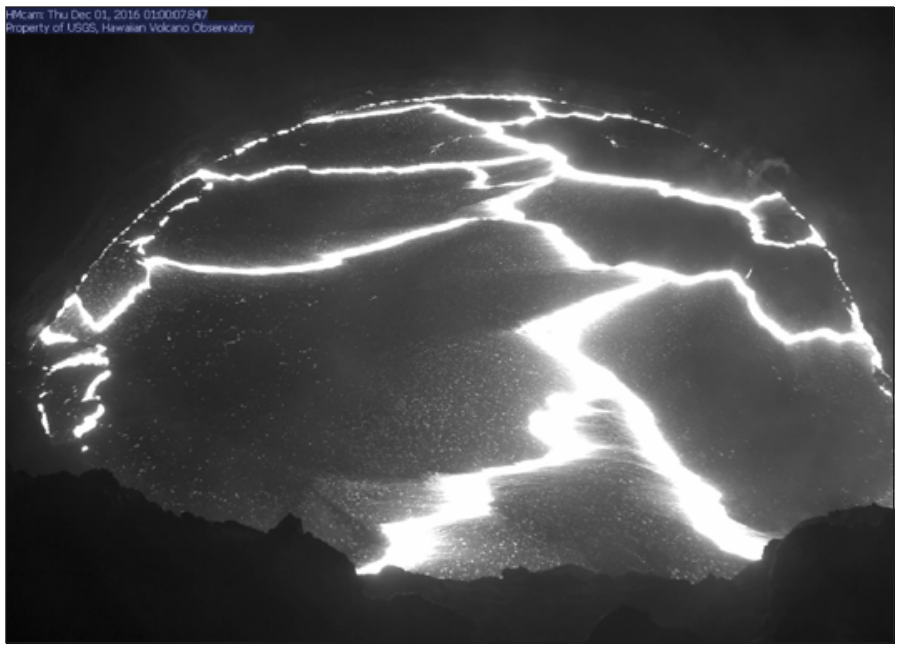


was sometimes surrounded by this differing surface texture, appearing as an island of older crust that was often distinct to the naked eye (fig. 39). Thermal camera images provided an even clearer distinction between the proto-plates and the newer lava, with the proto-plates having a much lower apparent temperature (about 45 degrees Celsius $\left[{ }^{\circ} \mathrm{C}\right]$ lower in the example in figure 39) than the newer lava owing to the greater exposure time of the proto-plate. Proto-plates were often portions of static plates (attached to the northern lake margin) that broke off and were shed into the southward current, as in the example shown in figure 39.
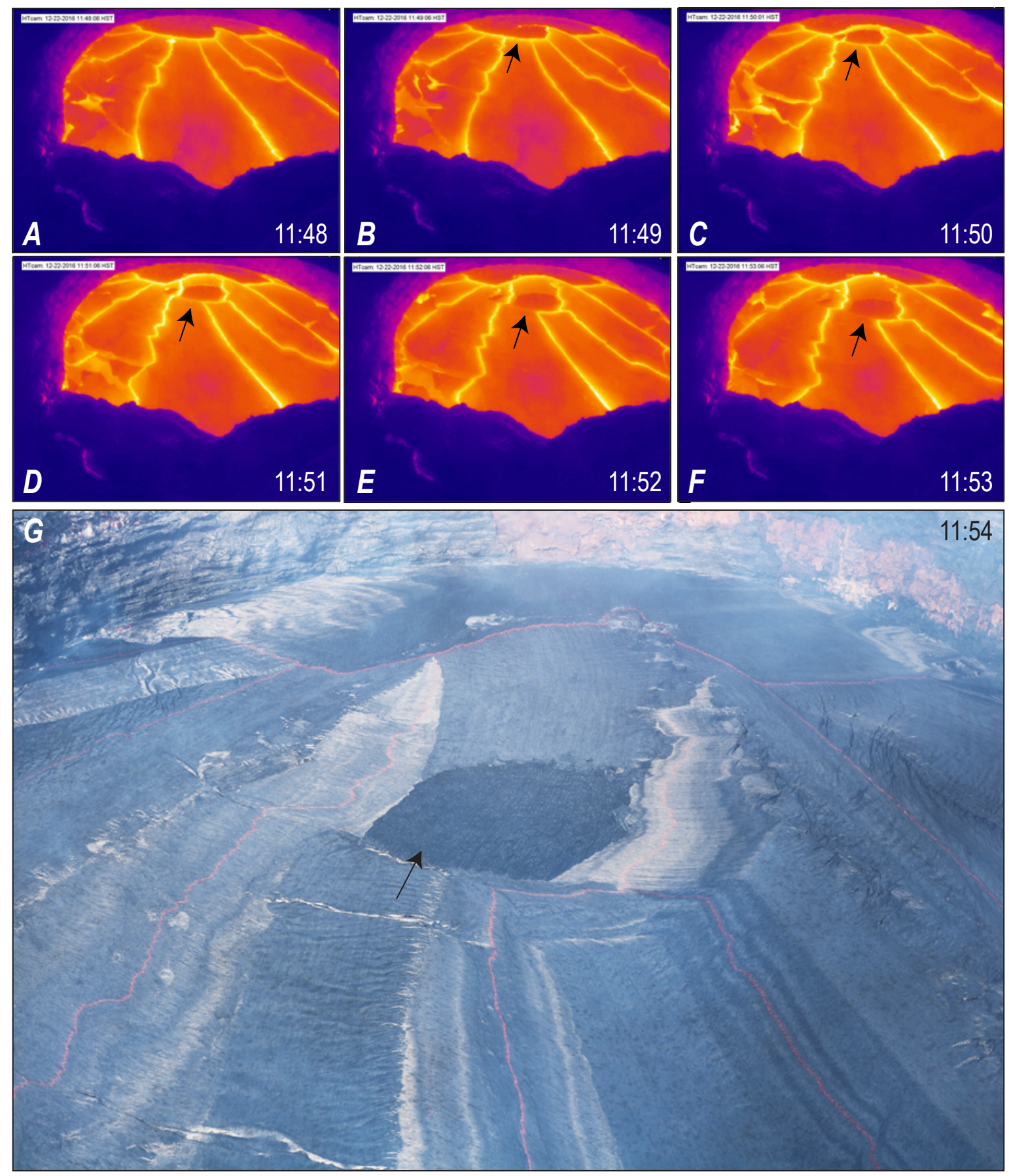

Figure 39. Sequence of images from December 22, 2016, showing proto-plates and their origin. Proto-plates are areas of older crust often entirely surrounded by newer crust, which form when new spreading zones split an existing plate. In this example, a sequence of thermal camera (HTcam, fig. 2) images (times are HH:MM HST) show a spreading zone form in a static plate along the northern lake margin, essentially breaking off a piece (black arrow) of the static plate and causing it to flow south. The original piece of static plate is evident in the thermal images owing to its cooler temperature (in other words, greater age), and is also obvious to the naked eye $(G)$ because of its different surface texture. 


\section{Lake Surface Motion}

For the majority of the time, the lake surface motion was stable and consisted of lava flowing radially from its upwelling zone near the northern lake margin (fig. 40). Because the upwelling zone was often situated 10-30 m out from the northern lake margin, most of the lake surface flowed to the south and only a small portion flowed west, east or north during periods of normal flow behavior.

During this normal mode of lake behavior, crust reaching the lake margins quietly subducted in a foundering zone that extended out from the lake margin by a few meters. When spattering in the southeast (SE) sink was active (see below), which was very common, this downwelling was enhanced at the SE sink and a large portion of the southward flow was directed towards the spattering in the sink, where crust was torn and consumed.
Localized disruptions to this stable, primarily southward surface flow were triggered by the appearance of new spattering sites. Spattering sites were areas of lava downwelling (never upwelling). Small rockfalls could trigger spattering and create a new downwelling area that locally pulled nearby crust into it. This downwelling processes was described by Perret (1913b) as the "siphon" effect, whereby the large bursting bubbles at spattering sites create void space and a localized depression that surrounding lava plunges into (Patrick and others, 2016c). Jaggar (1917) referred to the same process as "downsucking" in the early 1900s lava lake, and noted "a continuous fountain is always a place of rapid downsucking and engulfment." The resulting effect on surface motion is that moderate spattering could produce a very localized velocity field directed towards the spattering, and superimposed on the larger, southward oriented velocity field of the majority of the lake surface (fig. 40).
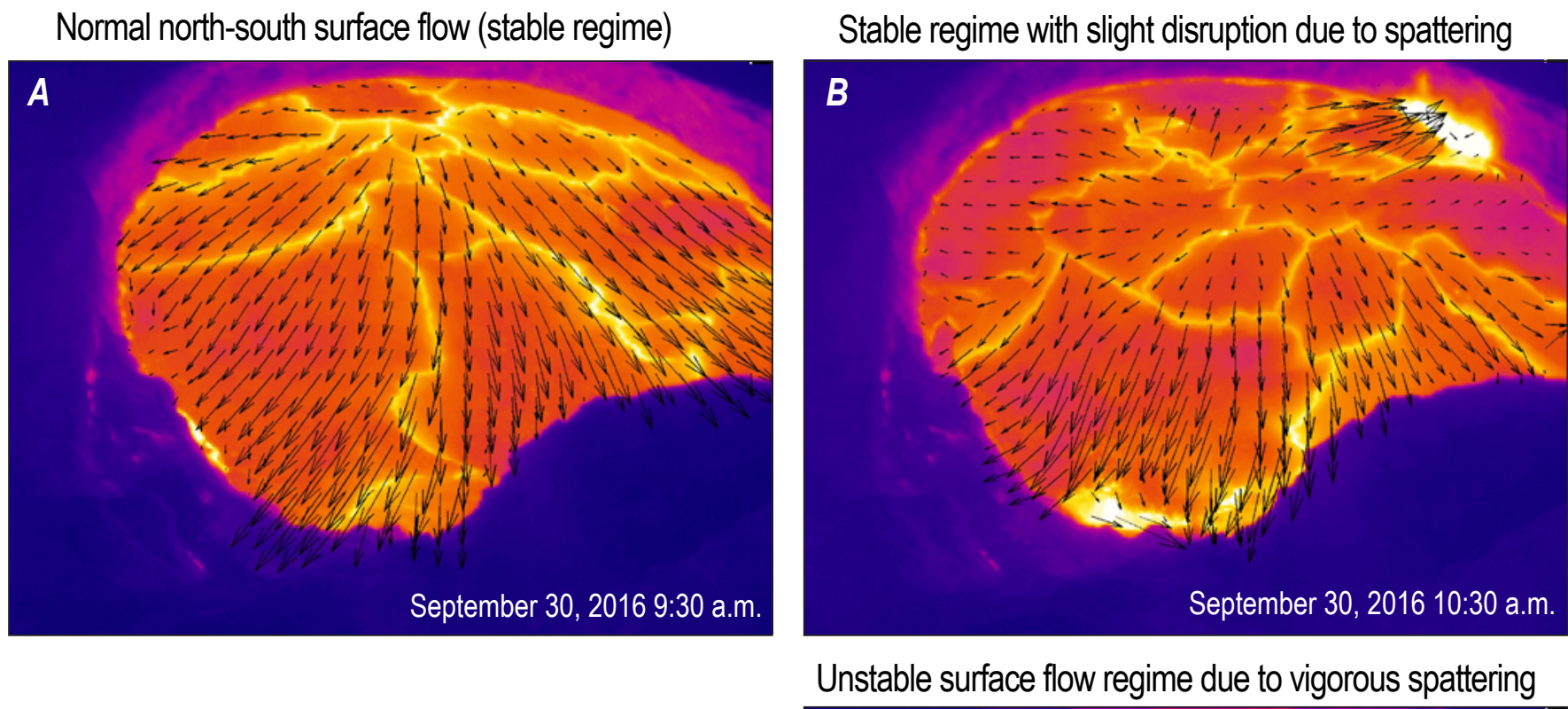

Figure 40. Thermal images showing lake surface motion regimes. $A$, Normal surface flow consisted of upwelling in the northern part of the lake (top of image), with surface crust radiating out and dominantly flowing south. This is called a stable surface flow regime (Patrick and others 2016c). B, Slight disruptions to this surface flow regime occurred when spattering created a sink and a localized shift in the surface flow field. C, Large scale spattering could trigger a complete change in the surface flow over the lake surface, often with the surface flowing north. Changing flow directions occurred as spattering sites migrated along the lake margins. This behavior is called an unstable surface flow regime (Patrick and others 2016c).

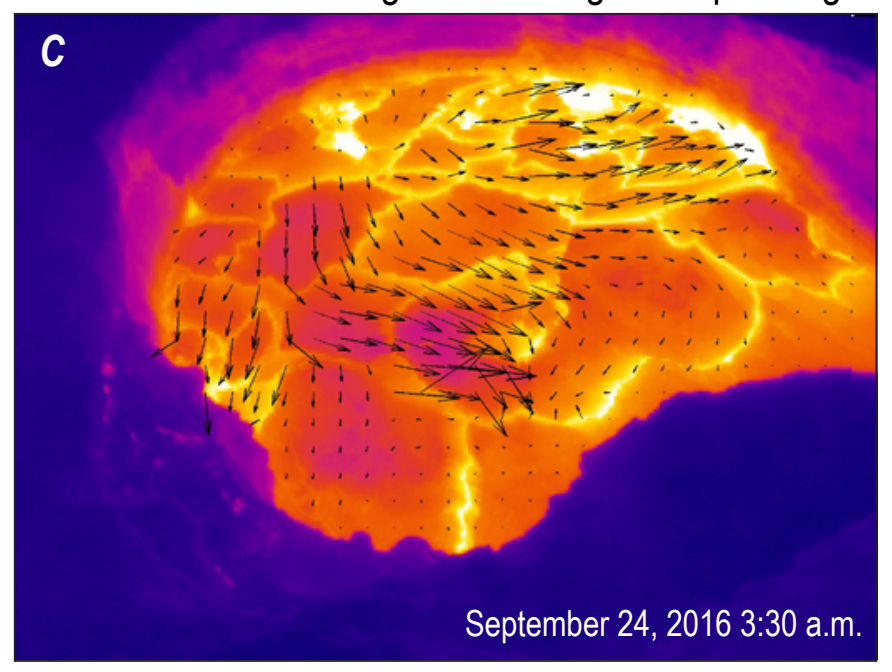


Occasionally, significant spattering that appeared along the northern lake margin was associated with wholesale reversal of the majority of the lake surface flow direction towards the north (fig. 40). This flow reversal resulted in a significant drop in surface velocity and the fusing of plates to create a megaplate (fig. 23). The spattering was mobile, migrating along the lake margin and changing the surface vector field, resulting in an unstable surface flow regime that could persist for several hours at a time. Patrick and others (2016c) contrast this unstable surface flow with the normal, stable north-south surface in a quantitative manner.

Large rockfalls into the lake-sometimes creating explosive events (Orr and others, 2013) — could produce an abrupt increase in the overall velocity of the lake surface. The lake motion was directed towards the vigorous spattering at the point of impact, with the crust seeming to pour into the spattering at the impact site. Presumably, this is an extreme example of the siphon effect described by Perret (1913b) and mentioned above. The unusually high velocities likely relate to the unusually vigorous spattering associated with large collapses into the lake. Once the spattering returned to normal, over tens of minutes, the lake surface velocity rapidly dropped to more typical levels.

\section{Spattering}

\section{Spattering and Nonspattering Phases}

Spattering was common in the lake, and was normally focused at one or more sites at a given time, with each site commonly 10-20 m wide. Spattering appeared to consist of pulsating bursts of large spherical bubbles, each decimeters in size, with doming and bubble bursts overlapping in both time and space at the spatter site (Houghton and others, 2014). Observations show that some bursts are from bubbles and others are rebounds of lava from the base of the bubbles. The bursts ejected a lattice work that extended to 5-10 $\mathrm{m}$ height above the lake, with small pieces of spatter thrown much higher ( $>15 \mathrm{~m}$ ) (fig. 41). Smaller bits of spatter are carried by the rising gas plume to the rim of Halema'uma'u.

Other than direct observations or webcam imagery, seismic tremor was the best means of tracking the intensity of spattering in the lake (fig. 42). The high-pass ( $>1$ hertz [Hz]) filtered component of nearby broadband station NPT (figs. $1 B$ and 2) provided a good proxy for spattering intensity and gas emission rates (Kern and others, 2015; Nadeau and others, 2015; Patrick and others, 2016a,c). Infrasonic tremor has shown a similar relation with spattering intensity (Patrick and others, 2011a; 2016a).

Spattering was present most of the time, but occasional periods of nonspattering could persist for spans of several hours. These nonspattering phases often correspond to a slight $(<5 \mathrm{~m})$ rise in the lake surface in a process of "gas pistoning" (Swanson and others, 1979; Patrick and others, 2016a). Gas pistoning in the lake at Halema'uma' $u$ has been explained as the accumulation of bubbles, perhaps as a foam, near the upper surface of the lake (Patrick and others, 2016a), following the explanation for similar activity at $\mathrm{Pu}^{\prime} \mathrm{u}^{\text {' }} \mathrm{O}^{`} \mathrm{o}$ by Orr and Rea (2012). Nonspattering phases
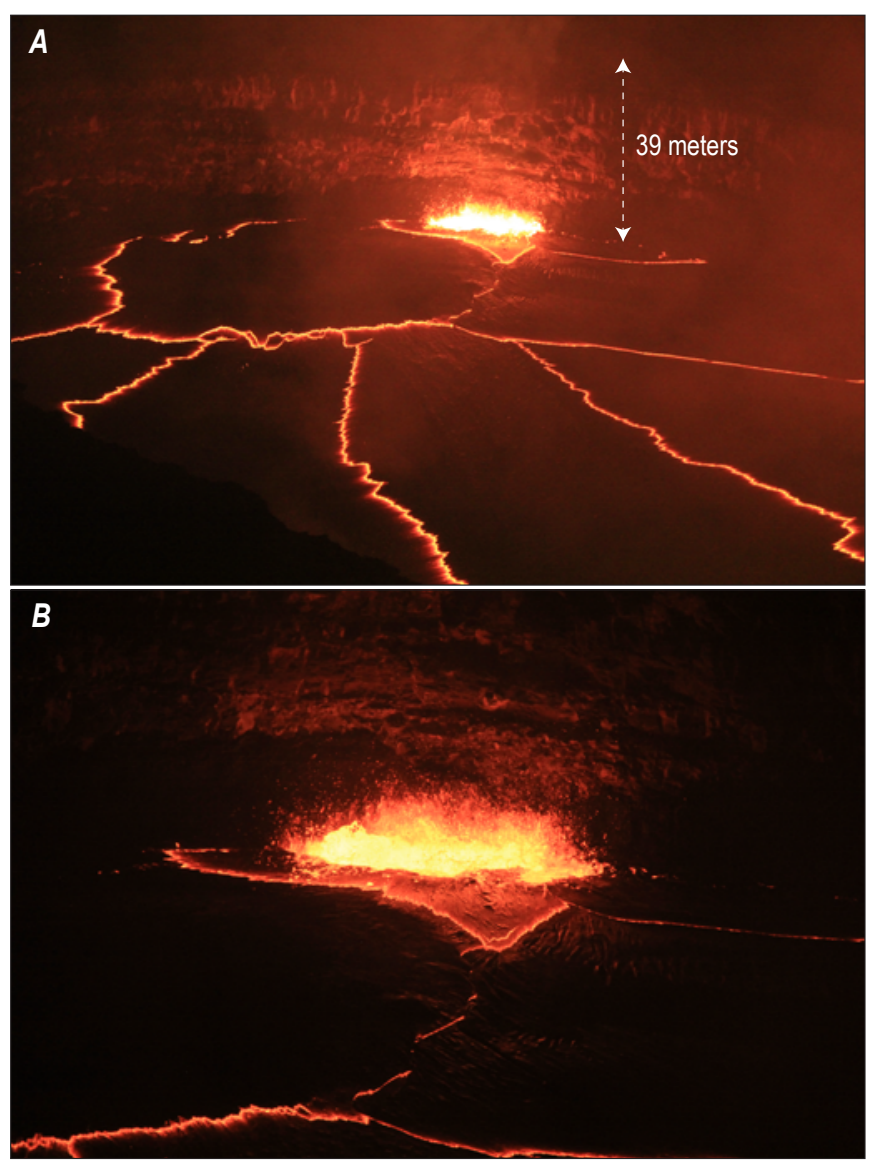

Figure 41. Photographs showing typical spattering in 2016. Spattering sites were normally at the lake margin, and were several tens of meters wide. The main body of the spattering site extended 5-10 meters (m)above the lake, throwing small bits of spatter to heights of more than 20 meters. $A$, Wide view of spattering at the northern lake margin. The Overlook crater wall, 39-m high, is shown for scale. $B$, Close-up of spattering in the same location. Photographs taken by Hans Schwaiger, U.S. Geological Survey, from station A4 on May 26, 2016.

were conspicuous in seismic tremor data owing to their unusually low tremor amplitudes, termed "tremor stagnation" (Patrick and others, 2016a) (fig. 42).

Using the high-pass filtered $(>1 \mathrm{~Hz})$ component at station NPT, we computed 1 minute real-time seismic amplitude measurement (RSAM) values (Endo and Murray, 1991) and applied a threshold of 100 counts (Patrick and others, 2016c) to discriminate between spattering and nonspattering phases. We estimate that spattering was active 96 percent of the time during 2016, while nonspatter phases accounted for 4 percent. This percentage marks a dramatic reduction in the frequency of nonspattering phases in 2016 compared to previous years. Using the same method, Patrick and others (2016c) estimated that nonspattering phases occurred 24 percent of the time between January 2013 and September 2015. Just focusing on 2015 for comparison, this approach yields a nonspattering frequency of 23 percent. The much lower frequency of nonspattering phases in 2016 may relate to the higher overall lava lake levels of 2016 . 


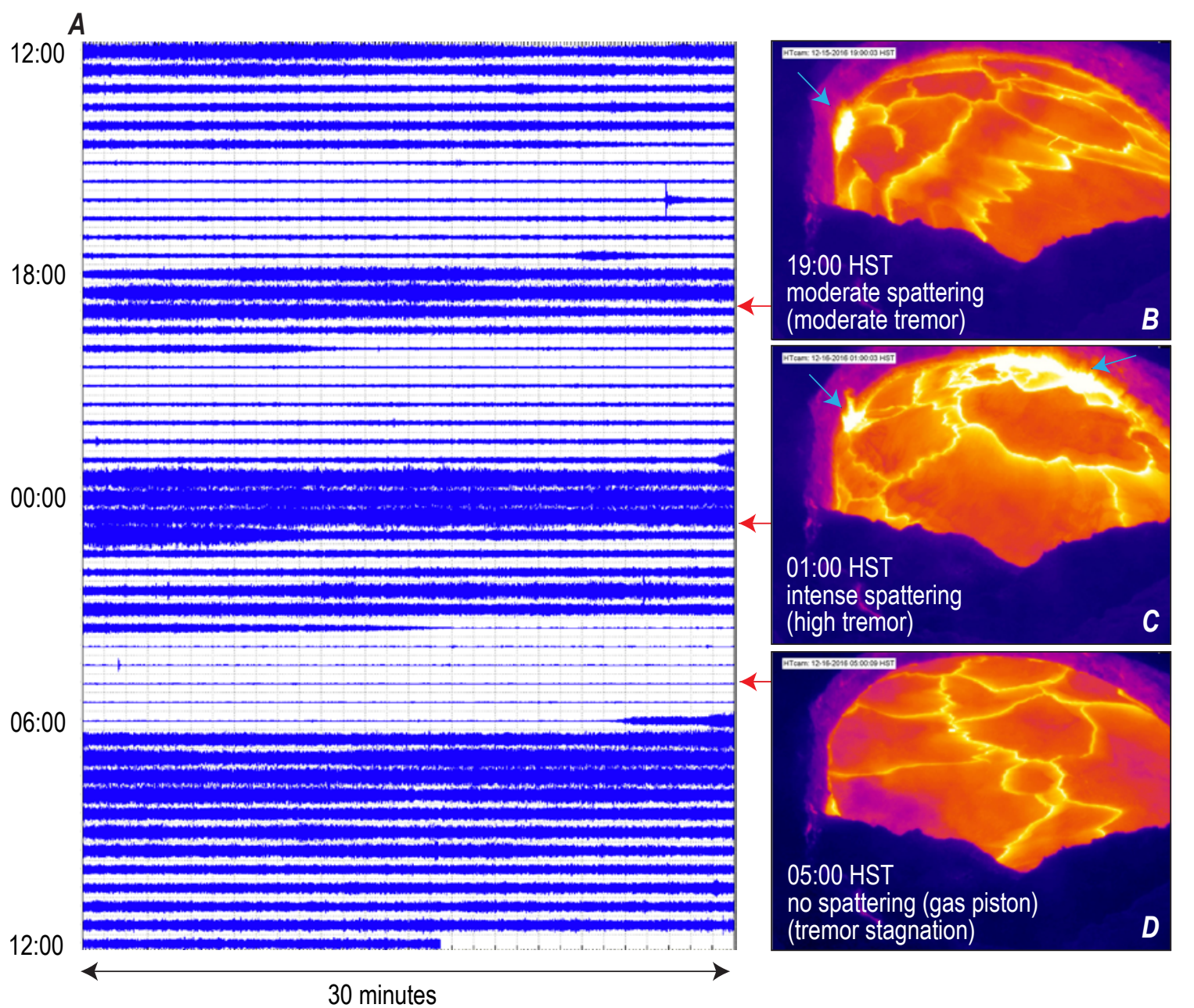

Figure 42. Relation between seismic tremor and spattering intensity. $A$, A helicorder plot showing the seismic trace from station NPT (fig. 1B) over 24 hours (December 15, 2016 12:00 HST to December 16, 2016 12:00 HST). These data have been high-pass filtered ( $>1$ hertz). Each horizontal trace spans 30 minutes. $B$, Moderate tremor corresponds with moderate spattering in the lake. $C$, High tremor corresponds with intense spattering in the lake. $D$, Very weak tremor, also called tremor stagnation, is associated with nonspatter phases, which corresponds with a gas pistoning phase (Patrick and others 2016a).

\section{The SE Sink}

The most common area of spattering was at a site called the southeast (SE) sink, which is in the east corner of the lake directly below where the Overlook crater rim intersects the Halema'uma'u Crater wall (figs. 2 and 43). This area is referred to as a sink because there is enhanced downwelling of the surface crust at the site of the spattering, with the surface around the SE sink being pulled towards the spattering by way of the siphon effect described by Perret (1913b). Note this was not the only area of downwelling; there was concurrent quiescent downwelling of lava along the lake margins elsewhere, whether or not the SE sink spattering was active.

The SE sink spattering was the most consistent spattering site in the lake, often persisting for days at a time. Spattering in the SE sink was often nestled in a small grotto built of solidified spatter attached to the crater walls (fig. 44). The overhanging roof and walls of the grotto often had unstable bulbous protrusions that commonly collapsed, changing the shape and geometry of the grotto on a daily or hourly basis. Sometimes these protrusions on the grotto roof and walls had dangling lava stalactites, which were semi-flexible and would swing back and forth in the turbulent air around the spattering (fig. 45).

It is not clear why spattering in the SE sink was so persistent. One possibility is that the subsurface geometry of the Overlook crater focuses a disproportionate amount of the southward flow into the southeast corner of the lake, and this focused downwelling may facilitate bubble coalescence and spattering, which then drives enhanced downwelling in a kind of feedback loop. Another possibility is that a submerged minor conduit exists below the SE sink, with downwelling into the conduit. In either case, spattering at the SE sink is not the driving force for the normal north-south surface flow direction. Patrick and others (2016c) showed that the northsouth surface flow direction is maintained, with little to no change, when spattering in the SE sink ceases. 

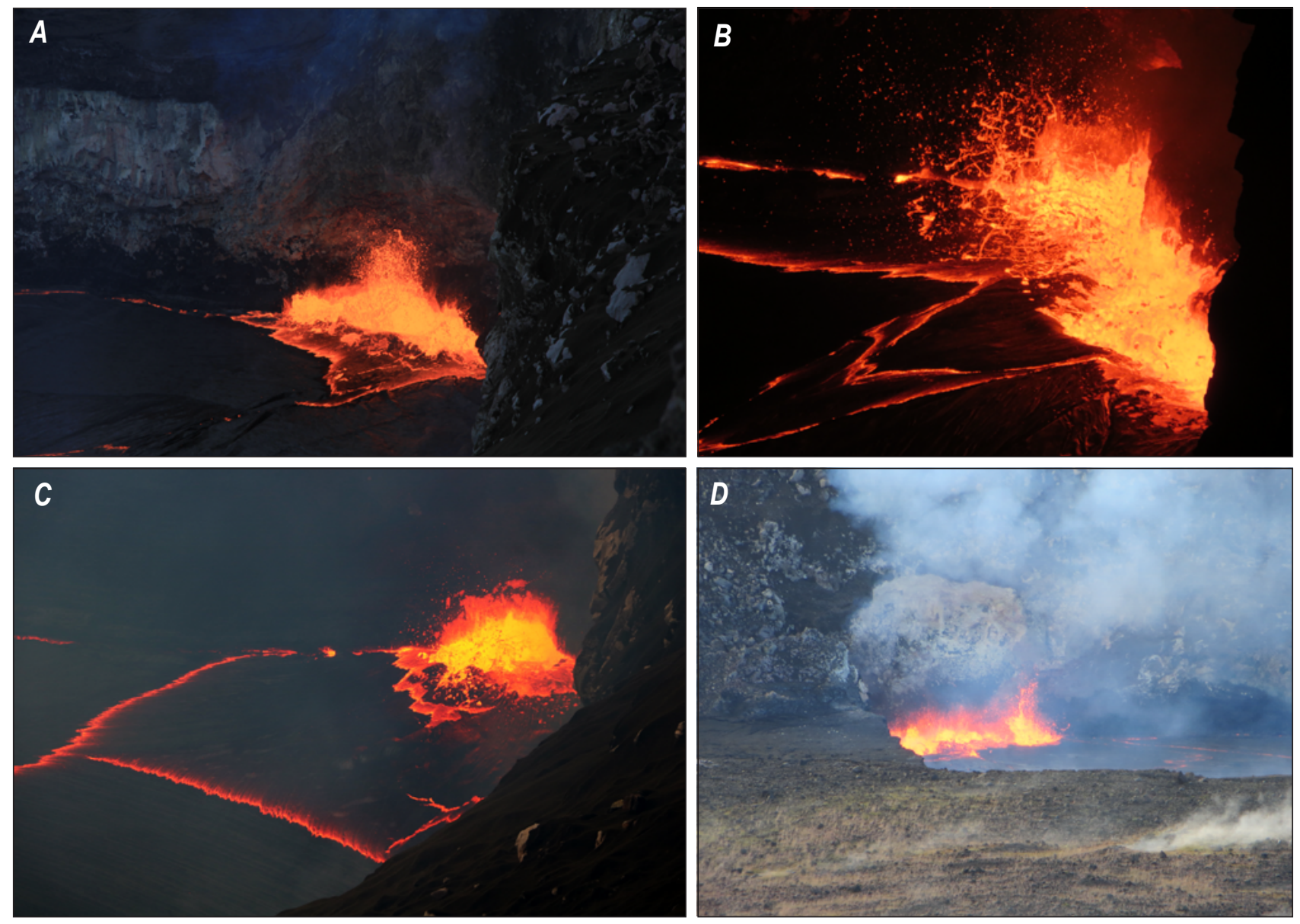

Figure 43. Photographs of the Southeast (SE) sink. The SE sink, an area of spattering in the southeast corner of the lava lake, was the most common area of spattering. A, View of the SE sink spattering, partly recessed within a grotto formed from overhanging spatter deposits. Photograph taken from station A4 on January 7, 2016. B, A close-up of spattering in the SE sink on June 27, 2016. C, Spattering in the SE sink. Photograph taken from station A4 on October 5, 2016. D, Spattering in the SE sink was visible from the Hawaiian Volcano Observatory (HVO) and Jaggar Museum when the lake level was high. Photograph taken from HVO on September 20, 2016.

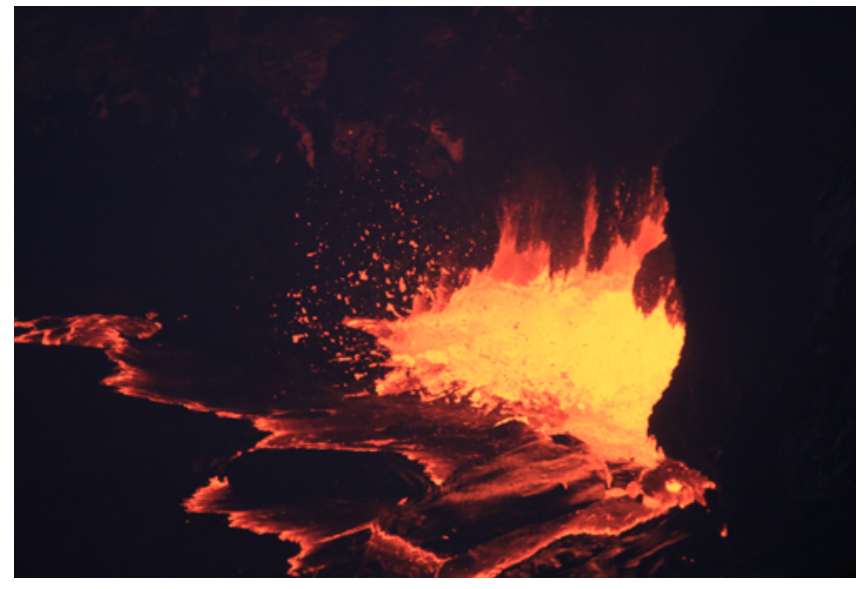

Figure 44. Photograph of a grotto surrounding the spattering in the SE sink. Note the overhanging bulbous features on the grotto roof. Photo by Hans Schwaiger, U.S. Geological Survey, on May 26, 2016.

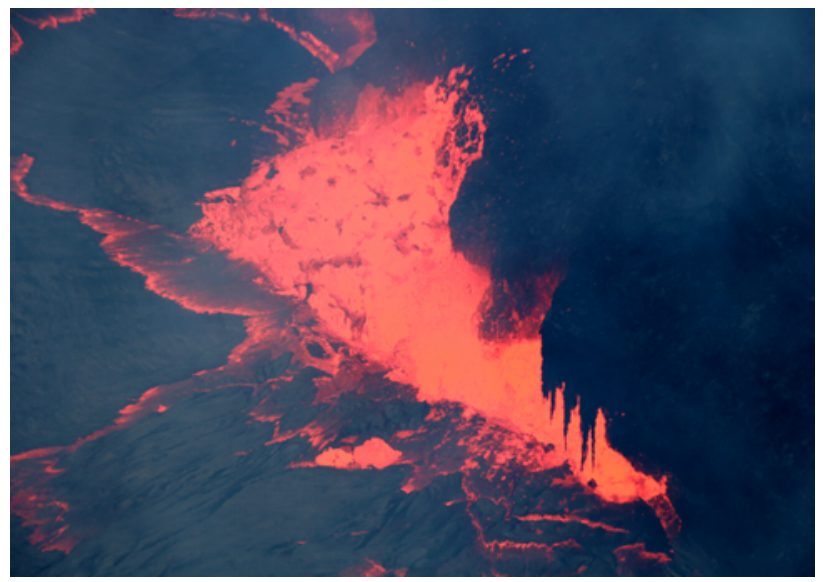

Figure 45. Photograph of stalactites at the spatter grotto along the eastern lake margin on October 3, 2016. Spattering sites were commonly set within a grotto, formed from solidified spatter deposits with an overhanging roof. Lava dripping down the overhang could form stalactites $\sim 2$ meters long. These stalactites were semi-flexible, and swayed back and forth in the turbulent air around the spattering. 


\section{Other Spatter Locations}

Although spattering was most frequently present in the SE sink, it was not uncommon in other portions of the lake (fig. 46). However, nearly all of the spattering sites outside of the SE sink were relatively transient, generally not persisting for more than a few hours. These additional spatter sites were nearly always at the lake margins, which could be the result of two factors. First, the spattering is often triggered by small rockfalls from the crater walls, which necessarily leads to spattering at the margins. Second, the downwelling at the lake margin might be a zone of weakness that allows gas escape to occasionally trigger larger scale spattering.

Less commonly, spattering was present well away from the lake margins, sometimes near the center of the lake. These spatter sites clearly were not triggered by rockfalls and must have been caused by other processes. Normally, spatter sites near the center of the lake were slowly carried south towards the southern margin and ledge by the prevailing current. This spattering sometimes occurred as a series of events.

\section{Migrating Spatter}

The spattering sites that occurred outside of the SE sink were also often mobile and tended to migrate slowly along the lake margins, normally towards the southern portion of the lake (fig. 47). Presumably the spattering sites were carried by the prevailing current, and this is one piece of evidence suggesting that the spattering in the lake is generally shallowly rooted (Patrick and others, 2016a,c). In the example shown in figure 47, a spattering site migrated roughly $120 \mathrm{~m}$ along the east lake margin over a span of 20 minutes, equivalent to a velocity of $0.1 \mathrm{~m} / \mathrm{s}$. This migration velocity of the spatter site is similar to measured surface crust velocities in the lake (Patrick and others, 2016c), supporting the idea that spatter
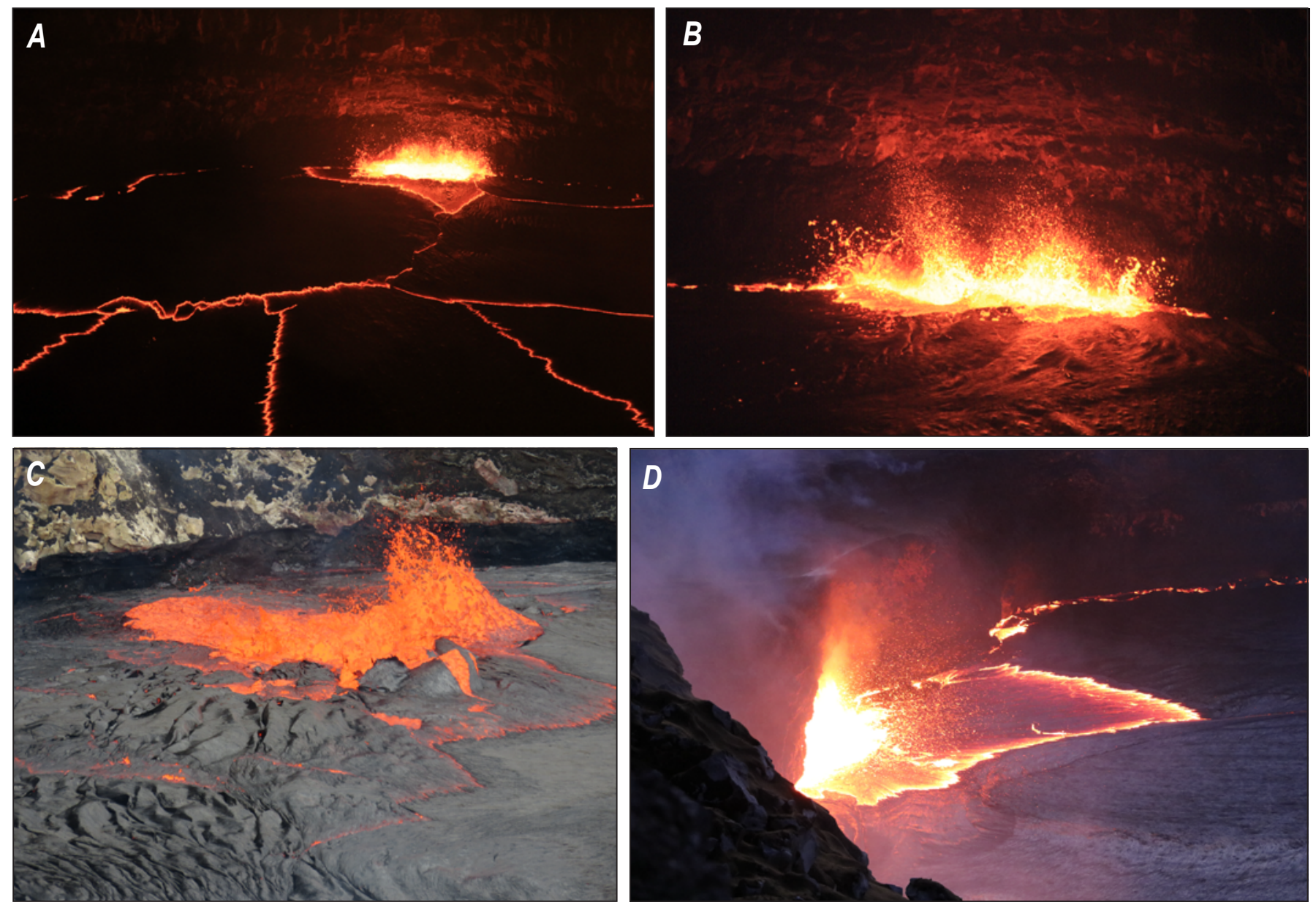

Figure 46. Photographs showing spattering outside of the SE sink area. A, Spattering along the northern lake margin. Photograph by Hans Schwaiger, U.S. Geological Survey, May 26, 2016. B, Close-up of spattering along the northern lake margin. Photograph by Hans Schwaiger, May 26, 2016. C, Spattering in the southern portion of the lake, about 20 meters $(\mathrm{m})$ from the lake margin. Photograph taken from a spot about $100 \mathrm{~m}$ east of the Halema'uma'u Overlook on September 10, 2016. D, Spattering at the base of the southern ledge. Photograph taken from a spot about $100 \mathrm{~m}$ east of the Halema'uma'u Overlook on November $26,2016$. 

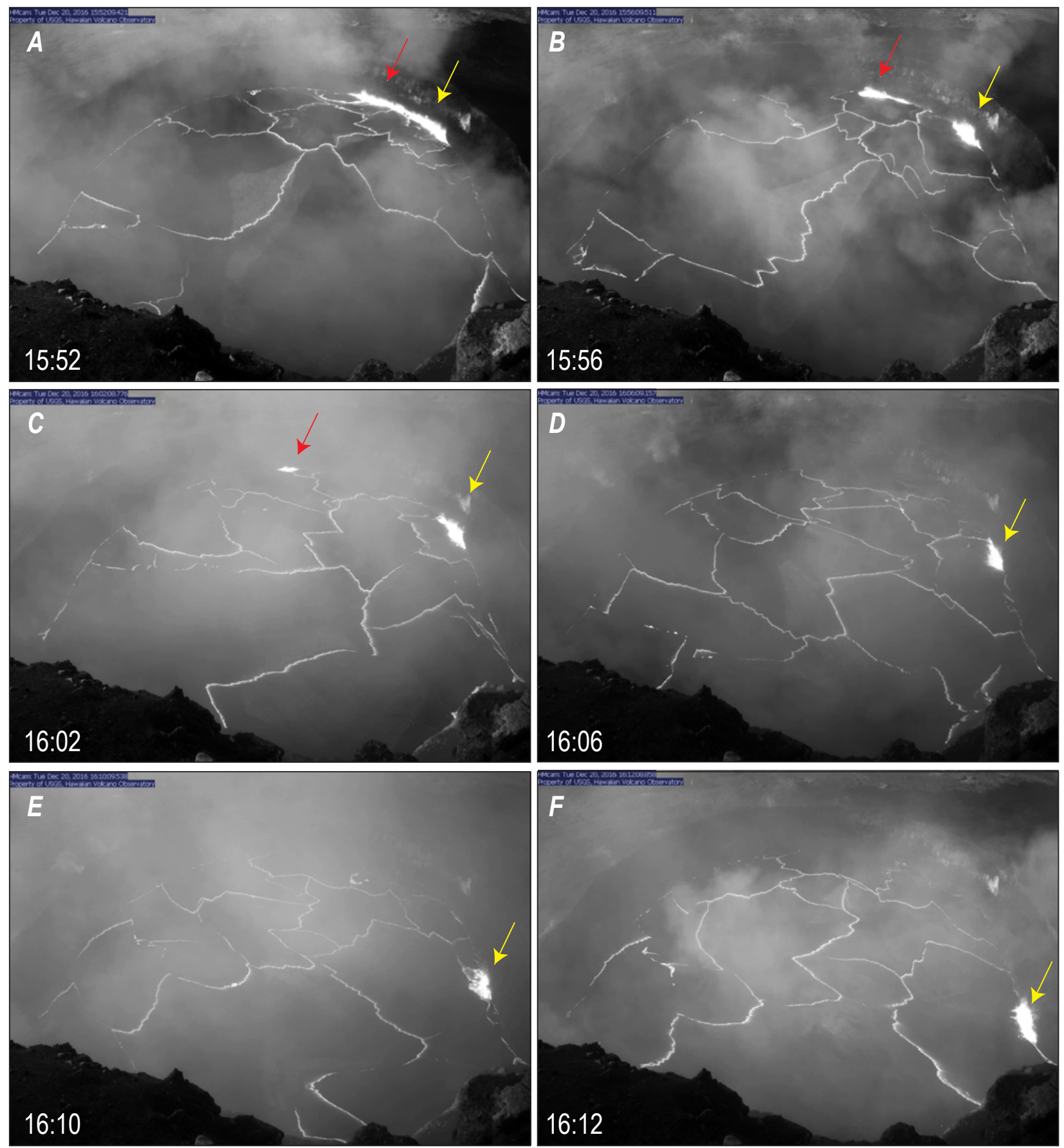

Figure 47. Sequence of images taken from the HMcam on December 20,2016, showing spattering that appears along the northern lake margin split, with the eastern spatter site (yellow arrow) gradually migrating southeast along the eastern lake margin. This eastern spatter site covers roughly 120 meters in 20 minutes, equivalent to a velocity of about 0.1 meter per second. Spattering that appeared in areas outside of the SE sink was normally carried towards the south, presumably by the current in the lake.

is carried by the lake current. However, more detailed work could investigate how closely the spatter migration velocity compares to the adjacent crust velocity. Migrating spatter sites have been observed many times before, and were a common phenomenon in the early 1900s lava lake in Halema 'uma'u. The reports from that time refer to this phenomenon as "traveling fountains" (Brigham, 1909; Perret, 1913a; and many HVO weekly bulletins compiled in Bevens and others, 1988; see also Patrick and others, 2016c). It is also likely similar to the migrating spatter observed at an elongate lava pond on the East Rift Zone in late 2007 (Patrick and others, 2011b). 


\section{Northern Bubble Bursts}

A common feature observed in the lake was sporadic bubble bursting in the upwelling zone (Orr and others, 2014) (fig. 48). These bursts seem to be quasi-periodic, separated by tens of seconds to minutes, and appeared to be individual decimetersize bubbles (slugs) or bubble clusters that abruptly burst at the surface, creating a circular exposure of fresh incandescent lava a few meters in diameter (fig. 49). Because these bubble bursts have been consistently clustered in the north section of the lake, coinciding with the zone of lava upwelling, we presume that they represent gas bubbles traveling directly upwards from the conduit that feeds lava into the base of the lake (Patrick and others, 2016c).
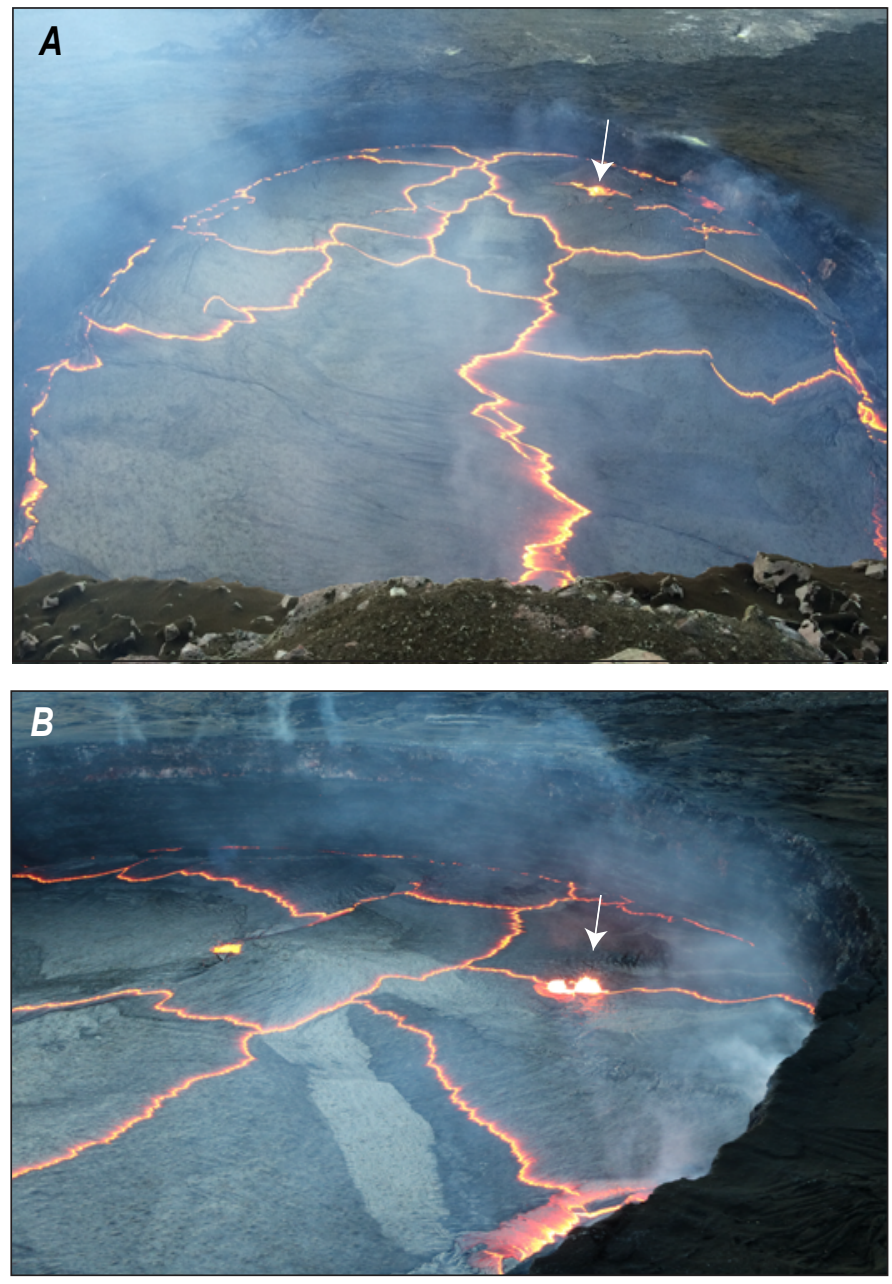

Figure 48. Photographs showing sporadic bubble bursts in the upwelling zone. Bubble bursts commonly occurred in the same general area in the northern section of the lake. The bursts were normally separated by tens of seconds. The correspondence of this area of bubble bursting with the upwelling zone suggests that these bubble bursts may represent gas bubbles rising upwards directly from the conduit that feeds lava into the lake. $A$, Photograph taken from the HMcam site (fig. 2), on September 11, 2016. B, Photograph taken roughly 100 meters east of the HMcam site on December 19, 2016.

\section{Post-explosion Spattering}

Large rockfalls into the lake triggered vigorous spattering, which could extend well beyond the point of impact and persist long after the initial explosive event. In the November 28 and December 2, 2016, collapses, this spattering persisted at a rapidly diminishing intensity for about an hour after the rockfall (fig. 50). The increased spattering may be the result of enhanced coalescence of smaller bubbles (in other words, previously exsolved gas) already accumulated in the upper portions of the lake, and some may be the result of triggered nucleation of bubbles (in other words, new exsolution) in the lake (Carey and others, 2012).

\section{Lava Level Changes}

The lake level in 2016 fluctuated constantly, over both short (minutes) and long (months) timescales. The lake level ranged from about 60 to $0 \mathrm{~m}$ below the Overlook crater rim, corresponding to an elevation above sea level of 971-1,031 m (fig. 51). There was little net change in lake level through the first eight months of the year (figs. 52 and 53), with an abrupt rise in September. The lake surface was sporadically visible from the Jaggar Museum overlook in the first half of the year (fig. 54) but became more consistently visible after the rise in September (fig. 55). On a day to day basis, the lake level fluctuated in concert with summit tilt, as in previous years (Patrick and others, 2015), and had the typical cycles associated with deflation-inflation (DI) events (Anderson and others, 2015; Patrick and others, 2015).

The lake surface reached the rim of the Overlook crater on just one day during 2016, when two small lobes spilled over the rim and flowed several tens of meters onto the Halema'uma'u Crater floor on October 15 (fig. 56). On November 29, 2016, HVO scientists visited the floor of Halema 'uma 'u Crater and sampled these overflows (as well as the 2015 overflows). Both the 2015 and 2016 overflows consisted of large sheets of shelly pāhoehoe.

Lava level fluctuations were the result of two main processes. The primary control on lake level has been summit magma reservoir pressure, which is tracked primarily with ground tilt. The correlation is sufficiently strong that the plot of lava lake level closely resembles the plot of summit tilt as measured at station UWE (fig. 57). Patrick and others (2015) showed that, based on 2012-14 data, the summit lake level changed by $5 \pm 0.8 \mathrm{~m}$ for every microradian of radial (along an azimuth of $327^{\circ}$ ) tilt change at UWE. These pressure-driven changes could result in lava lake level changes of tens of meters over timescales of several days. The secondary control on lava lake level is outgassing-driven changes related to spattering and gas-pistoning, producing more rapid changes (over minutes to hours) with a smaller amplitude (generally several meters).

Magma supply rate is one of the processes controlling summit magma reservoir pressure and lava level. On a scale of several months, monthly-averaged lake level rose and fell in concert with changing uplift rates at the summit as measured 


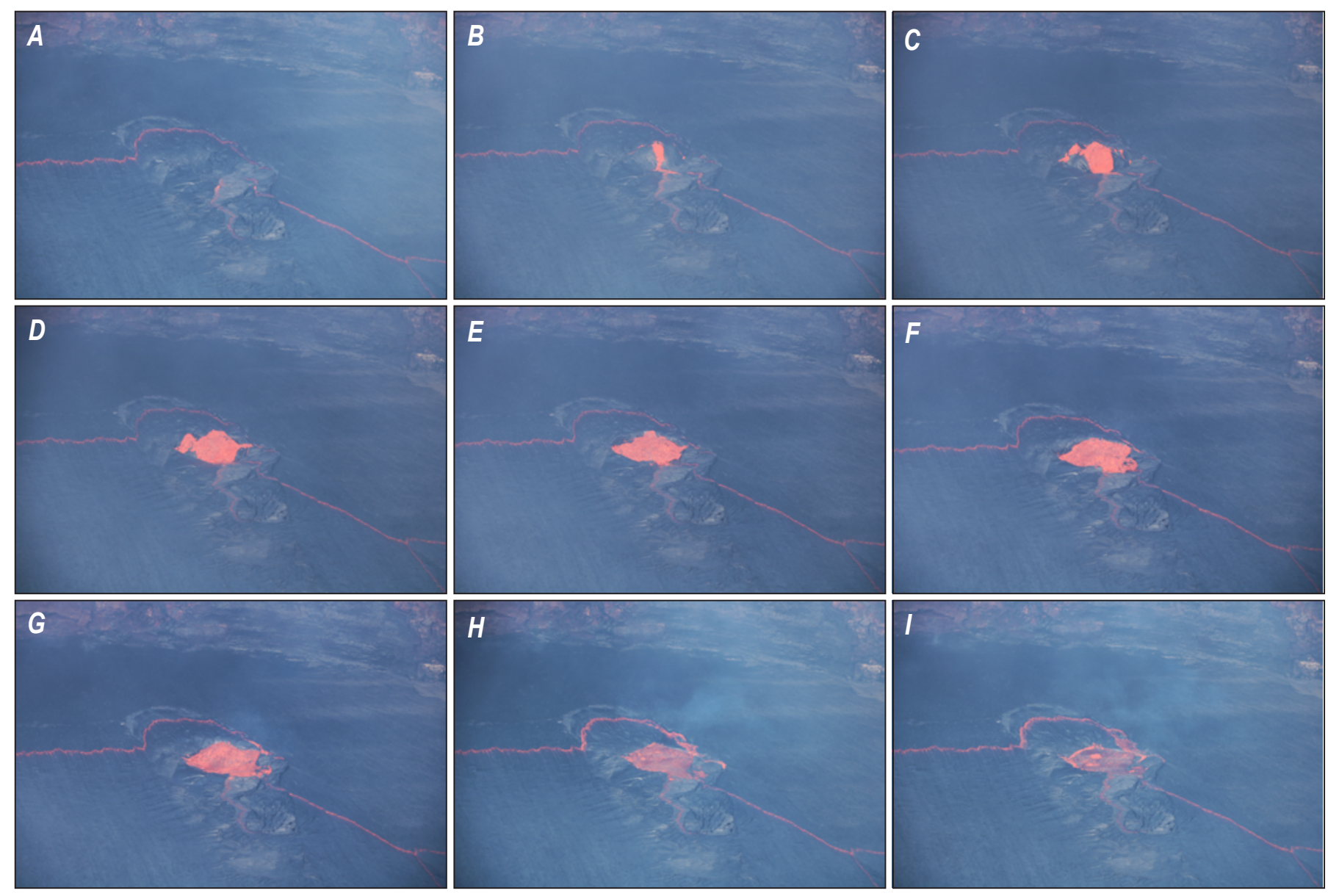

Figure 49. Photographic sequence of a bubble burst on December 22, 2016. A close-up of the bubble burst in the northern section of the lake, the sequence spans about 6 seconds. The disrupted area of lava is a few meters in diameter.

Figure 50. HMcam images of post-explosion spattering. Prolonged intense spattering was often present in the lake in the minutes following a rockfalltriggered explosive event. In both of these cases, the rockfall impacted the southern lake margin, which is at the bottom of the image. The spattering could occur well away from the rockfall's point of impact.
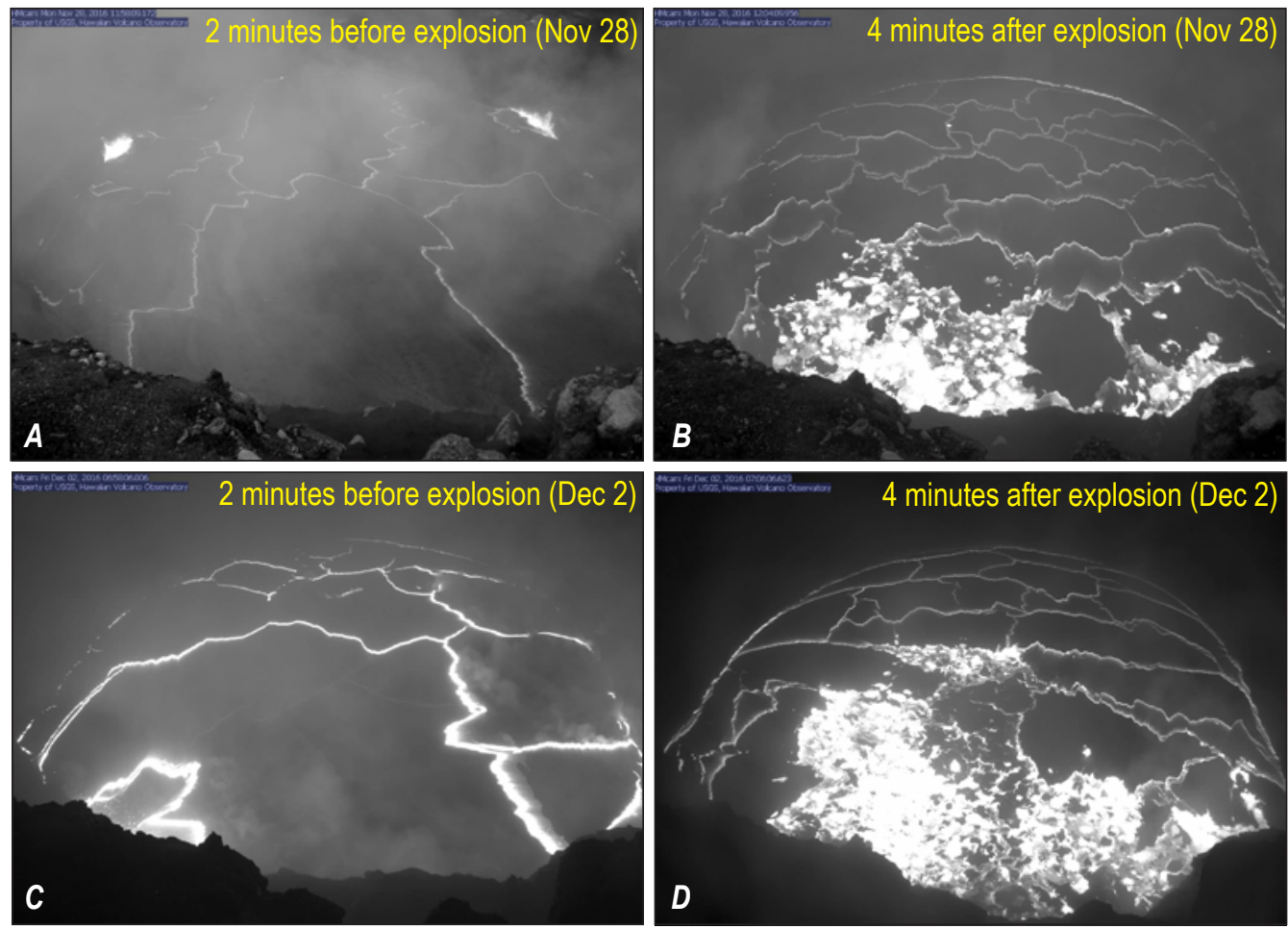

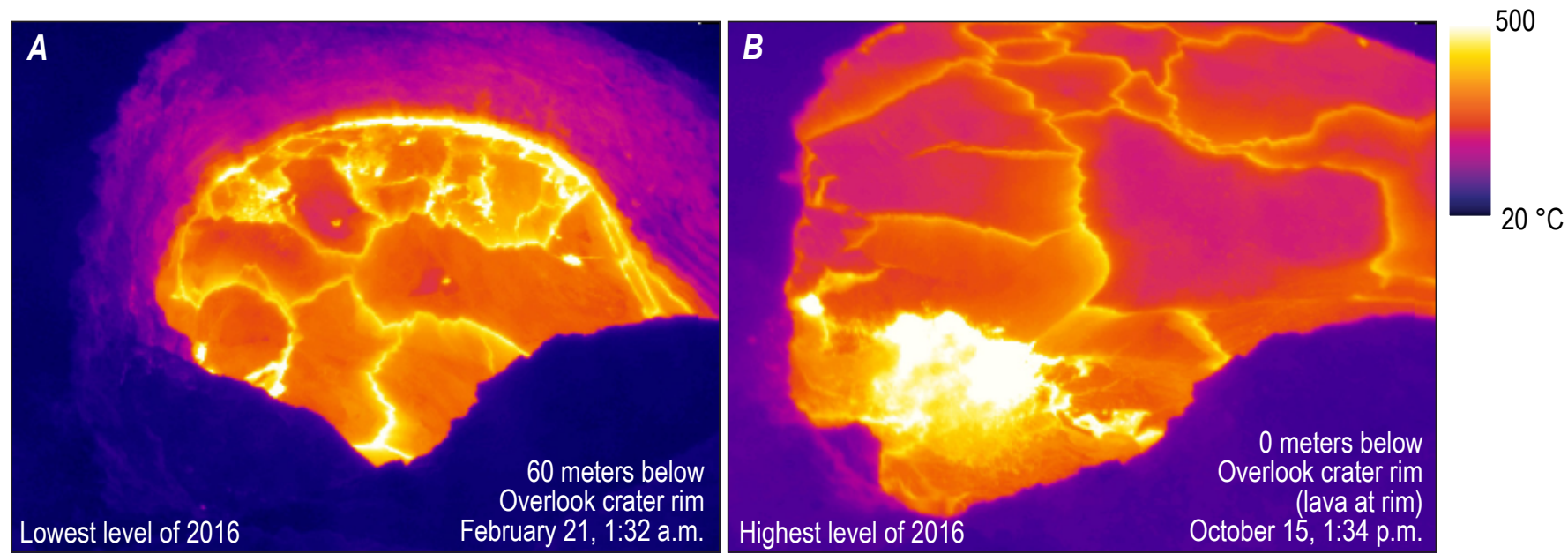

Figure 51. Thermal images from the HTcam showing the difference in lake level and appearance at the highest and lowest levels through the year. $A$, The lowest lake level was approximately 60 meters below the Overlook crater rim, on February 21. B, The highest lake level occurred on October 15, when lava slightly overflowed the Overlook crater rim.

Figure 52. Plot of lava lake elevation, summit ground tilt, and seismicity. $A$, Lake surface elevation was measured daily using a laser rangefinder. The highest measurement, on October 15 , occurred on the day that lava slightly overtopped the Overlook crater rim. $B$, The radial component (along an azimuth of $327^{\circ}$ ) of ground tilt at station UWE (fig. 2). Note the frequent deflation-inflation events in the tilt signal, which produced daily fluctuations in lava level (Anderson and others, 2015; Patrick and others, 2015). C, Located earthquakes per day in the summit region. Spikes in earthquake rates often correspond with higher lava levels (see also fig. 57). D, Daily average of real-time seismic amplitude measurement (RSAM) from station NPT, after high-pass filtering $(>1 \mathrm{~Hz})$.

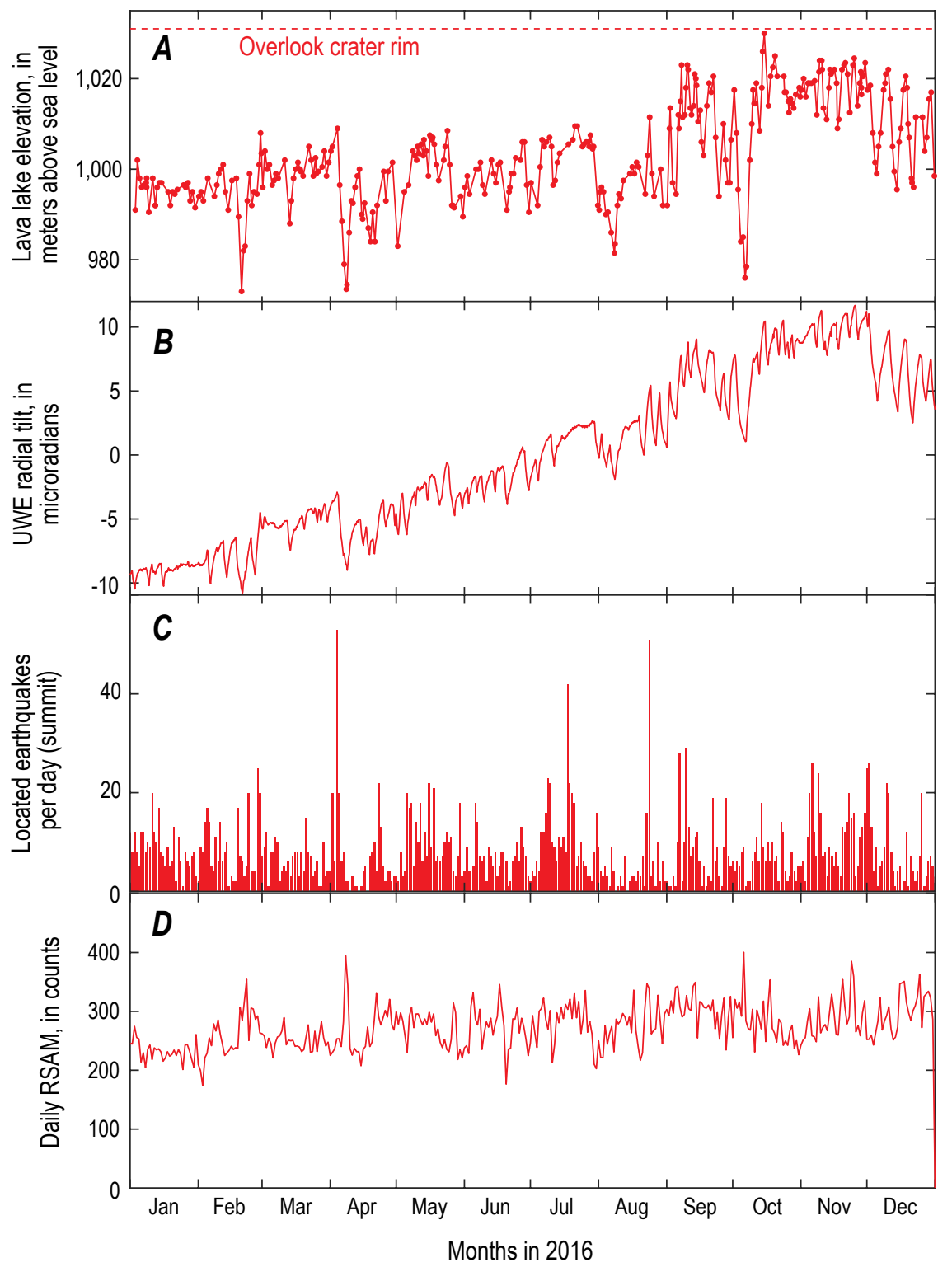



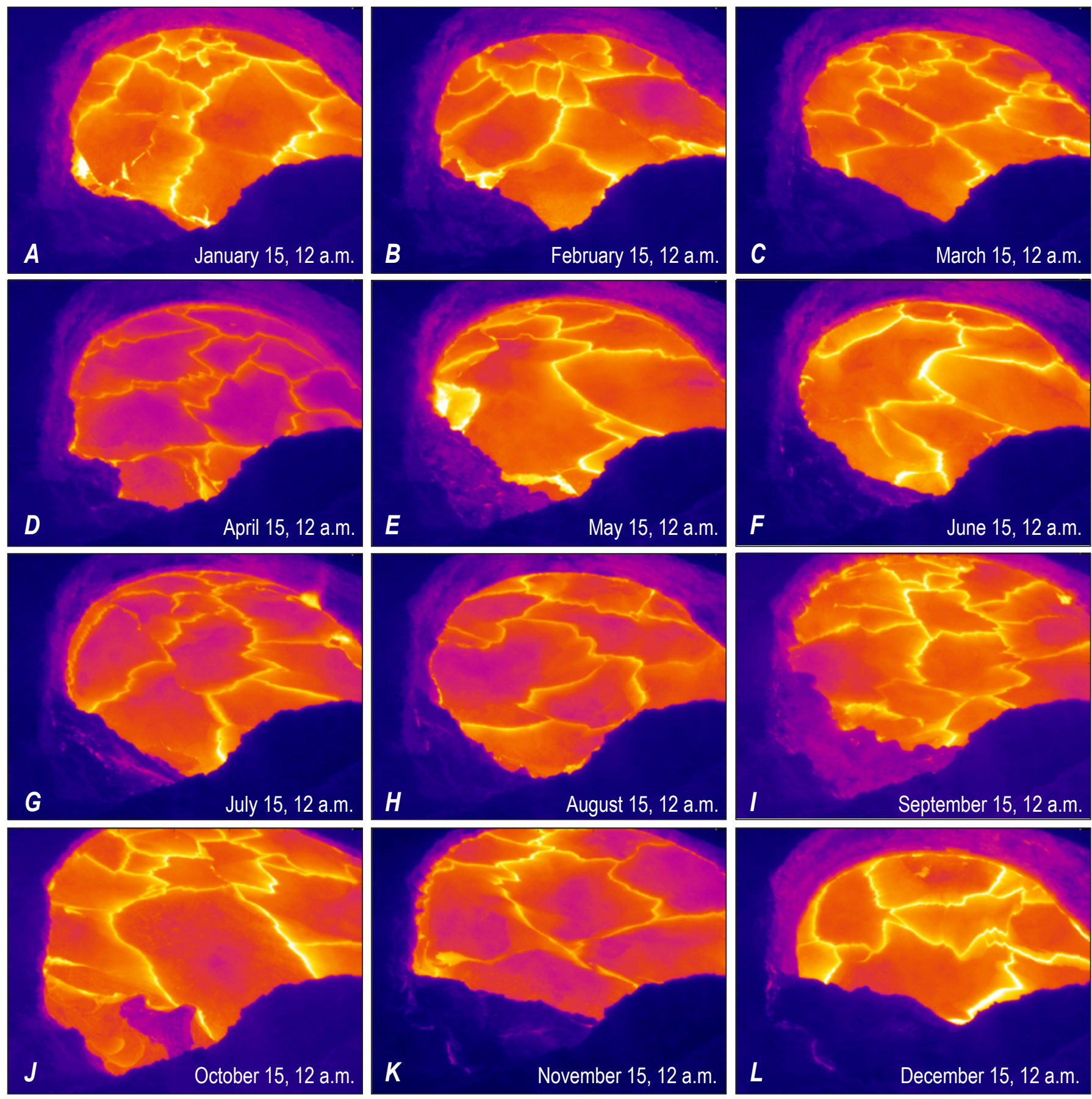

Figure 53. Monthly thermal camera images of the lava lake, showing level changes. Images taken from the HTcam on the 15th of each month at midnight. This collection is meant to provide a qualitative sense of lake level and geometry changes from a consistent viewing angle. 

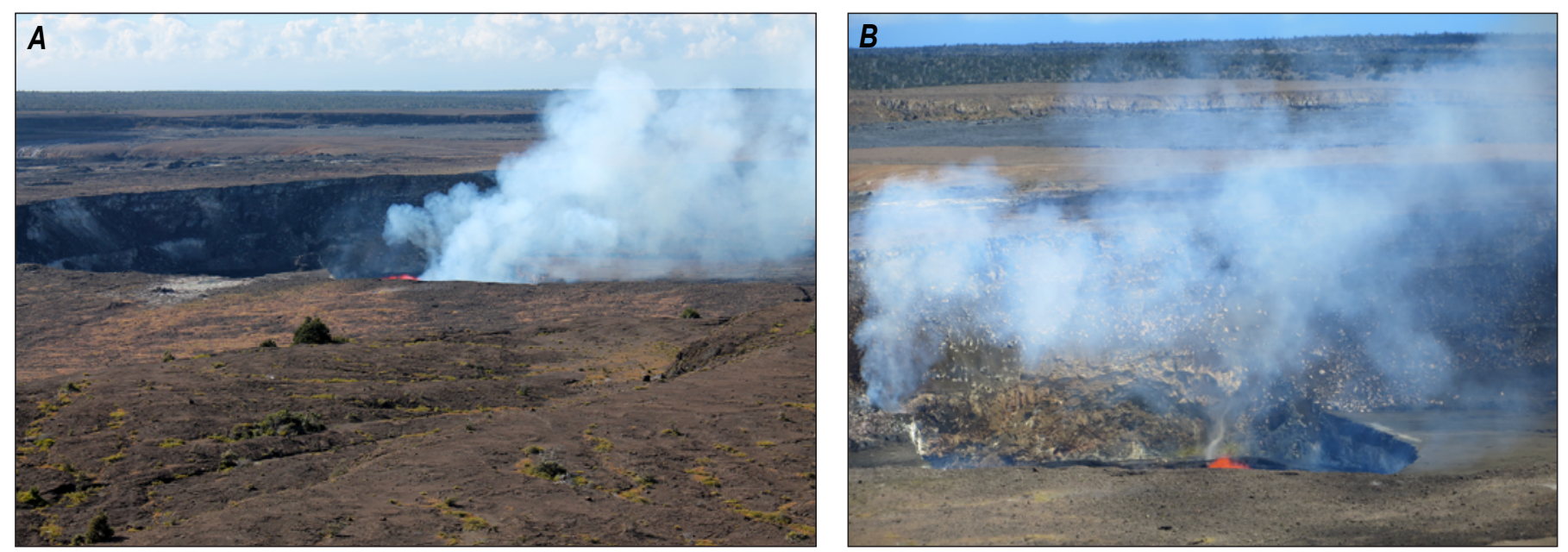

Figure 54. Views of the lava lake from the Hawaiian Volcano Observatory (HVO). Rising levels in mid-2016 provided the first sustained views of lava from HVO and the public viewing area at Jaggar Museum. A, Wide view of Halema'uma'u, with spattering visible along the southern lake margin on September 6 , 2016. B, Close-up view of spattering along the southern lake margin. Photograph by Janet Babb, U.S. Geological Survey, July 20, 2016.

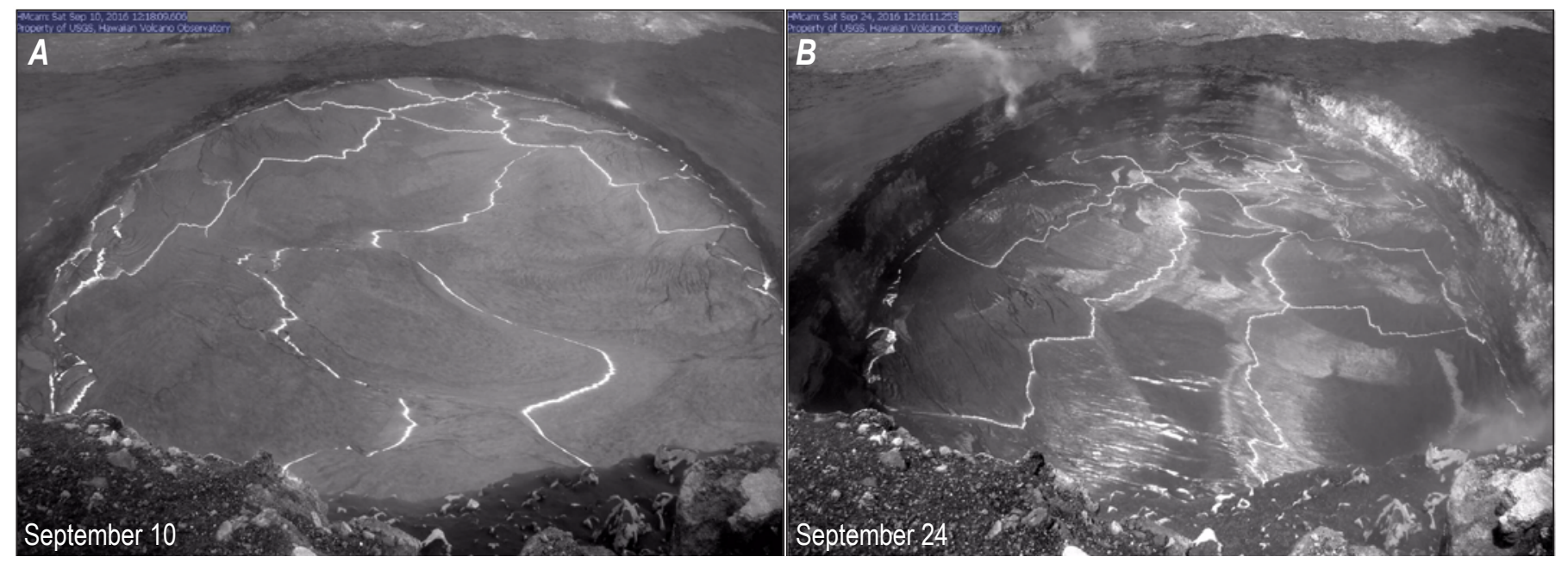

Figure 55. Images from the HMcam show the differing lake level and appearance in September 2016. The lake reached a high level in early September, but deflation-inflation events resulted in a large drop by the end of the month. $A$, September 10, when the lake level was roughly 8 meters below the Overlook crater rim. B, September 24, when the lake was about 37 meters below the Overlook crater rim. Note the Overlook crater walls on September 24 have a covering of veneer on the western wall, but the veneer has fallen away on the eastern wall, exposing the light colored lithic wall.

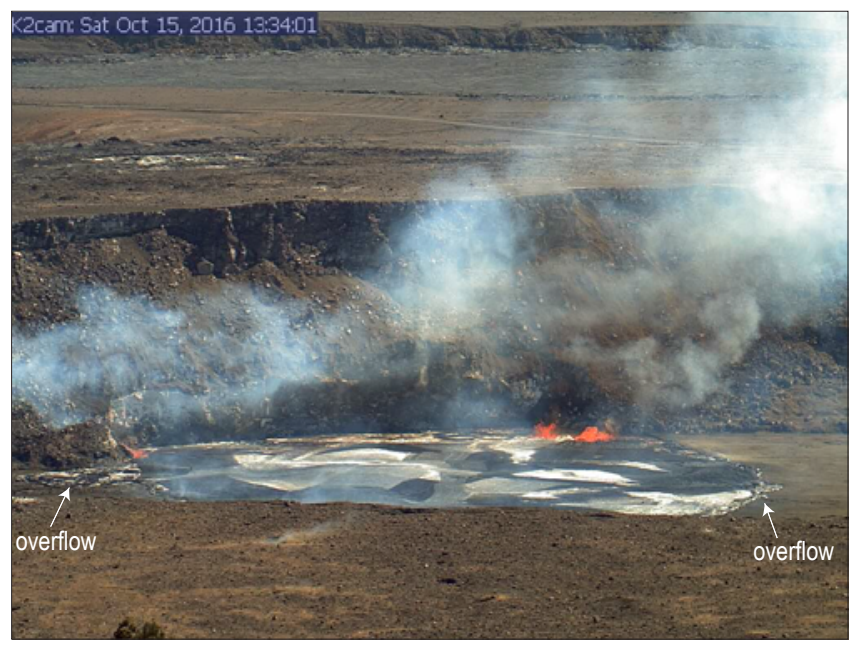

Figure 56. K2cam webcam image showing a small overflow of lava onto the floor of Halema'uma'u Crater, taken on October 15, 2016, at 13:34 HST from the Hawaiian Volcano Observatory tower. 

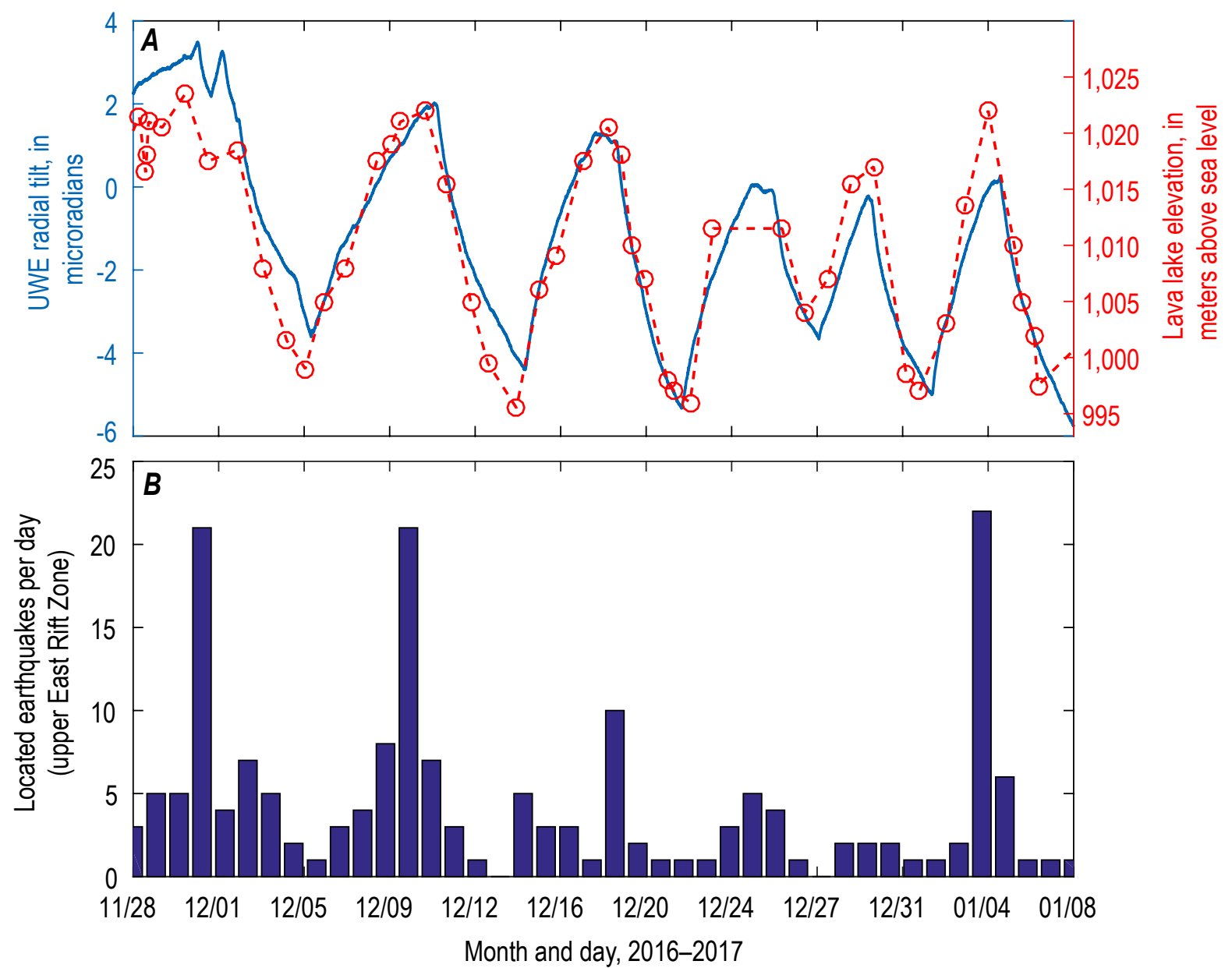

Figure 57. Graphs showing increase in small earthquakes during periods of inflation and high lava level. A, Plot of radial component (along an azimuth of $327^{\circ}$ ) of station UWE ground tilt, along with daily measurements of lake level. Note the close relation between these two trends (Anderson and others, 2015; Patrick and others, 2015). B, Number of located earthquakes per day in the upper East Rift Zone. The earthquake count area is defined by these bounds; latitude $=19.351$ to 19.411 , longitude $=-155.19$ to -155.272 .

by GPS. This has occurred throughout the eruption and has been ascribed to a slowly pulsing magma supply to the shallow storage reservoir under the summit of Kîlauea (Swanson and others, 2016).

Periods of unusually high lava levels and summit inflation were associated with swarms of shallow $(<5 \mathrm{~km})$ earthquakes in the summit and upper East Rift Zone (figs. 52 and 57). Most of these earthquakes were small, but several were greater than magnitude 3 and could be felt by staff at HVO. Sequential peaks in summit inflation and lava level during late 2016, owing to repeated DI events, produced repeated bursts of small earthquakes in this area that diminished when the lake level dropped with deflation. The earthquakes are inferred to represent response to higher magmastatic pressures in the East Rift Zone conduit (Thelen and Patrick, 2012), in a manner analogous to the pattern of increasing earthquakes that was observed with inflation and unusually high lava levels preceding the opening of new vents on the East Rift Zone in 2011 (Thelen and Patrick, 2012; Patrick and others, 2015) (fig. 57).

\section{Rockfalls and Explosions}

\section{Crater Wall Cracking}

Cracking and popping sounds were occasionally heard coming from the Overlook crater. These were normally associated with unusually high lava levels. The sounds ranged from a high-pitch pop or crack to a deep, loud cannon-like boom, and could range from occasional to an almost continuous cacophony resembling a popcorn popper or fusillade of military shelling. Presumably, the popping sounds are due to heating of the crater walls resulting in thermal expansion and cracking (Orr and others, 2013). Sporadic observations prior to 2015 indicated the popping and cracking sounds were commonly related to cracking and ejection of rock from the lithic walls (Orr and others, 2013). Observations in December 2015 documented this process; video shows that small chips of rock frequently burst from the lithic wall, with each burst corresponding to a clearly 
audible popping or cracking sound. The zone of cracking was a few meters above the lake surface, throwing dust and small chips onto the crusted lake surface.

Cracking noises were less common in 2016 compared to earlier years. In previous years thermal cracking most commonly originated from the overhanging wall at the north end of the crater. As the lake level rose, it would heat the overhang in an oven-like fashion owing to the favorable angle of the crater wall, leading to cracking. One reason that thermal cracking sounds were less common in 2016 is that the overhang has been reduced, minimizing this "reflector oven" effect.

\section{Veneer and Inner Ledge Collapse}

As noted earlier, a thin layer of lava was left adhered to the Overlook crater wall whenever the lake level dropped. This veneer was unstable and frequently broke off in large patches or slabs, impacting the lake and commonly triggering spattering. The frequency of these veneer collapses seemed to be greater during large summit deflation events when the lake level dropped significantly, providing both more time for collapses to occur as well as more exposed surface area of unstable veneer. The small inner ledges built out a few meters from the juvenile veneer at the lake margins were also prone to collapse during lava level drops, and also triggered spattering. The southern ledge was more stable, and tended to collapse only when the lava lake level dropped a significant distance.

\section{Crater Wall Collapses}

Numerous small collapses occurred on the portion of the Overlook crater wall that intersects the floor of Halema 'uma' $u$ Crater. Larger collapses - some triggering explosions originated from the southern Overlook crater wall, which

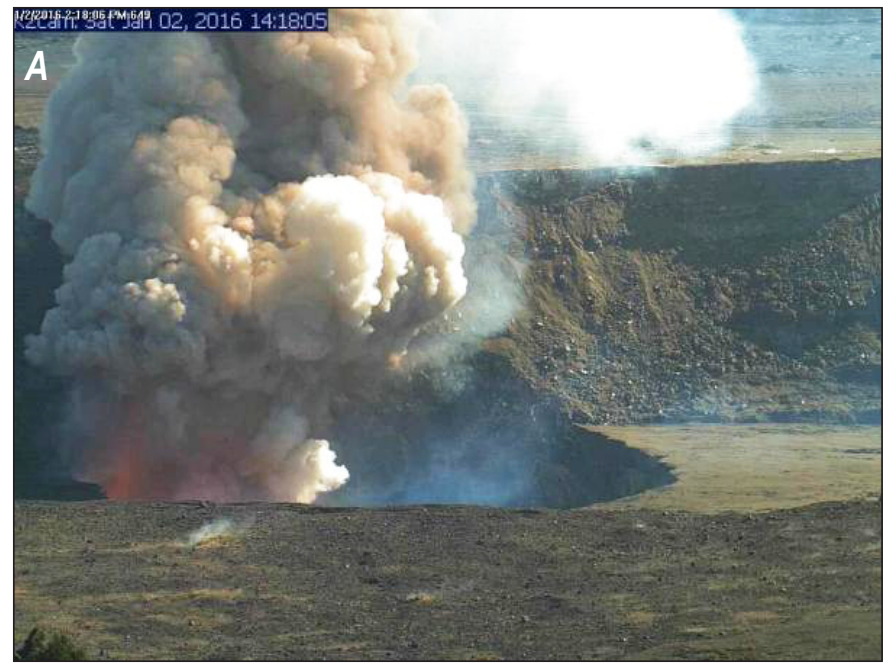

corresponded with the steep, highly altered, rubbly wall of Halema'uma'u Crater. The alteration of this part of the wall took place during outgassing around the margin of the 1967-68 lava lake; such wall-rock alteration can be traced completely around Halema'uma' $u$, extending upwards to the high lava mark of the 1967-68 lake. These collapses contributed to the enlargement of the Overlook crater by about 18 percent during 2016.

\section{Explosive Events}

Large rockfalls occasionally triggered explosive events at the lava lake (Orr and others, 2013). Although even small rockfalls could trigger spattering in the lake, for this discussion we consider explosive events to be those which throw juvenile bombs and (or) lithic blocks, volcanic ejecta more than about $6 \mathrm{~cm}$ in diameter, onto the rim of Halema 'uma'u Crater (Wooten and others, 2009; Orr and others, 2013). Based on this criterion, explosive events occurred on the following days in 2016 - January 2 and 8, August 6, September 19, October 19, October 20, November 28, and December 2. All of these were associated with collapses of wall rock from the southern wall of the Overlook crater, where it meets the steep, altered wall of Halema'uma' $u$ Crater. Each collapse deposited juvenile bombs around the Halema'uma'u Overlook.

The first explosive event of the year occurred at 14:17 Hawaii standard time (HST) on January 2 (fig. 58). The initial indication of a rockfall was visible in webcam (HMcam) images at 14:17:49, and the rockfall impacted the lake at 14:17:54 HST. Pyroclasts were visible falling out of the tephra cloud produced at the point of impact at 14:18:03 HST, with pyroclasts reaching the camera starting around 14:18:08 HST. Falling pyroclasts were visible in the webcam images until 14:19:18 HST. The main deposit, which consisted mostly of juvenile lapilli and a few small bombs, was scattered around the Halema'uma'u Overlook, extending roughly $30 \mathrm{~m}$ from the Halema'uma' $u$ Crater rim. Sparse, small lapilli reached the Halema'uma'u parking lot,

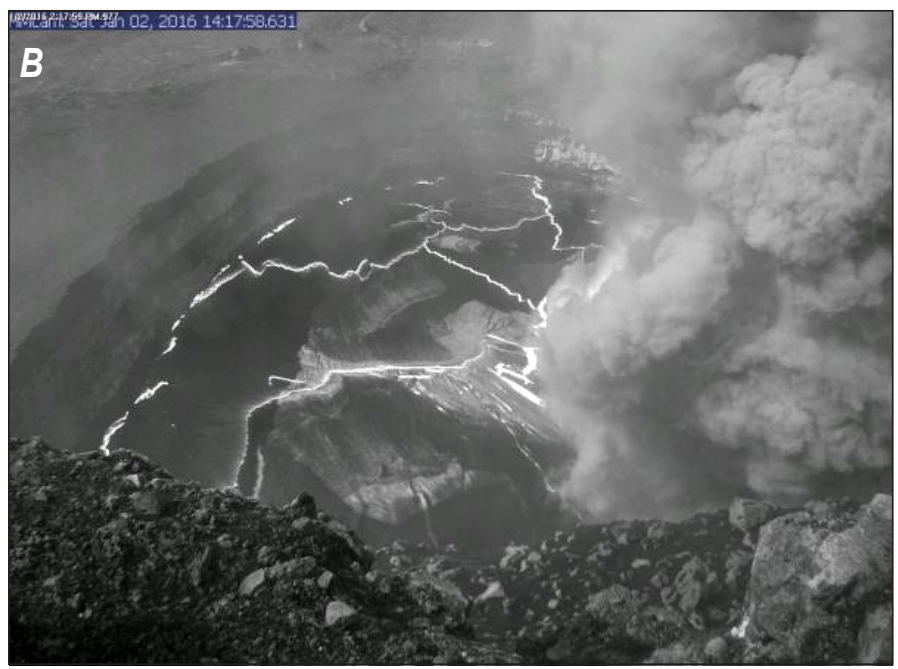

Figure 58. Images of the January 2, 2016, explosion. A, View of the Overlook crater from the K2cam in the Hawaiian Volcano Observatory observation tower, moments after the rockfall. Note the dark, particle-laden plume and incandescence in the area of the SE sink at 14:18:06 HST. $B$, View of the particle-laden plume produced from the rockfall near the SE sink at 14:17:59 HST. 
approximately $400 \mathrm{~m}$ from the explosion point. The juvenile pyroclasts were coated in a dusting of lithic ash, with lithic ash usually incorporated into the juvenile matrix as well. Additional small white flakes of altered lithic rock were deposited around the Halema'uma'u Overlook and parking lot. Overall, this event was one of the smaller explosions to occur at the lava lake.

A larger explosive event occurred a week later on January 8 at 03:51 HST. The rockfall that triggered the explosion originated from the southeast corner of the Overlook crater, near the SE sink. The main deposit was again concentrated around the Halema'uma'u Overlook, and primarily consisted of juvenile spatter with sparse Pele's hair and glassy tears (fig. 59). The largest bomb was $25 \mathrm{~cm}$ in the long dimension. The lithic component of the deposit consisted of thin flakes of a white secondary mineral, likely anhydrite.

The next explosive event occurred on August 6 at 22:02 HST and was again triggered by a rockfall from the Halema'uma'u
Crater wall, immediately above the SE sink. The main deposit began at the Halema'uma'u Overlook and extended about $100 \mathrm{~m}$ northeast, reaching about $30-40 \mathrm{~m}$ from the Halema'uma' $\mathrm{u}$ Crater rim. The main deposit consisted of a continuous layer of scoria, lapilli- to bomb- size (much of it elongate, twisted spatter), as much as $20 \mathrm{~cm}$ thick (fig. 60). Sparse, small angular blocks of wall material were also ejected, and small white lithic flakes were abundant throughout the deposit. Spatter slightly damaged the housing for a continuously running gravimeter (but did not damage the instrument) and completely melted and destroyed the large plastic case housing its power system, melting the batteries and electronics.

A small explosive event, triggered by a rockfall near the SE sink, occurred on September 19 at 21:32 HST, depositing ribbons of spatter as much as $15 \mathrm{~cm}$ long on the Halema' uma' $\mathrm{u}$ Crater rim. Another small explosive event on October 19 at 07:45 HST, triggered by a rockfall below the Halema'uma' $u$
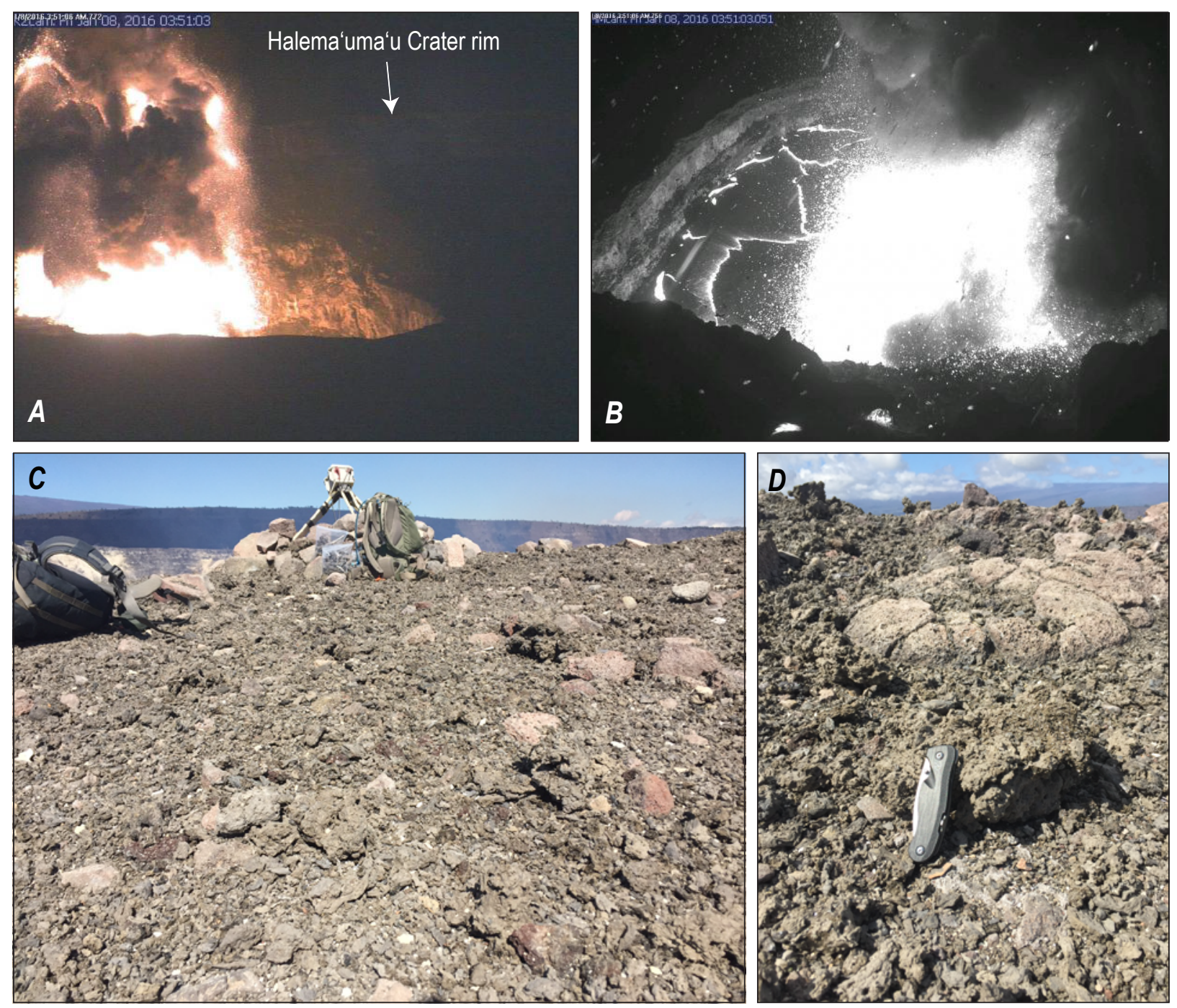

Figure 59. Images of the January 8, 2016, explosion. A, View of the explosion from the K2cam in the Hawaiian Volcano Observatory observation tower, showing hot particles thrown well above the Halema'uma'u Crater rim at 03:51:06 HST. B, View of the explosion from the HMcam at 03:51:06 HST, showing the explosion originating in the southeast portion of the lake. Hot clasts are visible in the air, with a few deposited on the crater rim in front of the camera (bottom of image). C, Spatter deposited around the HMcam (top of image), as seen January 8, 2016. D, Close-up of a typical bomb. The jackknife is resting against a bomb roughly 20 centimeters in diameter. 

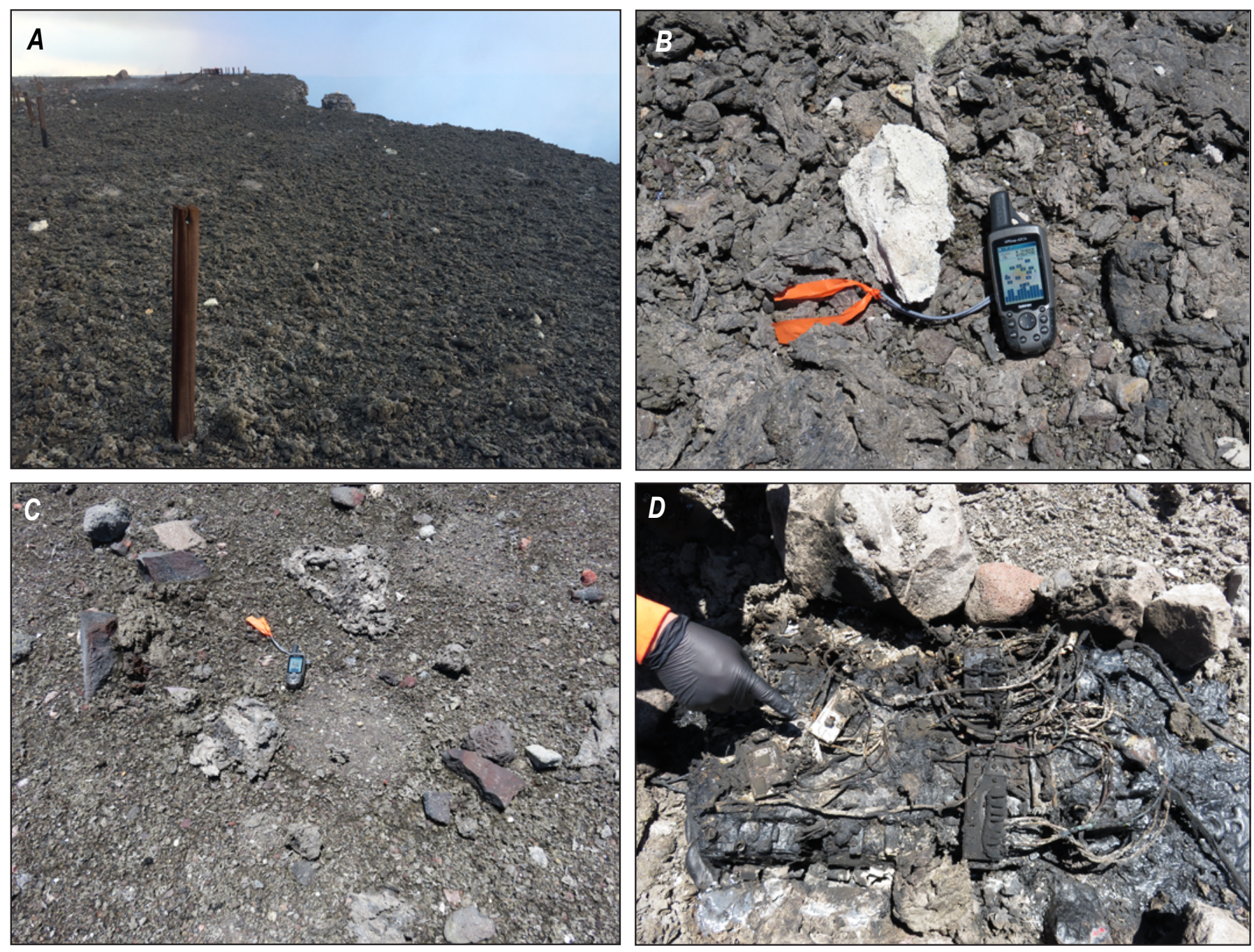

Figure 60. Images of the August 6, 2016, explosive

deposit. $A$, A continuous layer of spatter, as much as 20 centimeters thick, deposited about 100 meters east of the Halema'uma'u Overlook. The Halema'uma'u Overlook fencing is visible at the top of the photograph. Photograph taken August 7, 2016. B, White lithic block deposited on fresh spatter. Global positioning system (GPS) unit (16 centimeters long) for scale. Lithic clasts were presumably sourced from the collapsed portion of the highly altered Halema'uma'u Crater wall above the SE sink. Photograph taken August 8, 2016. C, Spatter impacting the ground adhered to small particles on the surface, leaving a small area where the ground covering was removed when the spatter bounced or slid from the impact point. The light colored area to the right of the GPS unit is the region lacking the ground cover. D, Hawaiian Volcano Observatory geologist points to a pile of black melted material that had previously consisted of four car batteries and assorted electronics, which powered the gravimeter near the Halema'uma'u Overlook. Photograph taken August 8, 2016. E, Collapsed area. The arrow points to a light colored area that is the new scarp created by collapse of a portion of the Halema'uma'u Crater wall directly above the SE sink. Photograph taken August 7, 2016. 
Overlook, deposited spatter as much as $30 \mathrm{~cm}$ long on the Halema' uma'u Crater rim. An explosive event on October 20 at 12:25 HST was triggered by a rockfall from the southern Overlook crater wall, directly below the HMcam (fig. 61). The talus slope below the HMcam was covered in a continuous deposit of spatter, and a sparse tephra deposit extended southwest past the Halema'uma'u parking lot. The material was again dominantly juvenile spatter, as large as bomb size.

Another large slice of the Overlook crater wall directly below the HMcam collapsed into the lake, triggering an explosive event on November 28 at 11:59 HST. The main deposit, consisting of sparse spatter, extended from the Halema'uma'u Overlook to a

Figure 61. Images of the October 20, 2016, explosion and resulting deposit. $A$, Incandescent cloud produced from the explosion. View is from the $\mathrm{K} 2$ cam in the Hawaiian Volcano Observatory observation tower.

Note a small amount of incandescent lava (white arrow) has overtopped the SE rim of the Overlook crater onto the floor of Halema'uma'u Crater, probably from sloshing of the lake. $B$, Airborne clasts captured by the HMcam. $C$, Juvenile lapilli and bombs on Crater Rim Drive (closed to the public), near the Halema'uma'u parking lot, roughly 400 meters from the lake (fig. 2). $D$, Ribbon spatter deposited near the Halema'uma'u Overlook. Clast is about 8 centimeters long. $E, A$ thick flake of white, altered lithic material presumably sourced from the collapsed portion of the Halema'uma'u Crater wall. $F$, Small piece of spatter (dark clast near tip of pen), resting on Pele's hair and lapilli from earlier events.
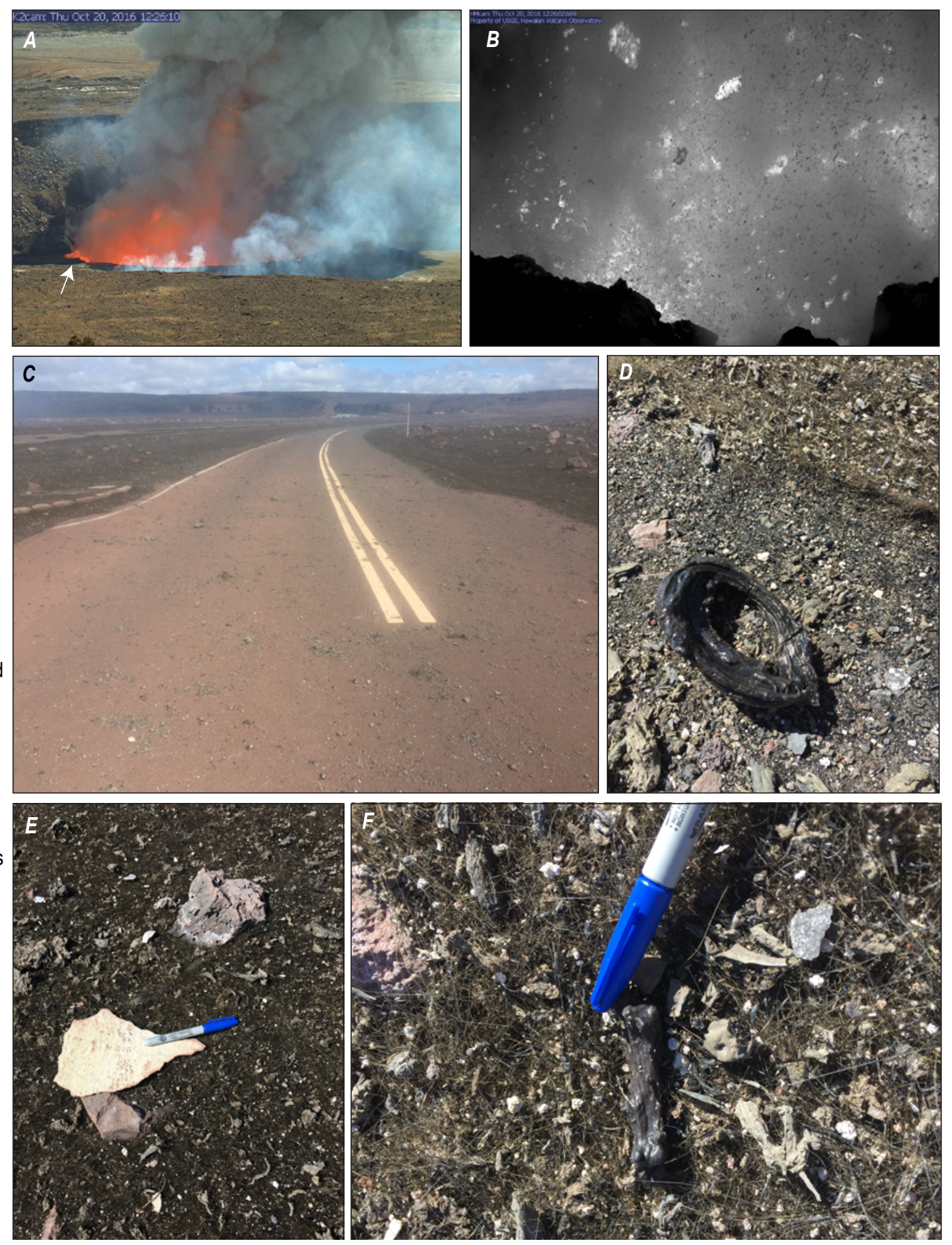
distance of about $100 \mathrm{~m}$ southwest (mainly spanning the distance between the HMcam and HTcam), reaching 30-40 m southeast of the Halema'uma'u Crater rim (fig. 62). The largest spatter bombs were about $160 \mathrm{~cm}$ long, but most were $<30 \mathrm{~cm}$. The bombs were fluid and stretched upon landing, accounting for their length. As with other explosions in 2016, the tephra was dominated by juvenile material but had a minor component of small white secondary minerals, often coating the juvenile spatter. Spatter from this event hit the HTcam enclosure but did not damage it. However, spatter also hit the HTcam's power and ethernet cable, partly melting them and interrupting the data stream.

The final explosive event of the year occurred on December 2 at 06:58 HST and, like the November 28 event, was triggered by a large slab of rock below the HMcam collapsing into the lake. The tephra deposit on the Halema'uma'u Crater rim was smaller than that of November 28, and consisted of sparse spatter bombs around the HMcam and Halema'uma'u Overlook.

Each of these rockfall-induced explosive events was associated with a composite seismic event (fig. 63) that consisted of a burst of high frequency and long-period energy, followed by several minutes of very-long-period oscillations (Chouet
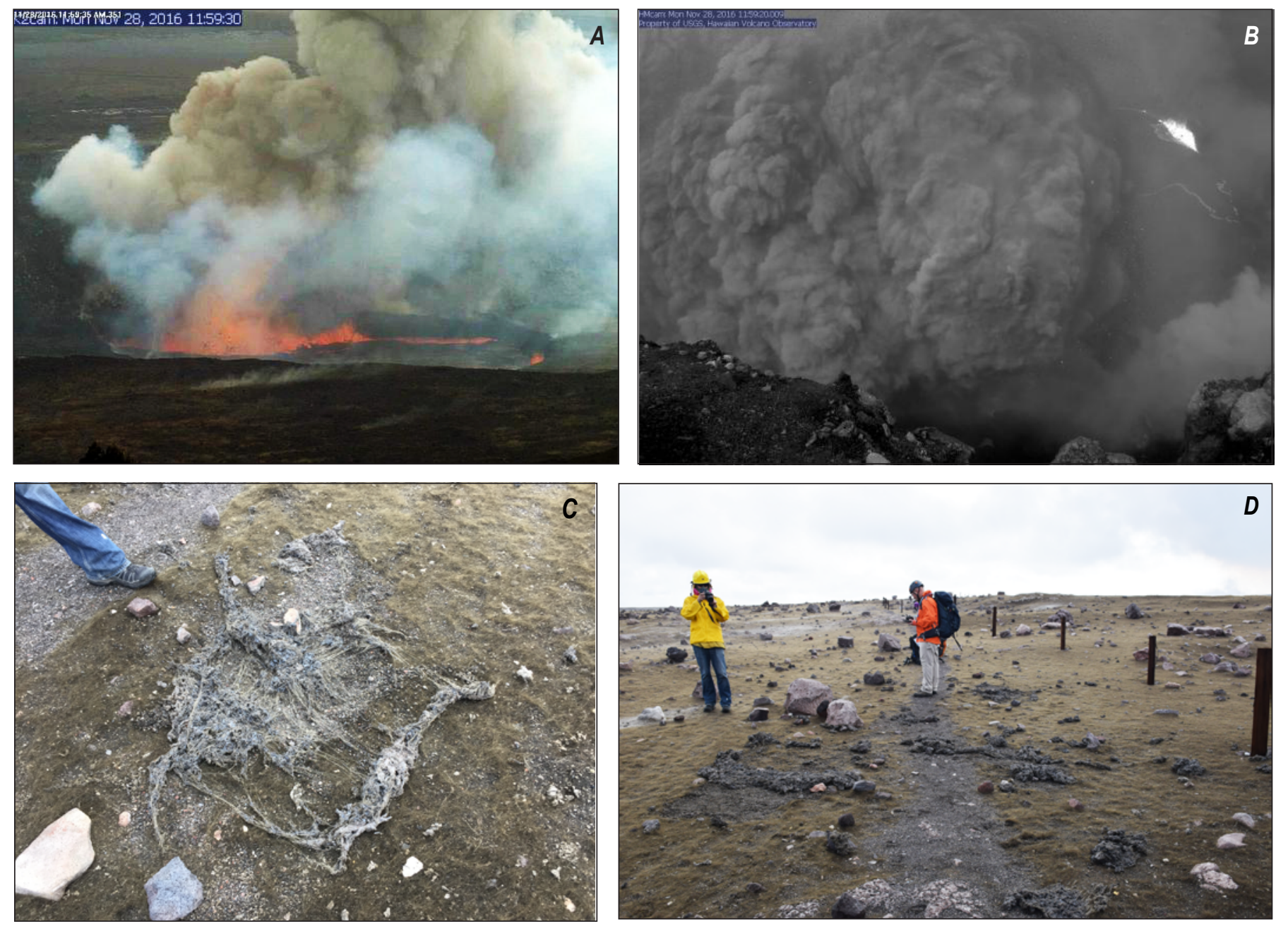

Figure 62. Images of the November 28, 2016, explosion and resulting deposit. A, Intense spattering and particle-laden plume captured from the K2cam in the Hawaiian Volcano Observatory observation tower. B, Dark particle-laden plume rising beneath the HMcam. C, Large spatter bomb near the HTcam (fig. 2). The bomb was semi-fluid and was pulled apart like taffy upon impact. $D$, Dark spatter bombs on the trail near the HTcam. The light-colored lithic blocks are from the 1924 explosions. 


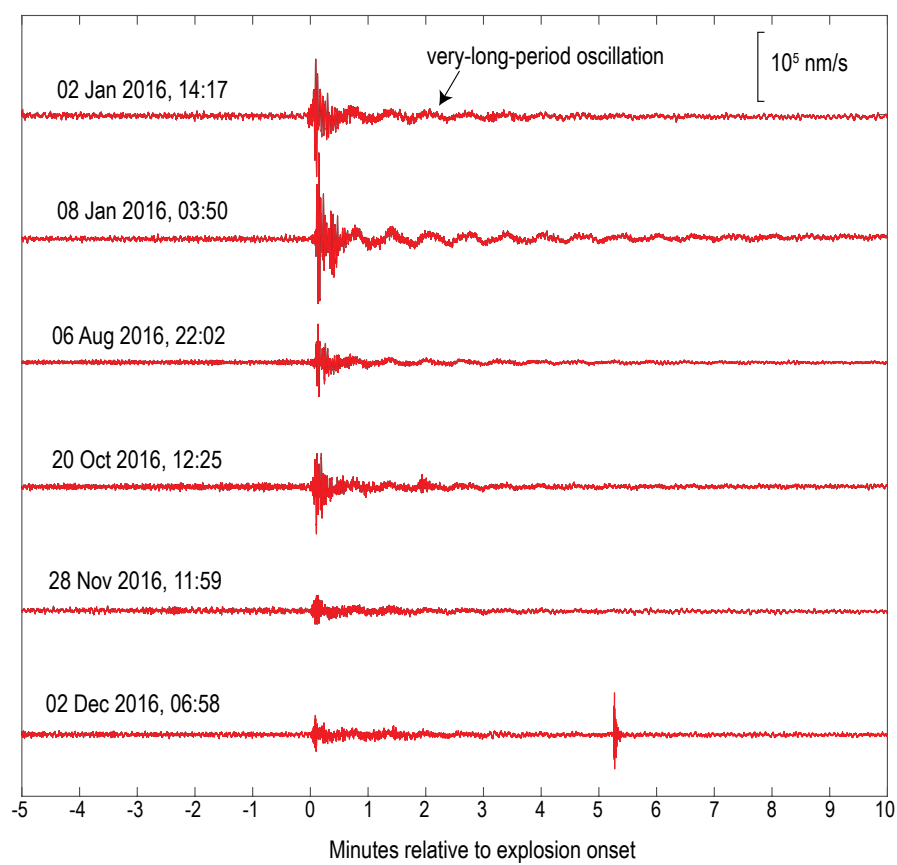

Figure 63. Composite seismic events associated with selected explosive events of 2016. Vertical component of broadband station NPT (fig. 1B). Composite events at Halema'uma'u began with a burst of high-frequency and long-period energy followed by several minutes of very-long-period (VLP) oscillation (Orr and others, 2013). The VLP signals are easily visible in these data. The September 19 and October 19 explosive events are not shown here and had very small seismic signals compared to the events shown. $\mathrm{nm} / \mathrm{s}$, nanometers per second.

the explosive event on January 2) to 100 percent (Swanson and others, 2016). Juvenile pyroclasts mainly consisted of Pele's hair and tears, as well as hollow glass spherules (fig. 64), which were produced by spattering in the lake and lofted upwards in the plume. One glass spherule, collected in January 2016, was eggshaped and roughly $1.5 \mathrm{~cm}$ long (fig. 65). There was no significant scoriaceous material collected during the normal, persistent spattering activity. The nonjuvenile component consisted of ashsize particles of lithic wallrock, often friable and altered, as well as secondary sulfates. The lithic component presumably originates from small, relatively insignificant, rockfalls from the Overlook crater walls. The amount of tephra collected in the buckets is generally proportional to lake level. When the level is high, so is the tephra accumulation, because the spattering sites are nearer the buckets.

Pele's hair was one of the most abundant types of tephra produced by the lava lake. From the Halema'uma'u Overlook, one could often see clumps of Pele's hair lofted upwards in the plume as it rose above the lake. In the proximal region, near the rim of Halema'uma'u Crater, the Pele's hair was coarse and commonly had Pele's tears forming at the ends (fig. 66A). The Pele's hair could be carried many kilometers downwind. In the distal region, the Pele's hair was normally very fine and could be decimeters long (fig. 66B), and was often accumulated on the lee side of obstacles.
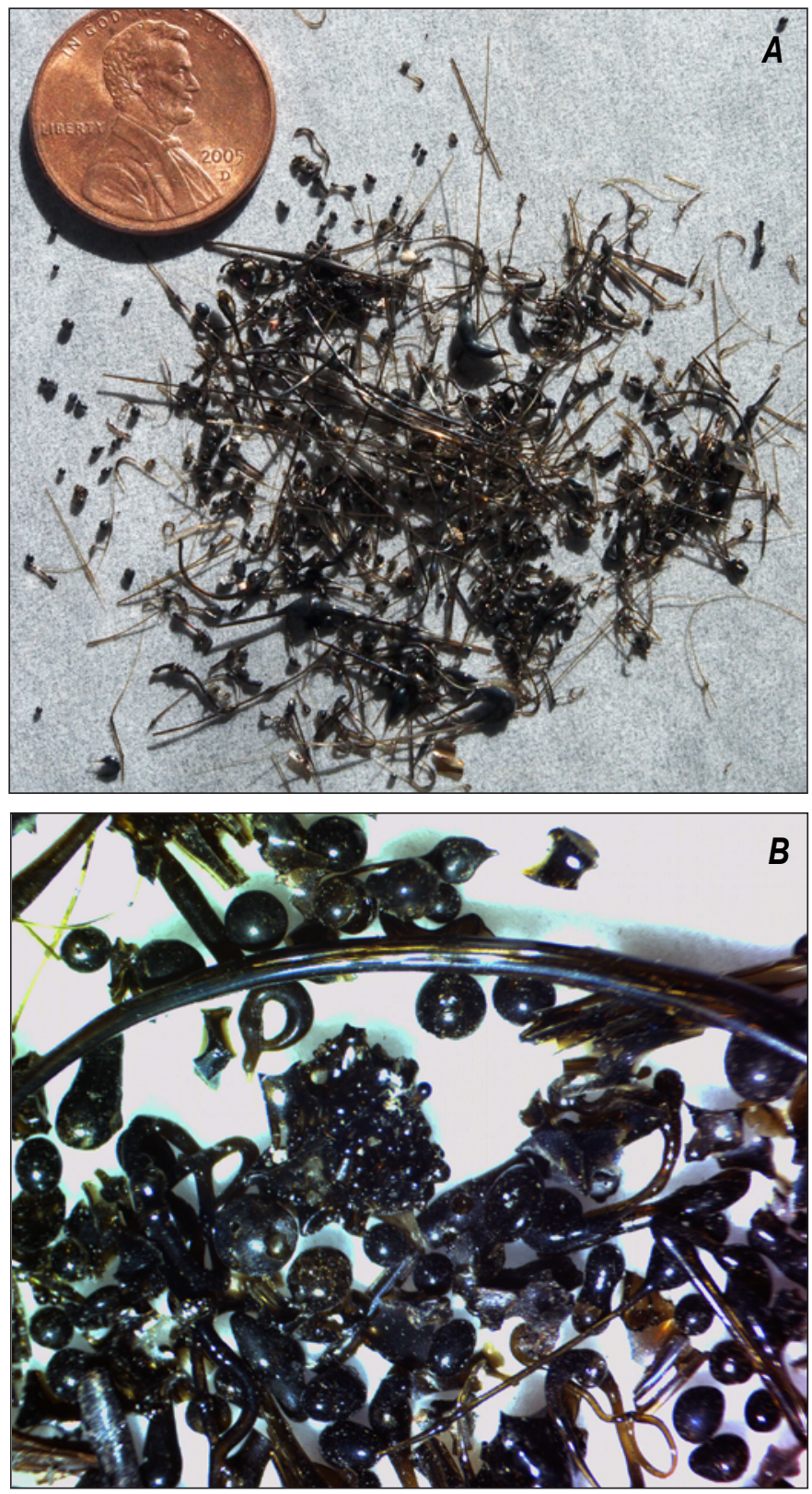

Figure 64. Photographs of tephra produced by spattering. $A$, Juvenile pyroclasts (Pele's hair and tears, hollow spherules) caught on 0.5-millimeter (mm) sieve on November 16, 2016. B, Hollow spherules and Pele's hair caught on 0.5-mm sieve on September 26, 2011.

Figure 65. Photograph of egg-shaped hollow glass spherule collected near the Halema'uma'u Overlook on January 8, 2016.

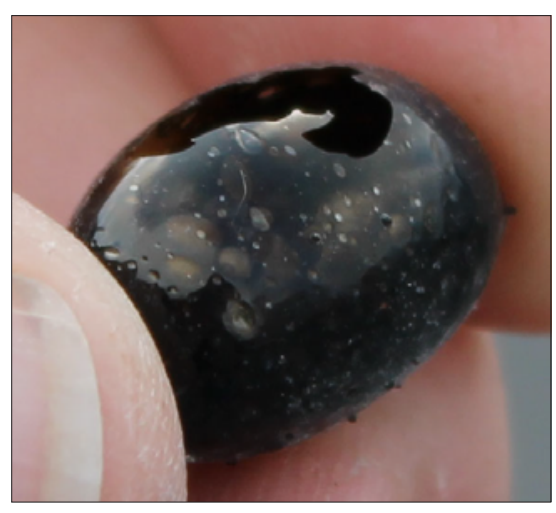


As a result of years of persistent spattering and tephra production in the Overlook crater, Pele's hair has accumulated in a thick, nearly continuous carpet in the immediate area downwind of the crater (fig. 67). On the southwestern rim of Halema 'uma'u Crater, the carpet of Pele's hair was a few centimeters thick, with even greater thicknesses where the hair could accumulate against rocks. The accumulation rate increased in 2016, compared to earlier years, as a result of high lake levels and tephra production. Large mats and clumps of Pele's hair accumulated in the Halema'uma'u parking lot, particularly against the curbs. An interesting reflective property of the Pele's hair was observed at low sun angles. When looking toward the sun, the carpet of Pele's hair had a lustrous golden appearance, but turning and looking away from the sun, the same deposit had a dull olive drab color. On Kona (southerly) wind days, Pele's hair commonly fell at HVO and Jaggar Museum, with HVO staff often finding long strands of Pele's hair on their vehicle windshields at the end of the workday and trees draped with hair like Christmas tinsel.

\section{Outgassing Plume}

Throughout 2016 the lava lake produced a persistent outgassing plume (fig. 68), which consisted primarily of $\mathrm{H}_{2} \mathrm{O}$,
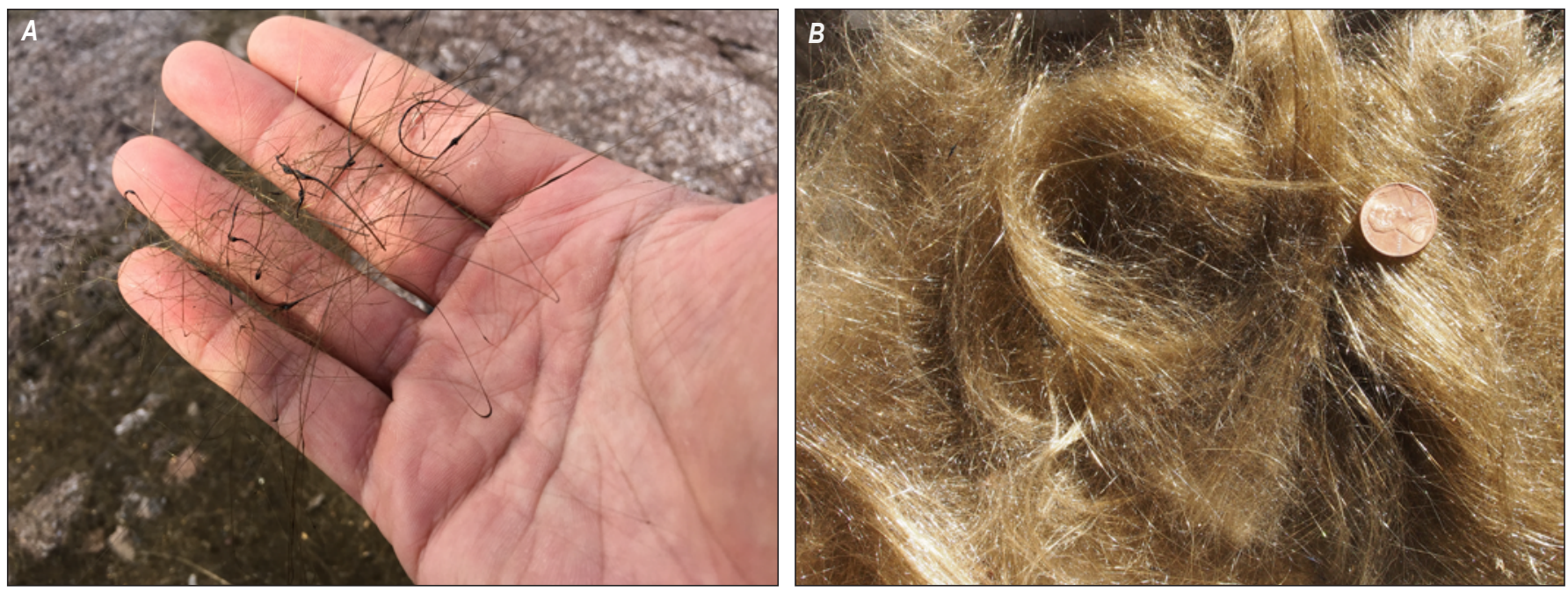

Figure 66. Photographs of Pele's hair. A, Pele's hair deposited on the rim of Halema'uma'u Crater. Proximal Pele's hair was commonly coarse and often terminated by Pele's tears. Photograph taken November 9, 2016. B, Pele's hair deposited 6 kilometers from Halema'uma'u Crater. Distal Pele's hair was typically very fine, and could be decimeters long. Photograph taken November 16, 2016.
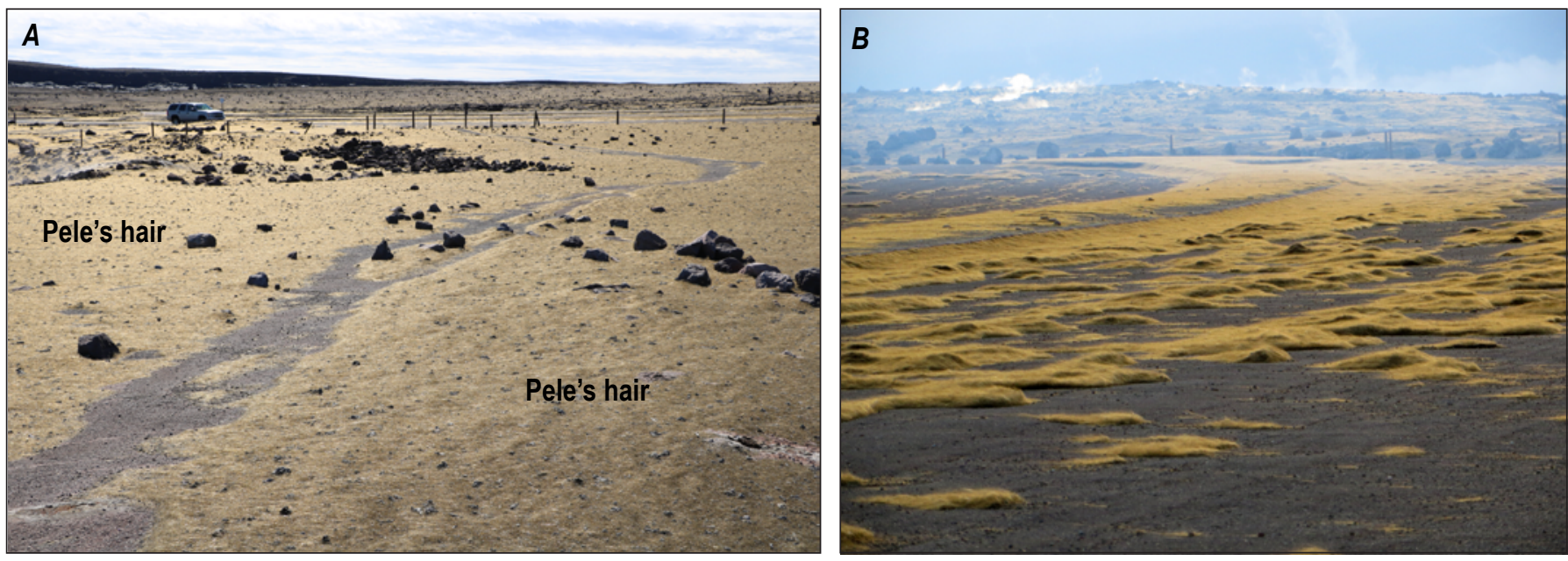

Figure 67. Photographs of carpet of Pele's hair downwind of lake. A, A continuous carpet of Pele's hair was present as much as several hundred meters downwind of the Overlook crater. This photograph was taken December 16, 2016, near station A4 (fig. 2). The trail to A4 is in the center of the photograph and the Halema'uma'u parking lot is near the top image. B, Discontinuous mats of Pele's hair in the Halema'uma'u parking lot. Photograph by Hannah Dietterich, U.S. Geological Survey, September 9, 2016. 


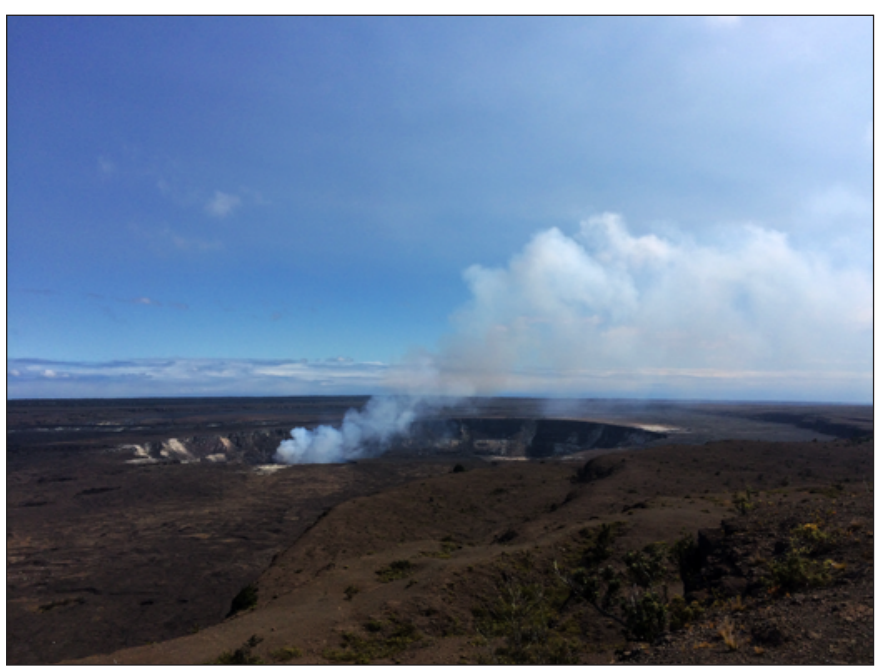

Figure 68. Photograph of a typical outgassing plume, taken from Uēkahuna Bluff (fig. 1A), near the Hawaiian Volcano Observatory, March 20,2016 . The outgassing plume from the lake was normally white in color and semi-transparent, and carried southwest (towards right side of photo) by the trade winds. The plume at this time was rising about 500 meters above the caldera floor.

$\mathrm{CO}_{2}$, and $\mathrm{SO}_{2}$ with minor amounts of $\mathrm{HCL}, \mathrm{HF}, \mathrm{CO}$, and other trace gases (Sutton and Elias, 2016; HVO unpub. data, 2016). Sulfates are an important aerosol component of the plume, and plume concentrations of many metallic elements, including gaseous elemental mercury, have been elevated above background air levels (Mather and others, 2012; Edmonds and others, 2013; Sutton and others, 2013; Sutton and Elias, 2016). Typical daily mean values for $\mathrm{SO}_{2}$ emission rate during 2016 ranged between 1,000 and 8,000 t/d (overall mean $=4,600 \mathrm{t} / \mathrm{d}$, standard deviation $=1,600 \mathrm{t} / \mathrm{d}$ ) (Elias and Sutton, 2017; HVO unpub. data, 2016).

The outgassing produced a relatively low, bent-over plume, resembling those produced by industrial stacks. This would be considered a weak volcanic plume, whose motion is determined largely by the prevailing winds, as opposed to a strong plume, which rises vertically despite local wind conditions (Sparks and others, 1997). In Hawai' $i$, the normal trade winds blow from the northeast, carrying the plume towards the $\mathrm{Ka}^{6} \mathrm{u}$ district. When trade winds are absent, Kona (southerly) winds commonly prevail, and the plume is carried towards the north, often into populated areas of the National Park such as Jaggar Museum, Kilauea Military Camp, and Kilauea Visitor Center, as well as the populated areas of east Hawai'i (figs. 69 and 70). On slack wind days, the plume would rise vertically more than a kilometer (fig. 71). When such weak winds occurred, the nighttime glow reflected off of the vertically rising plume could be easily seen from nearby communities. Local residents sometimes mistook the better visibility of the vertically rising plume at these times for an increase in lava lake activity. The vertical glowing plume was sometimes visible in nighttime images from webcams at $\mathrm{Pu}^{\mathrm{u}} \mathrm{u}$ ' $\overline{\mathrm{O}}{ }^{‘} \overline{0}$, located about $19 \mathrm{~km}$ to the east.

The appearance of the plume could range from opaque, white and puffy, to a thin, semi-transparent brown haze, presumably depending on both gas emission rates (described below) and atmospheric conditions. At any given time, the plume commonly exhibited this range of color and optical thickness in different regions. The plume also showed variations along its length, appearing as robust "puffs" separated by gaps of thinner plume (fig. 72). These puffs may be caused by fluctuations in outgassing at the source (spattering sites), with some contribution by turbulence as well. These puffs likely explain the high variability of $\mathrm{SO}_{2}$ emission rates over very short (tens of seconds) time spans, as recorded by the ultraviolet spectrometer array (Horton and others, 2012; Elias and others, 2016).

Another common feature of the plume was a diffuse groundhugging curtain of gas that extended down from the main body of the plume (fig. 72). The extent of plume grounding at Kìlauea, also referred to as plume fumigation, is controlled by a number of factors including wind speed, inversion layer height and strength, and atmospheric stability. Plume grounding is an important feature of gas release as it has a strong control on gas concentrations at ground level (Delmelle and others, 2002). The grounded gas curtain at Halema'uma'u could be maintained for kilometers, frequently producing high $\mathrm{SO}_{2}$ concentrations at ground level in downwind areas.

The optical thickness of the plume depended in large part on the gas and particle emission rates, which could fluctuate dramatically and corresponded with the intensity of spattering. Overall, more numerous and (or) intense spatter sites in the lake produced higher gas emissions and a more robust gas plume. Nonspattering phases, often lasting several hours at a time, corresponded with an unusually weak, wispy plume (fig. 73). Patrick and others (2016a) show that nonspattering phases corresponded to $\mathrm{SO}_{2}$ emission rates about one-third of those during spattering phases. Therefore, the unusually weak plume is mainly a result of a dramatic reduction in gas emission rates. Although plume appearance is also controlled by atmospheric factors, the link between spattering intensity and plume vigor was observed in many different atmospheric conditions and is well established both observationally and quantitatively (Patrick and others, 2016a,c). The appearance of the plume was also related to the particle abundance.

Plume optical thickness was not uniform across the span of the lava lake. The most robust portions of the plume originated directly from the spatter sites on the lake surface, each site several tens of meters across (fig. 74). The remainder of the lake surface emitted a diffuse plume. This relation is again consistent with previous outgassing estimates, which indicate that the majority of outgassing originates directly from the spattering. Patrick and others (2016a) showed that spattering accounted for roughly twothirds to three-fourths of the total $\mathrm{SO}_{2}$ emission rate, while passive outgassing from the lake surface produced the remainder. 

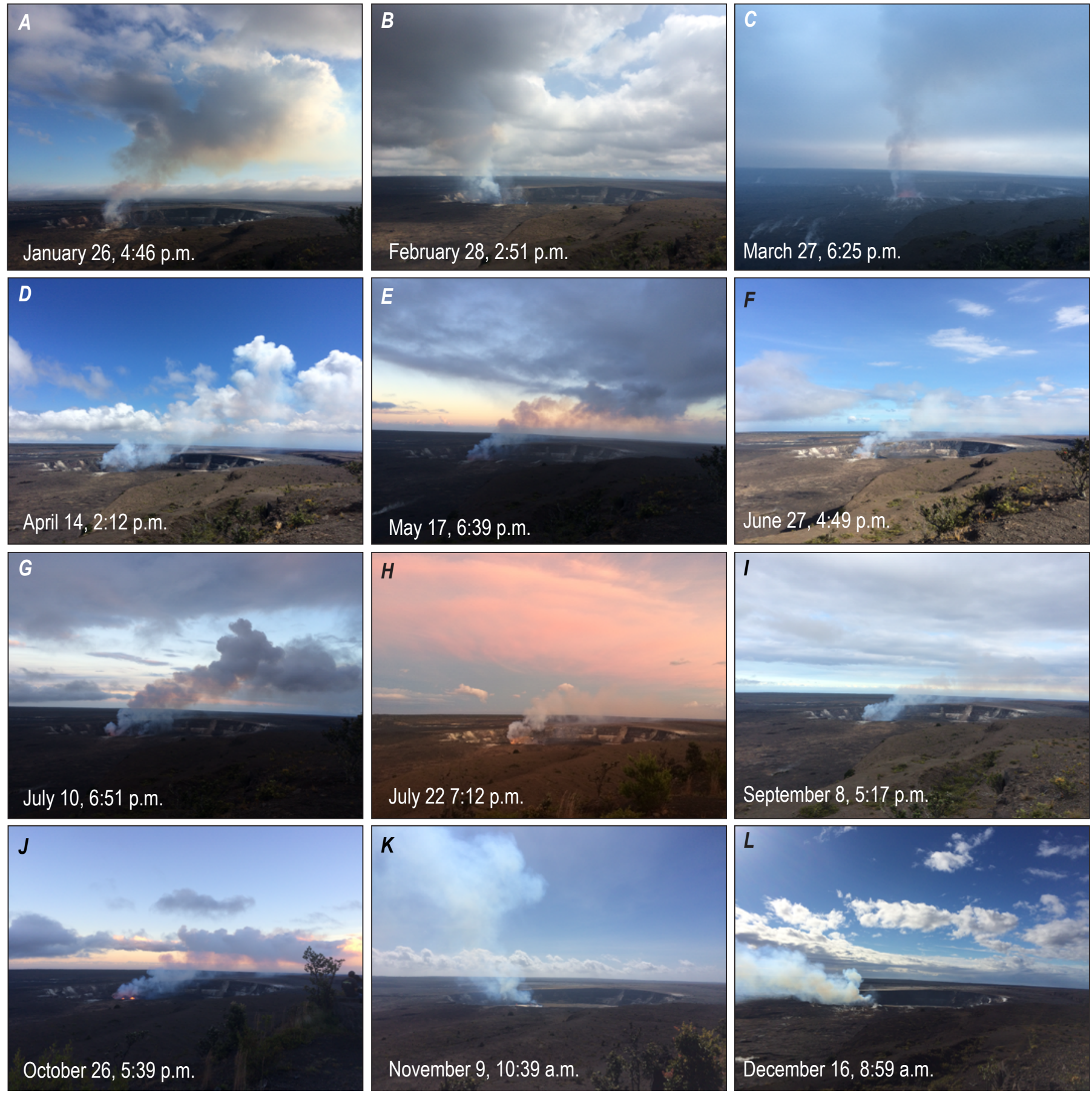

Figure 69. Monthly views of the outgassing plume. Photographs of the outgassing plume in varying conditions, all taken from Uēkahuna Bluff. Note that in most cases the plume is carried southwest (towards right side of image), but the plume direction could change when the trade winds ceased. 


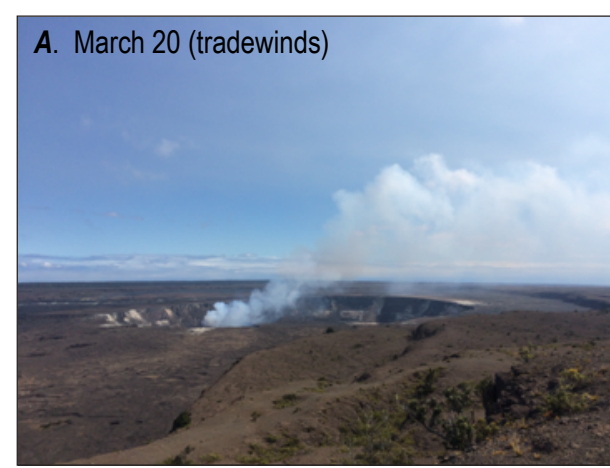

C. March 30 (Kona winds)

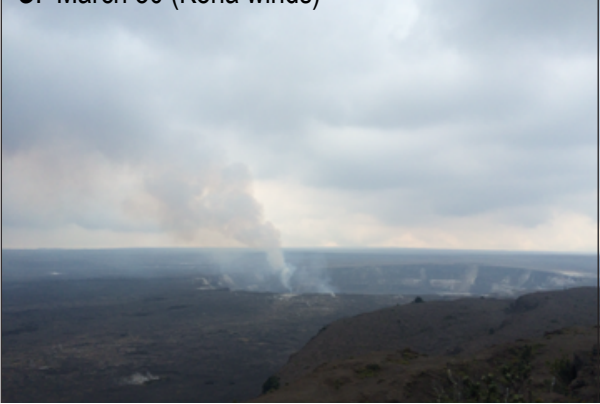

Figure 70. Photographs showing alternating trade wind and Kona wind effects on the plume. The photographs were taken from Uēkahuna Bluff during 2016.

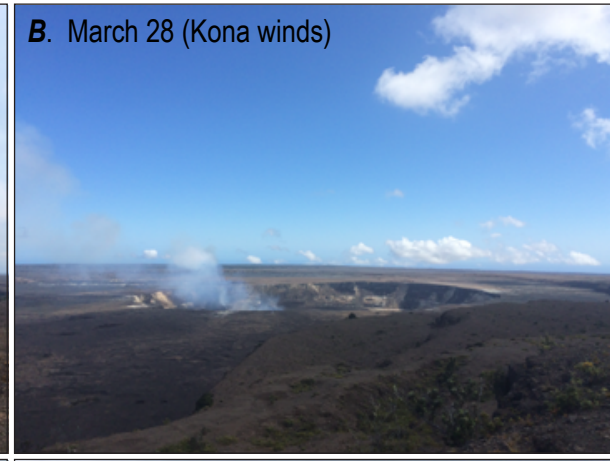

D. April 1 (tradewinds)

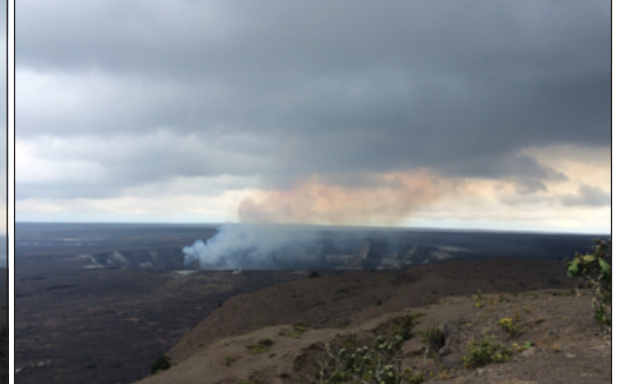

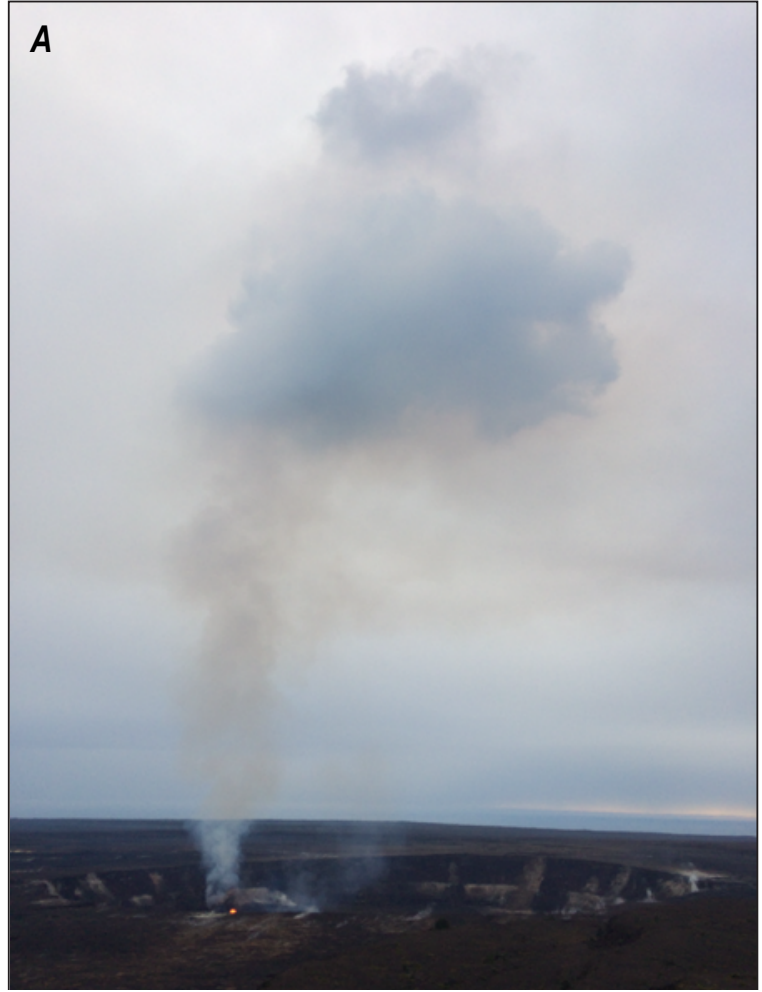

Figure 71. Photographs showing a vertical plume rise in slack winds. $A$, The plume rising vertically and reaching a neutral buoyancy height of about 1 kilometer above the lava lake. Photograph taken from Uēkahuna Bluff on December 2, 2016. B, Park visitors at Uēkahuna Bluff watching the vertically rising and expanding plume on a slack wind day, March 15, 2016. 


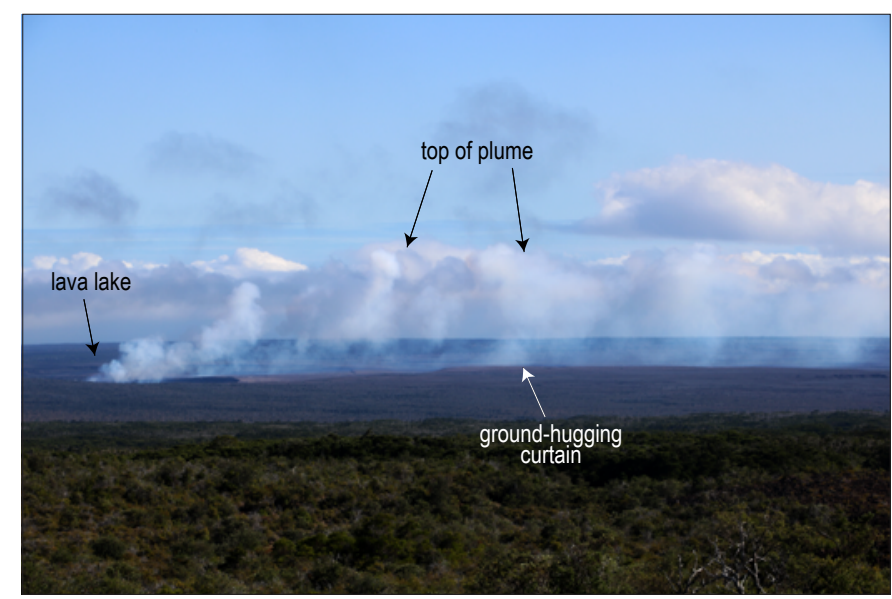

Figure 72. View of the plume from a distance. Photograph taken from the Mauna Loa strip road, about 12 kilometers northwest of the lava lake. The plume was carried southwest, rising to a height of about 500 meters. The plume often had a ground-hugging curtain, as it does here. Photograph taken December 28, 2016.

Figure 73. Photographs showing plume vigor changes in spattering and nonspattering phases. Spattering intensity controlled the rate of gas emission from the lake, which in turn contibuted to the optical thickness of the plume. Images are from the K2cam in the Hawaiian Volcano Observatory observation tower. $A$, Thin, wispy plume associated with very low gas emission rates during a nonspattering (gas pistoning) phase on December 19, 2016. $B$, More robust plume occurring 30 minutes later during a period of spattering and higher gas emission rates.
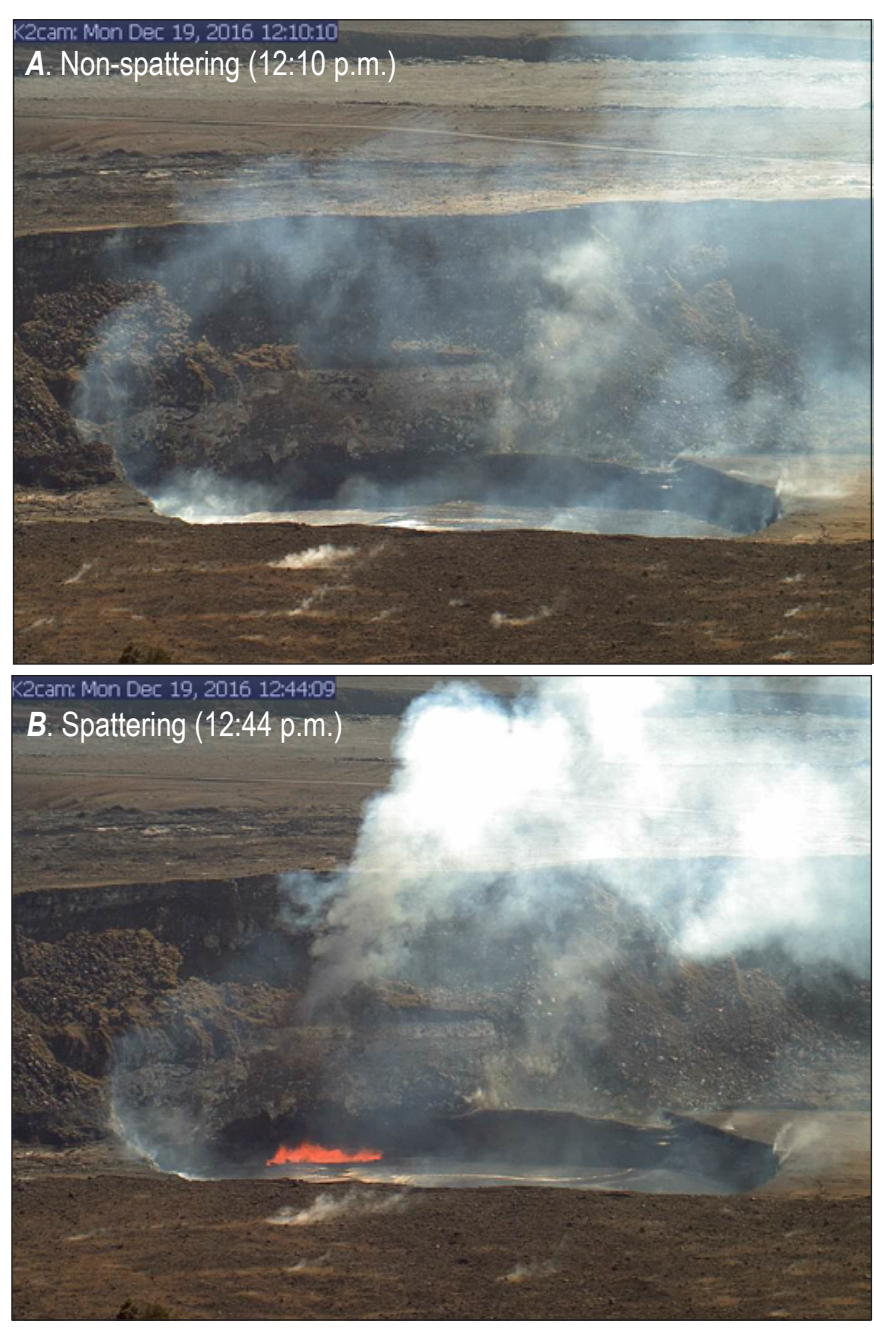
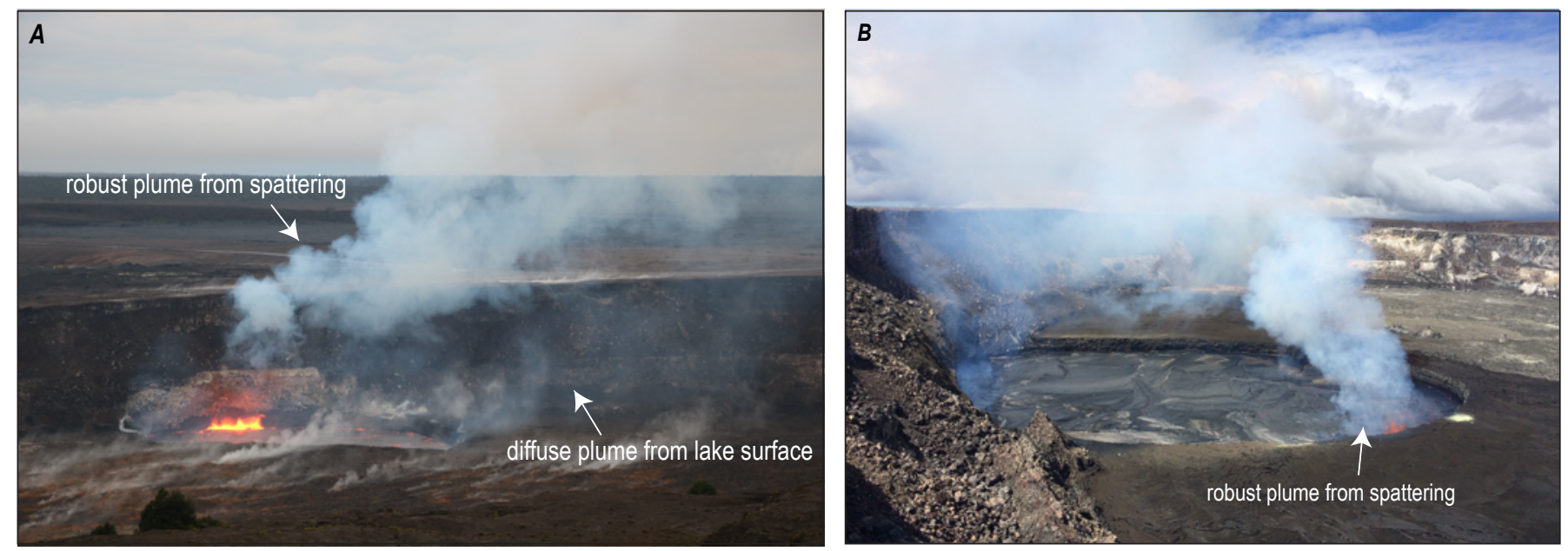

Figure 74. Photographs showing the robust portion of plume related to spattering. The most robust portion of the plume originated directly from distinct spattering sites, presumably because of the higher gas emission rates occurring at those sites compared to diffuse gas release from the remainder of the lake. $A$, Robust plume originating from spattering along the southern lake margin. A more diffuse plume comes from the rest of the lake surface. Photograph from the Hawaiian Volcano Observatory, December 18, 2016. B, Robust portion of plume originating from spattering along the northern margin of the lake. Photograph taken from the Halema'uma'u Crater rim on September 10, 2016. 


\section{Volcanic Air Pollution}

The primary hazard of the summit eruption has been volcanic air pollution, also known as vog (Elias and Sutton, 2017). Although potentially lethal explosive events have occurred, the ballistic fallout has been limited to the closed area of the park (Houghton and others, 2013), posing no threat to publicly accessible areas. Furthermore, the lake itself poses no immediate threat of inundation by overflows as it has been normally contained by the Overlook crater, which is itself confined by Halema' uma' $u$ Crater. Instead, the outgassing plume is carried far from the vent and affects wide areas of Hawai' $i$ with high concentrations of sulfur dioxide and (or) other vog constituents, such as solid sulfate and liquid sulfuric acid droplets.

Vog is a respiratory irritant that negatively affects human health (Sutton and others, 1997; Longo, 2013; Tam and others, 2016; Elias and Sutton, 2017), as well as agriculture in areas downwind of the vent. The opening of the summit vent in 2008 increased the effects of vog, which had already been a long-term issue on the Island of Hawai' 1 owing to the $\mathrm{Pu}^{\varsigma} \mathrm{u}$ ' ${ }^{\prime} \overline{\mathrm{C}}^{`} \mathrm{o}$ eruption that began in 1983 (Sutton and others, 1997; Elias and others, 1998; Longo and others, 2010; Elias and Sutton, 2017). The impact of vog on human health and the environment remains an important area of ongoing research. $\mathrm{SO}_{2}$ monitoring and vog forecasting (Businger and others, 2015; Elias and others, 2016) have been a part of island-wide efforts to better respond to vog conditions.

The Ka' $\bar{u}$ district, directly downwind of the summit vent during normal trade wind conditions, has been particularly hard hit (Longo and others, 2010). Farming and ranching have been impacted, which led to a U.S. Department of Agriculture disaster declaration in 2008, allowing affected growers to access federal assistance programs (Honolulu Advertiser Staff, 2008; Elias and Sutton, 2017). The Ka' $\bar{u}$ high school gymnasium, built in 2013, was designed to incorporate a vog shelter for sensitive residents during periods of poor air quality (Jensen, 2013). During prevailing trade wind conditions, air quality in this area of the island is routinely impacted; during 2016, the U.S. Environmental Protection Agency primary health standard for $\mathrm{SO}_{2}$ (hourly average of 0.075 parts per million [ppm]) was exceeded in Pāhala (fig. 1A) on 246 days of the year (State of Hawaii Department of Health, 2016).

Trade wind interruptions most commonly occur during the winter months, producing vog in the heavily trafficked areas of Hawai'i Volcanoes National Park and surrounding communities. Park rangers carry industrial hygiene $\mathrm{SO}_{2}$ monitoring badges, and make limited, temporary closures of areas in the park that have high gas concentrations. On November 6, 2016, such a closure was enacted at Jaggar Museum, owing to hazardous levels of $\mathrm{SO}_{2}$ gas. In 2016, the U.S. Environmental Protection Agency primary health standard for $\mathrm{SO}_{2}$ was exceeded on 107 and 77 days, respectively, at Jaggar Museum and Kilauea Visitor Center (https://ard-request.air-resource.com/data.aspx).

The Island of Hawai' $i$ is currently one of several communities worldwide that copes with the effects of persistent volcanic outgassing. Similar to Kīlauea, Masaya Volcano in Nicaragua is situated within a national park and emits a continuous plume as a result of open-vent basaltic activity, affecting vegetation and producing poor air quality downwind (Delmelle and others, 2002; van Manen, 2014a). Gas emissions at Turrialba volcano in Costa Rica have increased since 2007, affecting vegetation and air quality (Martini and others, 2010; van Manen, 2014b). Miyakejima volcano in Japan produces persistent outgassing that has required significant adaptive measures by local officials and the public (Delmelle, 2003; Ishimine, 2007). Continuous gas emissions from Ambrym volcano, in Vanuatu, produce environmental and human health impacts, including fluorosis (Cronin and Sharp, 2002; Allibone and others, 2012). These are just a few examples of other communities affected by persistent volcanic outgassing.

\section{Miscellaneous Observations}

\section{Sounds}

The most common sound from the Overlook crater resembled that of breaking waves on a distant seashore, which presumably represented unsteady outgassing. When spattering was active this sound was combined with the more energetic sounds of gas release owing to bubble bursting, resembling a pulsating roaring sound. It was also associated with the low percussive sounds and lumpy patter noises of large globs of spatter impacting the lake.

Rock cracking and popping sounds were only occasionally observed during 2016. These sounds were not as frequent or intense as the rock cracking sounds reported in earlier years.

\section{Heat}

When standing at the Halema'uma'u Overlook in 2016generally about $80-120 \mathrm{~m}$ above the lake surface - the radiant heat from the lake surface on one's face was obvious, but normally not uncomfortable. Only once during 2016, when spattering in the lake was intense and the lake level was relatively high, did HVO staff report that the radiant heat was almost unbearable. Notwithstanding the radiant heat, the near-constant winds at the Halema'uma'u Overlook maintained a relatively cool ambient temperature at the Halema'uma'u Crater rim. The ambient temperature was felt to warm slightly when HVO staff were sporadically enveloped by the outgassing plume. When HVO scientists visited the floor of Halema 'uma'u Crater on November 29,2016 , they approached to within about $20 \mathrm{~m}$ of the northern rim of the Overlook crater. At this spot the air was cool and radiant heat was minimal, probably because much of the lake surface was blocked by the Overlook crater rim.

\section{Effects of Heavy Rains}

During normal rains a sizzling sound could be heard, which resembled the sound commonly heard on the East Rift Zone flow field when rain falls on active pāhoehoe lobes. In very intense downpours, which may only happen a few times a year and persist for minutes at a time, the HTcam thermal images of the lake 
showed greatly depressed temperatures and the normal webcam (HMcam) images showed opaque clouds of condensed water vapor above the lake surface. Once the rain ceased, this mist would thin, but portions of it persisted over the center of large plates, where thermal camera images show the lowest surface temperatures on the lake (about $40{ }^{\circ} \mathrm{C}$ in fig. 75). Although the surface temperatures in the thermal images may be suspect owing to attenuation by the mist, the vestiges of the mist over the coolest portions of the plates might suggest that the surface temperature momentarily dropped below $100^{\circ} \mathrm{C}$ as a result of the heavy rain, allowing a thin layer of water to briefly accumulate. Otherwise, there was no obvious change in the lake surface activity, such as increased foundering or plate fusing, during intense downpours in 2016.

\section{Public Engagement}

HVO provides several regular information products directly to the public by way of the HVO website (https://volcanoes. usgs.gov/hvo). A daily update is posted each morning with a short summary of activity at the summit and East Rift Zone. Photographs and video are frequently posted to the website multimedia page and the USGS Volcanoes social media accounts (Twitter and Facebook). These images and videos are often widely shared by users on social media, and are sometimes featured on local television news. Four near-real-time webcam views of the lake are available on the HVO website. These videos and webcam views are valuable for the public to gain an understanding of the activity in the lava lake, as the immediate area is closed to the public. HVO staff write a weekly "Volcano Watch" article for the local newspaper (also posted directly on the HVO website) on volcano-themed topics, which often includes explanations of recent summit activity. In addition, public talks several times per year normally involve an update on summit eruptive activity.

The summit eruption has been a popular visitor attraction since it began in 2008, with the closest viewing area at the Jaggar Museum overlook (fig. 76). For much of the eruption the lake has been too deep to be directly visible from this vantage point, but the impressive glow and outgassing plume nevertheless provided good views. When lava first became directly visible to visitors at the Jaggar Museum overlook in April 2015 the popularity of this viewing location increased dramatically, with more vehicles arriving than the Jaggar parking lot could accommodate. With lava frequently visible at the Jaggar Museum overlook in late 2016, this viewing area remains popular, with national park rangers managing vehicles at the Jaggar parking lot during the busy dusk hours.

\section{Lake Activity in Context}

The 2016 lava lake activity we describe here is broadly similar to that of the preceding three years in many respects, including the lake surface textures and appearance, surface motion, explosions, outgassing and most aspects of the spattering behavior. There were several differences with previous years,
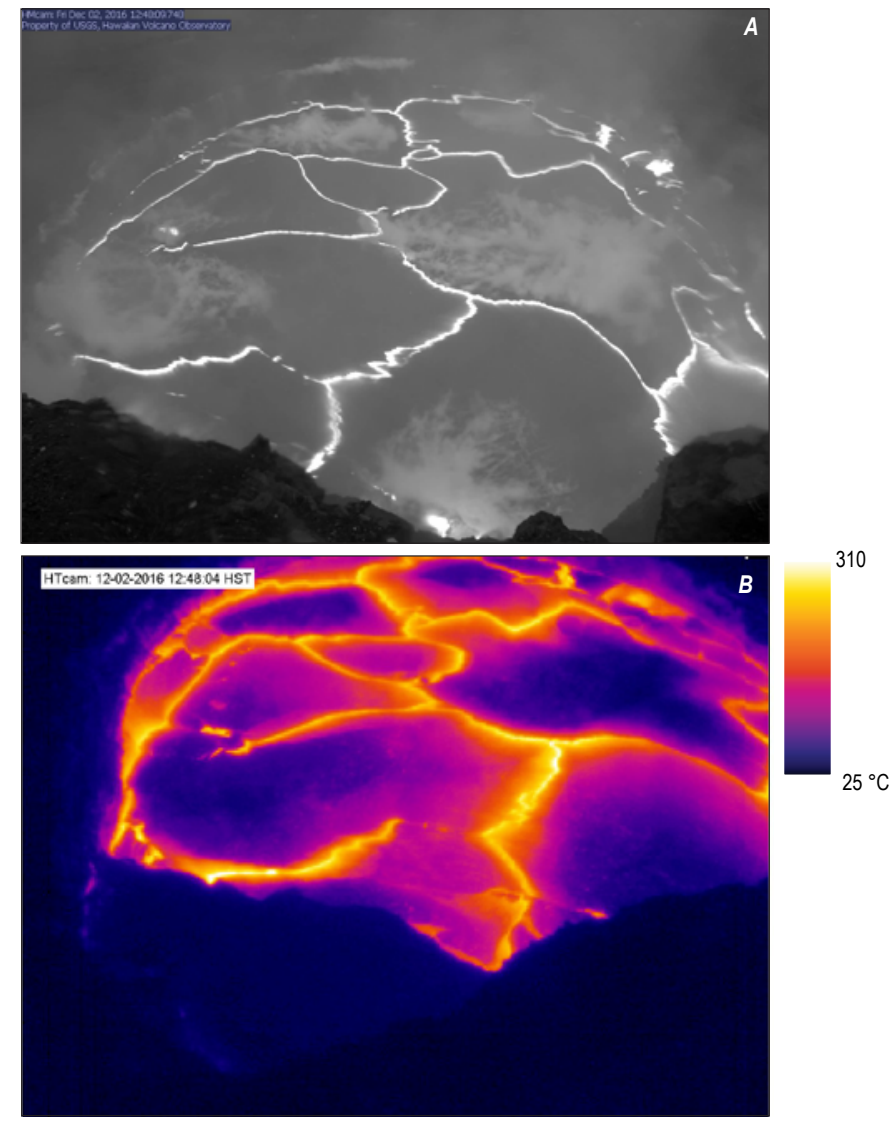

Figure 75. Images of the lake surface immediately following unusually heavy rains. $A$, HMcam near-infrared image of the lake surface, showing white clouds of condensed water vapor over the central portions of the largest crustal plates. Image taken at 12:48 HST on December 2, 2016. B, HTcam thermal image at the same time, showing greatly reduced temperatures in the areas containing mist. Note that the mist may be attenuating the radiance, partly contributing to the lower apparent temperatures.

however. First, the crater has continued to enlarge over the past few years, resulting in a greater surface area in 2016. Second, the frequency of nonspattering phases dropped dramatically. Third, the overall lake levels in 2016 were higher than those in previous years, resulting in an increasing verticality of the Overlook crater wall where it cuts the floor of Halema'uma'u. Tephra production increased substantially as a result of the increased spattering and higher lake level, and the juvenile proportion of the tephra grew higher as the crater wall became more stable and the lake level rose.

Overall, 2016 is notable for the remarkable consistency in the lava lake's behavior throughout the year. Despite common fluctuations in lake level and outgassing, the lake exhibited an overall steadiness in most respects. Combined with the higher overall lava levels and clearer views of the lake surface, the activity in 2016 therefore provides an unprecedented observational record of the nature of stable, persistent lava lake activity. Data from 2016 should be useful in further refining models concerning lake level changes, gas pistoning, and the relation between outgassing and seismic tremor. 
Figure 76. Photograph showing park visitors enjoying the view of the lake at the Jaggar Museum overlook, October 26, 2016. Photograph taken from the Hawaiian Volcano Observatory observation tower at dusk, a popular time for visitation.

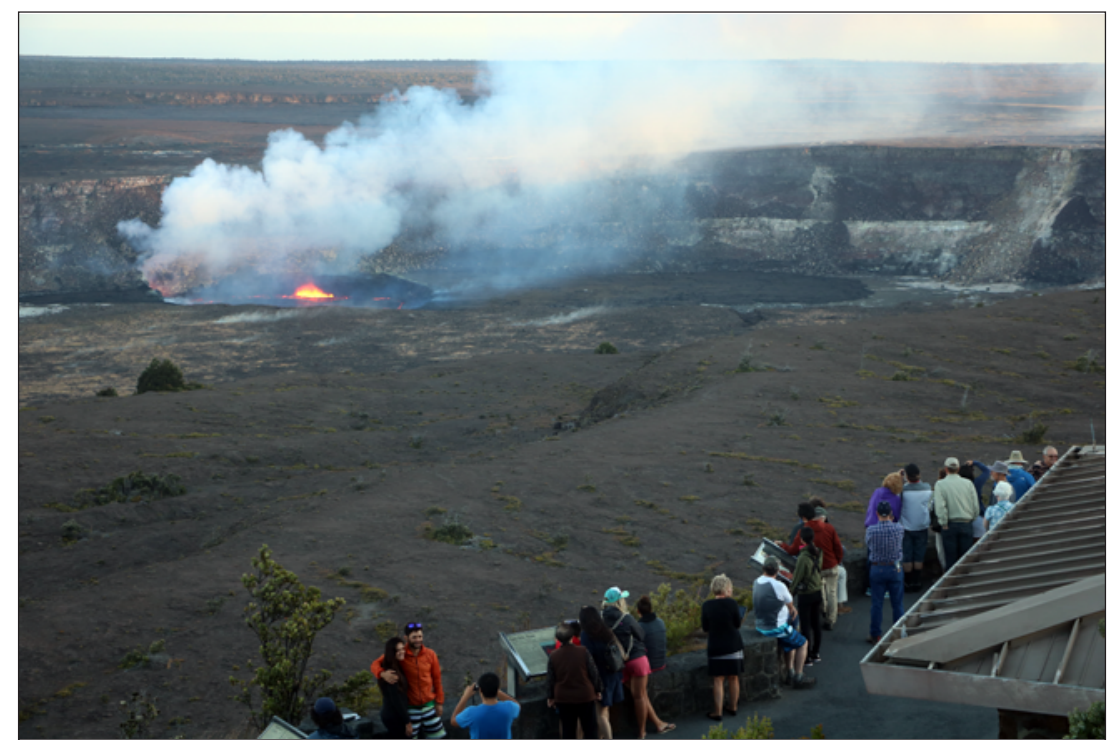

\section{Relation to the East Rift Zone Eruption at Pu'u 'Ō'ō}

The 2016 summit activity described here was concurrent with the $\mathrm{Pu}^{\prime} \mathrm{u}$ ' $\mathrm{O}^{`} \mathrm{o}$ eruption, which began in 1983 (Heliker and Mattox, 2003; Orr and others, 2015). For the Pu'u ' $\overline{\mathrm{O}}^{`}$ ō eruption, the first five months of 2016 consisted of slow-moving pāhoehoe flows roughly $5 \mathrm{~km}$ northeast of $\mathrm{Pu} \mathrm{u}^{\prime} \mathrm{u}$ ' $\overline{\mathrm{O}}$ 'o (Patrick and others, 2017). This activity marked the final stages of Episode 61e, also called the "June 27th flow," which had threatened the town of Pāhoa (fig. 1A) in 2014-2015 (Poland and others, 2016; Patrick and others, 2017). Episode 61e ended roughly a week after new fissures formed on $\mathrm{Pu}{ }^{‘} \mathrm{u}$ ' $\mathrm{O}^{‘}$ ō on May 24, 2016 (Patrick and others, 2017). These new fissures eventually focused on a single vent east of $\mathrm{Pu}^{\prime} \mathrm{u}$ ' $\overline{\mathrm{O}}^{`} \overline{\mathrm{o}}$, feeding lava to a new flow (the Episode $61 \mathrm{~g}$ flow; Orr and others, 2017). This lava flow moved southeast and reached the ocean on July 26, 2016, forming the Kamokuna ocean entry, which was active for the remainder of the year. Throughout these changes on the flow field, a small lava lake remained active within the western portion of $\mathrm{Pu}^{\prime} \mathrm{u}{ }^{\prime} \overline{\mathrm{O}}^{‘}{ }^{\prime} \mathrm{o}$ crater (fig. 77). This lava lake, in what we call the "west pit", was roughly $50 \mathrm{~m}$ in diameter and about $20 \mathrm{~m}$ below the rim of the west pit. The lake surface had an elevation that varied between 843 and $856 \mathrm{~m}$ above sea level, which was roughly $120-180 \mathrm{~m}$ below the level of the lava lake in Halema'uma'u.

The opening of the Episode 61g vent on May 24, 2016, may correspond with an abrupt drop in summit lava lake level of about $16 \mathrm{~m}$ between May 24 and May 26. If so, this relation would follow previous patterns in which an East Rift Zone vent opening, and subsequent draining of the shallow magma reservoir at $\mathrm{Pu}^{6} \mathrm{u}$ 'Ō'o , triggered a drop in summit lake level (Patrick and others, 2015). This drop in summit lake level, however, also occurred during a phase of deflation associated with a deflation-inflation cycle, so it is difficult to isolate what portion of this drop was the result of the East Rift Zone vent.
Figure 77. Photograph of the small lava lake in Pu'u 'Ō'ō crater, on Kīlauea's East Rift Zone June 23, 2016. The lake was active throughout 2016 and concurrent with the summit lava lake. The lake is roughly 50 meters in diameter.

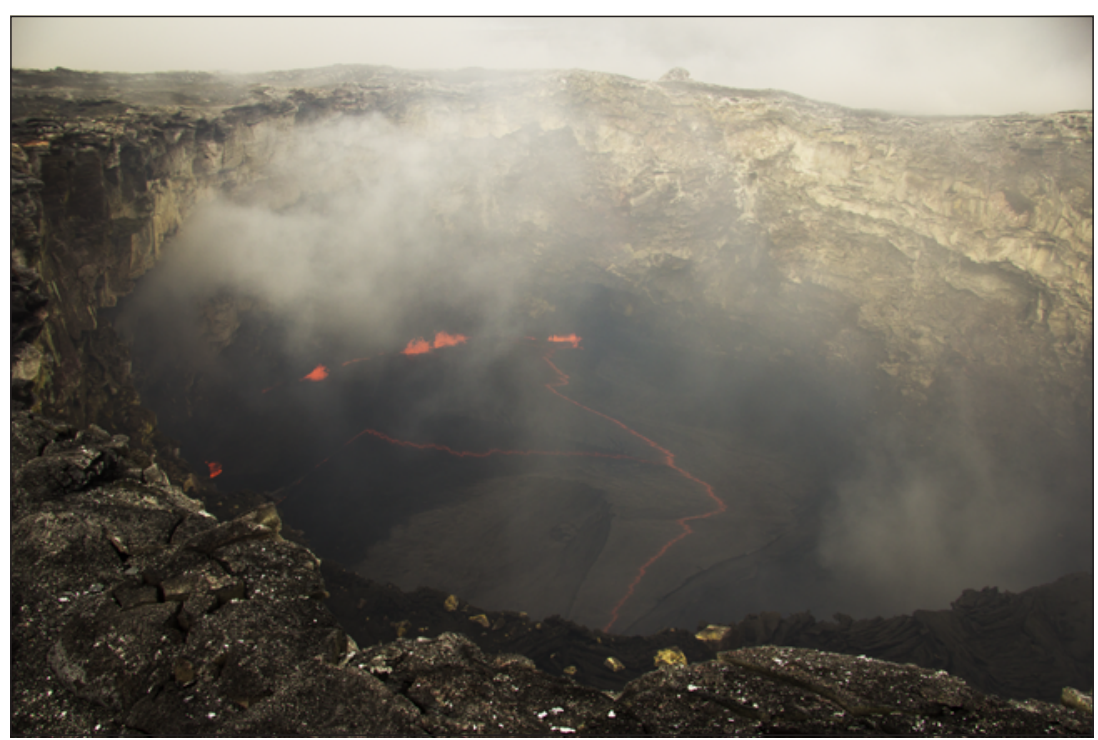




\section{Comparison with Other Lava Lakes on Earth}

The lava lake in Halema'uma' $u$ Crater is one of several persistent lava lakes on Earth. Other long-standing lakes include those at Erta Ale (Ethiopia; Harris and others, 2005), Nyiragongo (Democratic Republic of the Congo; Spampinato and others, 2013), Erebus (Antarctica; Oppenheimer and others, 2009), Ambrym (Vanuatu; Allard and others, 2016), and Villarrica (Chile; Moussallam and others, 2016). Recent lava lakes have become active at Nyamuragira (Democratic Republic of the Congo; Campion, 2014) and Masaya (Nicaragua; Global Volcanism Program, 2016) as well.

Of these lakes, only those at Halema'uma' $u$ and Nyiragongo exceed $30,000 \mathrm{~m}^{2}$ in surface area, to our knowledge. The remainder are generally much smaller $\left(<6,000 \mathrm{~m}^{2}\right)$. The Halema'uma' $u$ lake bears the most resemblance to the lakes in Nyiragongo and Erta Ale. For instance, Erta Ale has many similarities in surface behavior, with large crustal plates and varying spreading zones, and sparse spattering sites that locally disrupt surface motion (Oppenheimer and Yirgu, 2002; Spampinato and others, 2008). Recent observations of Nyiragongo lava lake indicate a more active surface than the lake at Halema'uma'u, with many scattered spattering sites active at a given time. Significant lake level changes have been recorded at Erta Ale and Nyiragongo (Burgi and others, 2014; Barnie and others, 2016), but measurements of short term lake level changes have been sparse (Spampinato and others, 2013; Burgi and others, 2014). With rough similarities in appearance, we expect that some of the observed patterns and processes in the Halema'uma'u lake may be relevant for Nyiragongo and Erta Ale. Patrick and others (2016c), for instance, suggested that phases of shallowly driven lake surface motion, common at Halema'uma'u, may also occur at Erta Ale.

\section{Conclusions}

This report provides a descriptive and visual summary of lava lake activity at the summit of Kîlauea Volcano, Hawai' $i$, during 2016. A synopsis of the activity is as follows:

- The summit eruption in 2016 consisted of continuous lava lake activity. The lake was $250 \times 190 \mathrm{~m}$ in size $\left(\sim 39,000 \mathrm{~m}^{2}\right)$, and was one of the largest lava lakes on Earth during 2016.

- The lake surface consisted of large crustal plates (on average about $60 \mathrm{~m}$ in the longest dimension) separated by narrow incandescent spreading zones.

- The lake motion was normally from north to south, but episodes of spattering could produce transient disruptions to the typical motion.
- Spattering took place most of the time but could shut down for episodes lasting several hours (driving gas pistoning). Seismic tremor at the summit was closely correlated with spattering intensity and gas emission rates.

- The Overlook crater was modified by unstable deposits of juvenile lava on the crater walls. This lava veneer commonly collapsed into the lake, triggering spattering, particularly during periods of summit deflation and lava level drops.

- Large collapses of the Overlook crater walls triggered several small explosive events that deposited spatter on the rim of Halema'uma' $u$ Crater, but these events did not threaten public areas.

- Lake level varied over several tens of meters, controlled both by magma reservoir pressure and, to a smaller degree, outgassing processes. High lava levels were associated with an increase in the frequency of small earthquakes in the upper East Rift Zone.

- The lake produced an outgassing plume with typical daily average $\mathrm{SO}_{2}$ emission rates of 1,000-8,000 t/d (mean=4,600 t/d). The plume was normally carried southwest in the trade winds, and produced volcanic air pollution (vog) affecting large portions of the island.

- The lake has been a major tourist attraction in Hawai' $\mathrm{i}$ Volcanoes National Park, and rising lake levels in 2016 provided frequent views of the lake from public viewing areas.

The summit eruption has provided new insights into lava lake dynamics and open-vent basaltic eruptions, including (1) the triggering of explosions by rockfalls (Orr and others, 2013), (2) the low density (and hence high gas content) of the lava lake (Carbone and others, 2013; Poland and Carbone, 2016), (3) the fact that the lake level acts as a piezometer of summit magma reservoir pressure (Patrick and others, 2015), (4) that gas pistoning in the lake is driven by shallow gas accumulation near the top of the lake (Patrick and others, 2016a), (5) the real-time modeling and forecasting of vog hazards (Businger and others, 2015), (6) the strong correlation between outgassing rates and seismic tremor (Kern and others, 2015; Nadeau and others, 2015; Patrick and others, 2016a), and (7) the recognition of slowly pulsing magma supply to the summit (Swanson and others, 2016).

Much remains to be learned about the summit eruption and lava lake. More frequent and precise measurements of lava lake level could provide new insights on gas dynamics in the lake. Analog and computational modeling may help link lake surface motion with convection dynamics within the lake. Gas accumulation within the lake has been inferred from lava level measurements and other indicators (Patrick and others, 2010, 2016a; Carbone and others, 2013), but the distribution of bubbles within the lake is still not known. It is unclear how bubble distribution changes during gas pistoning 
or as a result of changes in spattering and lake motion. Analog modeling, such as that performed by Spina and others (2016), could provide more insight on gas segregation, accumulation, and bubble coalescence in the lake. However, from a hazards perspective, the most pressing need for future research is a better understanding of the impact of the outgassing and vog on human health (Tam and others, 2016).

Two factors should aid in improving our understanding of the eruption and its hazards. First, if the eruption persists into the coming years, it will provide an even more robust, continuous dataset for formulating and testing hypotheses. Although the common steadiness of the activity is an advantage in many respects, the longer the eruption lasts the more likely we are to see additional "extreme" events, such as the March 2011 draining of the lake or the May 2015 rise and overflows, which are particularly instructive for revealing lake processes. Second, improving technology will allow the characterization of lake behavior in more detail. Higher resolution thermal cameras would provide finer precision in lake surface textures and temperatures. Continuous lava level measurements, either through a stereo-camera setup or other instrument, would allow better study of rapid, gas-driven processes in the lake. Overall, the lava lake in Halema'uma' $u$ provides an ideal venue for testing instruments and techniques that could be applied to other lava lakes or open-vent basaltic eruptions.

\section{Acknowledgments}

The entire HVO staff, along with many volunteers, contributed to monitoring the summit eruption, as well as the concurrent long-lived eruption on Kīlauea's East Rift Zone at $\mathrm{Pu}^{\prime} \mathrm{u}{ }^{\prime} \overline{\mathrm{O}}^{`} \overline{\mathrm{o}}$. We thank the U.S. National Park Service, the land manager for the area containing the summit eruption, for facilitating HVO work in the restricted areas of Hawai' $i$ Volcanoes National Park. We also thank Heather Wright and Ingrid Johanson for reviews, which improved the manuscript.

\section{References Cited}

Allard, P., Burton. M., Sawyer, G., and Bani, P., 2016, Degassing dynamics of basaltic lava lake at a top-ranking volatile emitter-Ambrym volcano, Vanuatu arc: Earth and Planetary Science Letters, v. 448, p. 69-80, doi: 10.1016/j. eps1.2016.05.014.

Allibone, R., Cronin, S.J., Charley, D.T., Neal, V.E., Stewart, R.B., and Oppenheimer, C., 2012, Dental fluorosis linked to degassing of Ambrym volcano, Vanuatu-A novel exposure pathway: Environmental Geochemistry and Health, v. 34, p. $155-170$.
Anderson, K., Poland, M., Johnson, J., and Miklius, A., 2015, Episodic deflation-inflation events at Kîlauea Volcano and implications for the shallow magma system, chap. 11 of Carey, R., Poland, M., Cayol, V., and Weis, D., eds., Hawaiian volcanism-From source to surface: American Geophysical Union Geophysical Monograph 208, p. $229-250$.

Anderson, S.W., LeWinter, A.L., Finnegan, D.C., Patrick, M.R., and Orr, T.R., 2014, Repeat terrestrial LiDAR scanning at Kīlauea Volcano reveals basaltic lava lake surface slope, structure and micro-pistoning [abs.]: American Geophysical Union, Fall meeting, abstract V43A4851.

Apple, R.A., 1987, Thomas A. Jaggar Jr. and the Hawaiian Volcano Observatory, chap. 61 of Decker, R.W., Wright, T.L., and Stauffer, P.H., eds., Volcanism in Hawaii: U.S. Geological Survey Professional Paper 1350, p. 1619-1644.

Barnie, T.D., Oppenheimer, C., and Pagli, C., 2016, Does the lava lake of Erta 'Ale volcano respond to regional magmatic and tectonic events? An investigation using Earth Observation data: Geological Society of London, Special Publications 420, p.181-208, doi: 10.1144/SP420.15.

Bevens, D., Takahashi, T.J., and Wright, T.L., 1988, The early serial publications of the Hawaiian Volcano Observatory: Hawaii Natural History Association, Hawaii National Park, vol. 2, $1273 \mathrm{p}$.

Brigham, W.T., 1909, The volcanoes of Kilauea and Mauna Loa on the Island of Hawaii-Their variously recorded history to the present time: Honolulu, HI, Bishop Museum Press, Memoirs of the Bernice Pauahi Bishop Museum, v. 2, no. 4, 222 p., plus plates.

Burgi, P-Y., Darrah, T.H., Tedesco, D., and Eymold, W.K., 2014, Dynamics of the Mount Nyiragongo lava lake: Journal of Geophysical Research, v. 119, p. 4106-4122, doi: 10.1002/2013JB010895.

Businger, S., Huff, R., Pattantyus, A., Horton, K., Sutton, A.J., Elias, T., and Cherubini, T., 2015, Observing and forecasting vog dispersion from Kilauea Volcano, Hawaii: Bulletin of the American Meteorological Society, v. 96, p. 1667-1686, doi: 10.1175/BAMS-D-14-00150.1.

Campion, R., 2014, New lava lake at Nyamuragira volcano revealed by combined ASTER and $\mathrm{OMI} \mathrm{SO}_{2}$ measurements: Geophysical Research Letters, v. 41, p. 7485-7492, doi: 10.1002/2014GL061808.

Carbone, D., Poland, M.P., Patrick, M.R., and Orr, T.R., 2013, Continuous gravity measurements reveal a low-density lava lake at Kîlauea Volcano, Hawai' $i$ : Earth Planetary Science Letters, v. 376, p. 178-185, doi: 10.1016/j.eps1.2013.06.024. 
Carey, R.J., Manga, M., Degruyter, W., Swanson, D., Houghton, B., Orr, T., and Patrick, M., 2012, Externally triggered renewed bubble nucleation in basaltic magmaThe 12 October 2008 eruption at Halema 'uma 'u Overlook vent, Kilauea Volcano, Hawai'i, USA: Journal of Geophysical Research B, Solid Earth, v. 117, B11202.

Carey, R.J., Swavely, L., Swanson, D.A., Houghton, B.F., Orr, T.R., Elias, T., and Sutton, A.J., 2015, Onset of a basaltic explosive eruption from Kilauea's summit in 2008, chap. 19 of Carey, R.J., Cayol, V., Poland, M., and Weis, D., eds., Hawaiian volcanoes-From source to surface: American Geophysical Union Geophysical Monograph 208, p. 421-437.

Cervelli, P.F., and Miklius, A., 2003, The shallow magmatic system of Kīlauea Volcano, in Heliker, C., Swanson, D.A., and Takahashi, T.J., eds., The $\mathrm{Pu}^{\prime} \mathrm{u}$ ' ${ }^{\circ}{ }^{‘} \overline{\mathrm{o}}-\mathrm{Kupaianaha}$ eruption of Kīlauea Volcano, Hawai' $i$-The first 20 years: U.S. Geological Survey Professional Paper 1676, p. $149-163$.

Chouet, B.A., and Dawson, P.B., 2013, Very long period conduit oscillations induced by rockfalls at Kīlauea Volcano, Hawaii: Journal of Geophysical Research Solid Earth, v. 118, p. 5352-5371, doi:10.1002/jgrb.50376.

Chouet, B.A., Dawson, P.B., James, M.R., and Lane, S.J., 2010, Seismic source mechanism of degassing bursts at Kîlauea Volcano, Hawaii-Results from waveform inversion in the 10-50 s band: Journal of Geophysical Research Solid Earth, v. 115, B09311, doi:10.1029/2009JB006661.

Cronin, S.J., and Sharp, D.S., 2002, Environmental impacts on health from continuous volcanic activity at Yasur (Tanna) and Ambrym, Vanuatu: International Journal of Environmental Health Research, v. 12, p. 109-123.

Dawson, P.B., Dietel, C., Chouet, B.A., Honma, K., Ohminato, T., and Okubo, P., 1998, Digitally telemetered broadband seismic network at Kīlauea Volcano, Hawaii: U.S. Geological Survey Open- File Report 98-108, 121 p.

Delmelle, P., 2003, Environmental impacts of tropospheric volcanic gas plumes, in Oppenheimer, C., Pyle, D.M., and Barclay, J., eds., Volcanic degassing: Geological Society, London, Special Publications, v. 213, p. 381-399.

Delmelle, P., Stix, J., Baxter, P.J., Garcia-Alvarez, J., and Barquero, J., 2002, Atmospheric dispersion, environmental effects and potential health hazard associated with the lowaltitude gas plume of Masaya volcano, Nicaragua: Bulletin of Volcanology, v. 64, p. 423-434.

Duffield, W.A., 1972, A naturally occurring model of global plate tectonics: Journal of Geophysical Research, v. 77, p. 2543-2555.
Dvorak, J., 2011, The origin of the Hawaiian Volcano Observatory: Physics Today, v. 64, no. 5, doi 10.1063/1.3592003.

Dvorak, J., 2016, The last volcano-A man, a romance, and the quest to understand nature's most magnificent fury: New York, Pegasus Books, 356 p.

Edmonds, M., Sides, I.R., Swanson, D.A., Werner, C., Martin, R.S., Mather, T.A., Herd, R.A., Jones, R.L., Mead, M.I., Sawyer, G., Roberts, T.J., Sutton, A.J., and Elias, T., 2013, Magma storage, transport and degassing during the 2008-10 summit eruption at Kilauea Volcano, Hawai ${ }^{1}$ : Geochimica et Cosmochimica Acta, v. 123, p. 284-301, doi: 10.1016/j. gca.2013.05.038.

Elias, T., and Sutton, A.J., 2012, Sulfur dioxide emission rates from Kīlauea volcano, Hawaii 2007-2010: U.S. Geological Survey Open-File Report 2012-1107, 37 p.

Elias, T., and Sutton, A.J., 2017, Volcanic air pollution hazards in Hawaii: U.S. Geological Survey Fact Sheet 2017-3017, 4 p., https://doi.org/10.3133/fs20173017.

Elias, T., Sutton, A.J., Businger, S., Horton, K., and Garbeil, H., 2016, From plume to public-Tracing the path from gas measurements to air quality forecasts in Hawai' i [abs.]: International Association of Volcanology and Chemistry of the Earth's Interior, Cities on Volcanoes 9 Conference, Puerto Varas, Chile, Nov. 20-25, 2016.

Elias, T., Sutton, A.J., Stokes, J.B., and Casadevall, T.J., 1998, Sulfur dioxide emission rates of Kilauea Volcano, Hawaii, 1979-1997: U.S. Geological Survey Open-File Report 98-462.

Ellis, W., 1825, A journal of a tour around Hawaii, the largest of the Sandwich Islands: Boston, Crocker and Brewster, $264 \mathrm{p}$.

Endo, E.T., and Murray, T., 1991, Real-time seismic amplitude measurement (RSAM) - A volcano monitoring and prediction tool: Bulletin of Volcanology, v. 53, p. 533-545.

Global Volcanism Program, 2016, Report on Masaya (Nicaragua), in Venzke, E., ed., Bulletin of the Global Volcanism Network: Smithsonian Institution, v. 41, no. 8.

Guffanti, M., Diefenbach, A.K., Ewert, J.W., Ramsey, D.W., Cervelli, P.F., and Schilling, S.P., 2010, Volcano-monitoring instrumentation in the United States, 2008: U.S. Geological Survey Open-File Report 2009-1165, 32-p. text plus Volcano-Monitoring Instrumentation Database, available online at https://pubs.usgs.gov/of/2009/1165.

Harris, A.J.L., Carniel, R., and Jones, J., 2005, Identification of variable convective regimes at Erta Ale lava lake: Journal of Volcanology and Geothermal Research, v. 142, p. 207-223, doi: 10.1016/j.jvolgeores.2004.11.011. 
Heliker, C., and Mattox, T.N., 2003, The first two decades of the Pu'u 'O'o-Kupaianaha eruption - Chronology and selected bibliography, in Heliker, C., Swanson, D.A., and Takahashi, T.J,. eds., The Pu'u 'O`o-Kupaianaha eruption of Kilauea Volcano, Hawai $\mathrm{i}$ - The first 20 years: U.S. Geological Survey Professional Paper 1676, p. 1-27.

Hon, K., Kauahikaua, J., Denlinger, R., and Mackay, K., 1994, Emplacement and inflation of pāhoehoe sheet flowsObservations and measurements of active lava flows on Kîlauea Volcano, Hawaii: Geological Society of America Bulletin, v. 106, p. 351-370.

Honolulu Advertiser Staff, 2008, USDA approves disaster declaration for vog damage: Honolulu Advertiser, July 30, 2008, accessed November 2017, at http:// the.honoluluadvertiser.com/article/2008/Jul/30/br/ hawaii80730062.html.

Horton, K., Garbeil, H., Sutton, A.J., Elias, T., and Businger, S., 2012, Early monitoring results from the Halema'uma' $u$ vog measurement and prediction FLYSPEC array [abs.]: American Geophysical Union Chapman Conference on Hawaiian Volcanoes-From Source to Surface, Waikoloa, HI, August 20-24, abstract TH-34, http://hilo.hawaii.edu/ kenhon/ HawaiiChapman/documents/1HawaiiChapmanAbstracts.pdf.

Houghton, B.F., Orr, T.R., Taddeucci, J., Gonnerman, H.M., Scarlato, P., Del Bello, P., Carey, R., and Patrick, M.R., 2014, The dynamics of prolonged low fountaining behavior at Halemaumau, Kîlauea [abs.]: American Geophysical Union, Fall meeting, abstract V23C-4803.

Houghton, B.F., Swanson, D.A., Carey, R.J., Rausch, J., and Sutton, A.J., 2011, Pigeonholing pyroclasts - Insights from the 19 March 2008 explosive eruption of Kîlauea Volcano: Geology, v. 39, p. 263-266, doi: 10.1130/G31509.1.

Houghton, B.F., Swanson, D.A., Raush, J., Carey, R.J., Fagents, S.A., and Orr, T.R., 2013, Pushing the Volcanic Explosivity Index to its limit and beyond - Constraints from exceptionally weak explosive eruptions at Kîlauea in 2008: Geology, v. 41, p. 627-630, doi: 10.1130/G34146.1.

Ishimine, Y., 2007, Measures taken by local officials against sulfur dioxide emissions from Miyakejima Volcano [abs.]: Cities on Volcanoes 5 Conference, Shimabara, Japan, Nov. 19-23, 2007, abstract 13-P-08. Poster available online at https://volcanoes. usgs.gov/vsc/file_mngr/file-166/06_CoV5poster.pdf.

Jaggar, T.A., 1917, Volcanological investigations at Kilauea: American Journal of Science, Fourth series, v. 44, p. 160-218.

Jaggar, T.A., 1947, Origin and development of craters: Geological Society of America Memoir 21, $508 \mathrm{p}$.

Jaggar, T.A., and Finch, R.H., 1924, The explosive eruption of Kîlauea in Hawaii, 1924: American Journal of Science, series 5, v. 8, p. 353-374.
Jensen, C., 2013, Gym, shelter rises: West Hawaii Today, November 3, 2013, accessed November 2017, at http:// westhawaiitoday.com/sections/news/local-news/gym-shelterrises.html.

Johnson, J.H., and Poland, M.P., 2013, Seismic detection of increased degassing before Kilauea's 2008 summit explosion: Nature Communications, v. 4, no. 1668, doi:10.1038/ ncomms2703.

Kern, C., Sutton, J., Elias, T., Lee, L., Kamibayashi, K., Antolik, L., and Werner, C., 2015, An automated $\mathrm{SO}_{2}$ camera system for continuous, real-time monitoring of gas emissions from Kīlauea Volcano's summit Overlook Crater: Journal of Volcanology and Geothermal Research, v. 300, p. 81-94, doi: 10.1016/j. jvolgeores.2014.12.004.

Kinoshita, W.T., Koyanagi, R.Y., Wright, T.L., and Fiske, R.S., 1969, Killauea Volcano-The 1967-68 summit eruption:

Science, v. 24, p. 459-468.

Lev, E., Ruprecht, P., Patrick, M., Oppenheimer, C., Peters, N., Spampinato, L., Perez, P.H., Unglert, K., and Barreyre, T., 2015, A rare window into magmatic conduit processes - Time series observations from active lava lakes [abs.]: American Geophysical Union, Fall meeting, abstract V51D-3060.

Longo, B.M., 2013, Adverse health effects associated with increased activity at Kilauea Volcano-A repeated population-based survey: ISRN Public Health, v. 2013, article 475962, 10 p., accessed November 2017, at http://dx.doi. org/10.1155/2013/475962.

Longo, B.M., Yang, W., Green, J.B., Crosby, F.L., and Crosby, V.L., 2010, Acute health effects associated with exposure to volcanic air pollution (vog) from increased activity at Kilauea Volcano in 2008: Journal of Toxicology and Environmental Health, Part A, v. 73, p. 1370-1381, doi: 10.1080/15287394.2010.497440.

Macdonald, G.A., Abbot, A.T., and Peterson, F.L., 1983, Volcanoes in the sea-The geology of Hawaii ( $2 \mathrm{~d}$ ed.): Honolulu, HI, University of Hawai'i Press, 517 p.

Martini, F., Tassi, F., Vaselli, O., Del Potro, R., Martinez, M., Van del Laat, R., and Fernandez, E., 2010, Geophysical, geochemical and geodetical signals of reawakening at Turrialba volcano (Costa Rica) after almost 150 years of quiescence: Journal of Volcanology and Geothermal Research, v. 198, p. 416-432, doi: 10.1016/j. jvolgeores.2010.09.021.

Mather, T.A., Witt, M.L., Pyle, D.M., Quayle, B.M., Aiuppa, A., Bagnato, E., Martin, R.S., Sims, K.W., Edmonds, M., Sutton, A.J., and Ilyinskaya, E., 2012, Halogens and trace metal emissions from the ongoing 2008 summit eruption of Kîlauea volcano, Hawaii: Geochimica et cosmochimica acta., v. 83, p. 292-323. 
Miklius, A., Cervelli, C., Sako, M., Lisowski, M., Owen, S., Segal, P., Foster, J., Kamibayashi, K., and Brooks, B., 2005, Global Positioning System measurements on the Island of Hawai' $i$-1997 through 2004: U.S. Geological Open-File Report 2005-1425, 48 p.

Moussallam, Y., Bani, P., Curtis, A., Barnie, T., Moussallam, M., Peters, N., Schipper, I., Aiuppa, A., Giudice, G., Amigo, A., Velasquez, G., and Cardona, C., 2016, Sustaining persistent lava lakes - Observations from high-resolution measurements at Villarrica volcano, Chile: Earth and Planetary Science Letters, v. 454, p. 237-247, doi: 10.1016/j.epsl.2016.09.012.

Nadeau, P.A., Werner, C.A., Waite, G.P., Carn, S.A., Brewer, I.D., Elias, T., Sutton, A.J., and Kern, C., 2015, Using $\mathrm{SO}_{2}$ camera imagery and seismicity to examine degassing and gas accumulation at Kīlauea Volcano, May 2010: Journal of Volcanology and Geothermal Research, v. 300, p. 70-80, doi:10.1016/j.jvolgeores.2014.12.005.

Okubo, P.G., Nakata, J.S., and Koyanagi, R.Y., 2014, The evolution of seismic monitoring systems at the Hawaiian Volcano Observatory, chap. 2 of Poland, M.P., Takahashi, T.J., Landowski, C.M., eds., Characteristics of Hawaiian volcanoes: U.S. Geological Survey Professional Paper 1801, p. 67-94.

Oppenheimer, C., and Yirgu, G., 2002, Thermal imaging of an active lava lake-Erta `Ale volcano, Ethiopia: International Journal of Remote Sensing, v. 23, no. 22, p. 4777-4782, doi: 10.1080/01431160110114637.

Oppenheimer, C., Lomakina, A.S., Kyle, P.R., Kingsbury, N.G., and Boichu, M., 2009, Pulsatory magma supply to a phonolite lava lake: Earth and Planetary Science Letters, v. 284, p. 392-398, doi: 10.1016/j.epsl.2009.04.043.

Orr, T.R., and Hobblit, R.P., 2008, A versatile time-lapse camera system developed by the Hawaiian Volcano Observatory for use at Kīlauea Volcano, Hawai'i: U.S. Geological Survey Scientific Investigations Report 2008-5117, 8 p.

Orr, T.R., Houghton, B.F., Taddeucci, J., Del Bello, E., Scarlato, P., and Patrick, M.R., 2014, The bubble's wake-Localized rebound of Kilauea's summit lava lake following minor bubble bursts [abs.]: American Geophysical Union, Fall meeting, abstract V41D-05.

Orr, T.R., Poland, M.P., Patrick, M.R., Thelen, W.A., Sutton, J., Elias, T., Thornber, C.T., Parcheta, C., and Wooten, K.M., 2015, Kìlauea's 5-9 March 2011 Kamoamoa fissure eruption and its relation to $30+$ years of activity from $\mathrm{Pu}^{\prime} \mathrm{u}$ ' ${ }^{`}{ }^{‘} \overline{\mathrm{o}}$, chap. 18 of Carey, R., Poland, M., Cayol, V., and Weis, D., eds., Hawaiian volcanism - From source to surface: American Geophysical Union Geophysical Monograph 208, p. 393-420.

Orr, T.R., and Rea, J.C., 2012, Time-lapse camera observations of gas piston activity at $\mathrm{Pu}^{\prime} \mathrm{u}$ ' $\overline{\mathrm{O}}^{`} \overline{\mathrm{o}}$, Kīlauea volcano, Hawai ${ }^{‘} \mathrm{i}$ : Bulletin of Volcanology, v. 74, p. 2353-2362, doi: 10.1007/ s00445-012-0667-0.
Orr, T.R., Thelen, W.A., Patrick, M.R., Swanson, D.A., and Wilson, D.C., 2013, Explosive eruptions triggered by rockfalls at Kīlauea Volcano, Hawai'i: Geology, v. 41, p. 207-210, doi: 10.1130/G33564.1.

Orr, T.R., Zoeller, M.H., Patrick, M.R, and DeSmither, L.G., 2017, GIS shapefiles for Kîlauea's episode 61g lava flow, $\mathrm{Pu}^{\prime} \mathrm{u}^{\prime} \overline{\mathrm{O}}^{‘}$ ō eruption-May 2016 to May 2017: U.S. Geological Survey data release, accessed November 2017, at https://doi.org/10.5066/F7DN43XR.

Patrick, M.R., Anderson, K.R., Poland, M.P., Orr, T., and Swanson, D., 2015, Lava lake level as a gauge of magma reservoir pressure and eruptive hazard: Geology, v. 43, p. 831-834, doi: 10.1130/G36896.1.

Patrick, M.R., and Orr, T., 2018, Operational tracking of lava lake surface motion at Kīlauea Volcano, Hawai' ${ }^{i}$,: U.S. Geological Survey Techniques and Methods 13-A3, 12 p., https://doi.org/10.3133/tm13A3.

Patrick, M.R., Orr, T., Fisher, G., Trusdell, F., and Kauahikaua, J., 2017, Thermal mapping of a pahoehoe lava flow, Kilauea Volcano: Journal of Volcanology and Geothermal Research, v. 332, p. 71-87, accessed November 2017, at http://dx.doi. org/10.1016/j.jvolgeores.2016.12.007.

Patrick, M.R., Orr, T., Lee, L., Antolik, L., and Kamibayashi, K., 2014, Continuous monitoring of Hawaiian volcanoes with thermal cameras: Journal of Applied Volcanology, v. 3, no. 1, doi: 10.1186/2191-5040-3-1.

Patrick, M.R., Orr, T., Sutton, A.J., Elias, T., and Swanson, D., 2013, The first five years of Kîlauea's summit eruption in Halema'uma'u, 2008-2013: U.S. Geological Survey Fact Sheet 2013-3116, 4 p.

Patrick, M.R., Orr, T., Sutton, A.J., Lev, E., and Fee, D., 2016a, Shallowly driven fluctuations in lava lake outgassing, Kīlauea Volcano, Hawai' $i$ : Earth and Planetary Science Letters, v. 433, p. 326-338, doi: 10.1016/j.eps1.2015.10.052.

Patrick, M.R., Orr, T., Swanson, D.A., and Lev, E., 2016c, Shallow and deep controls on lava lake surface motion at Kîlauea Volcano: Journal of Volcanology and Geothermal Research, v. 328, p. 247-261, doi: 10.1016/j.jvolgeores.2016.11.010.

Patrick, M.R., Orr, T., Wilson, D., Dow, D., and Freeman, R., 2011b, Cyclic spattering, seismic tremor, and surface fluctuation within a perched lava channel, Kīlauea Volcano: Bulletin of Volcanology, v. 73, p. 639-653, doi: 10.1007/ s00445-010-0431-2.

Patrick, M.R., Orr, T.R., Wilson, D., Sutton, A.J., Elias, T., Fee, D., and Nadeau, P.A., 2010, Evidence for gas accumulation beneath the surface crust driving cyclic rise and fall of the lava surface at Halema' uma'u, Kîlauea Volcano [abs.]: American Geophysical Union, Fall meeting, abstract V21C-2339. 
Patrick, M.R., Swanson, D.A., and Orr, T., 2016b, Automated tracking of lava lake level using thermal images at Kîlauea Volcano, Hawai'i: Journal of Applied Volcanology, v. 5, no. 6, doi: 10.1186/s13617-016-0047-0.

Patrick, M., Wilson, D., Fee, D., Orr, T., and Swanson, D., 2011a, Shallow degassing events as a trigger for very-long-period seismicity at Kîlauea Volcano, Hawai' 1 : Bulletin of Volcanology, v. 73, p. 1179-1186, doi:10.1007/s00445-011-0475-y.

Patrick, M.R., Wilson, D., Fee, D., Orr, T., Swanson, D., Sutton, A.J., and Elias, T., 2008, Gas-pistoning associated with the 2008 summit eruption of Kīlauea Volcano, Hawai'i: American Geophysical Union, Fall meeting supplemental, abstract V51E-2082.

Perret, F.A., 1913a, The lava fountains of Kīlauea: American Journal of Science, series 4, v. 35, p. 139-148.

Perret, F.A., 1913b, The circulatory system in the Halemaumau lake during the summer of 1911: American Journal of Science, series 4, v. 35, p. 337-349.

Perret, F.A., 1913c, The floating islands of Halema 'uma 'u: American Journal of Science, series 4, v. 35, p. 273-282.

Peters, N., Oppenheimer, C., Killingsworth, D.R., Frechette, J., and Kyle, P., 2014, Correlation of cycles in lava lake motion and degassing at Erebus Volcano, Antarctica: Geochemistry, Geophysics, Geosystems, v. 15, no. 8, p. 3244-3257, doi:10.1002/2014GC005399.

Poland, M., Orr, T.R., Kauahikaua, J.P., Brantley, S.R., Babb, J.L., Patrick, M.R., Neal, C.A., Anderson, K.R., Antolik, L., Burgess, M., Elias, T., Fuke, S., Fukunaga, P., Johanson, I.A., Kagimoto, M., Kamibayashi, K., Lee, L., Miklius, A., Million, W., Moniz, C., Okubo, P.G., Sutton, A.J., Takahashi, T.J., Thelen, W.A., Tollett, W., and Trusdell, F.A., 2016, The 2014-2015 Pahoa lava flow crisis at Kilauea Volcano, Hawai $i$ - Disaster avoided and lessons learned: GSA Today, v. 26, p. 4-10, accessed November 2017, at http://www.geosociety.org/gsatoday/archive/26/2/pdf/ i1052-5173-26-2-4.pdf.

Poland, M.P., and Carbone, D., 2016, Insights into shallow magmatic processes at Kilauea Volcano, Hawai i, from a multiyear continuous gravity time series: Journal of Geophysical Research, v. 121, p. 5477-5492, doi: 10.1002/2016JB013057.

Poland, M.P., Miklius, A.M., Sutton, A.J., and Thornber, C.R., 2012, A mantle-driven surge in magma supply to Kîlauea Volcano during 2003-2007: Nature Geoscience, v. 5, p. 295-300, doi: 10.1038/ngeo1426.

Rowe, M.C., Thornber, C.R., and Orr, T.R., 2015, Primitive components, crustal assimilation, and magmatic degassing during the early 2008 Kîlauea summit eruptive activity, chap. 20 of Carey R.J., Cayol, V., Poland, M., and Weis, D., eds., Hawaiian volcanoes-From source to surface: American Geophysical Union Monograph 208, p. 439-455.
Sawyer, G.M., Carn, S.A., Tsanev, V.I., Oppenheimer, C., and Burton, M., 2008, Investigation into magma degassing at Nyiragongo volcano, Democratic Republic of the Congo: Geochemistry, Geophysics, Geosystems, v. 9, Q02017, doi:10.1029/2007GC001829.

Spampinato, L., Ganci, G., Hernandez, P.A., Calvo, D., Tedesco, D., Perez, N.M., Calvari, S., Del Negro, C., and Yalire, M.M., 2013, Thermal insights into the dynamics of Nyiragongo lava lake from ground and satellite measurements: Journal of Geophysical Research, v. 118, p. 5771-5784, doi: 10.1002/2013JB010520.

Spampinato, L., Oppenheimer, C., Calvari, S., Cannata, A., and Montalto, P., 2008, Lava lake surface characterization by thermal imaging - Erta 'Ale volcano (Ethiopia): Geochemistry, Geophysics, Geosystems, v. 9, Q12008, doi:10.1029/2008GC002164.

Sparks, R.S.J., Bursik, M.I., Carey, S.N., Gilbert, J., Glaze, L.S., Sigurdsson, H., and Woods, A., 1997, Volcanic plumes: Chichester, Wiley, 590 p.

Spina, L., Scheu, B., Cimarelli, C., Arciniega-Ceballos, A., and Dingwell, D.B., 2016, Time scales of foam stability in shallow conduit - Insights from analogue experiments: Geochemistry, Geophysics, Geosystems, v. 17, p. 4179-4194, doi: 10.1002/2016GC006455.

State of Hawaii Department of Health, 2016, Notification of exceedance of a national ambient air quality standard: State of Hawaii Department of Health web page, accessed June 1, 2017, at http://health.hawaii.gov/cab/notification-of-exceedance-of-anational-ambient-air-quality-standard/.

Stovall, W.K., Houghton, B.F., and Harris, A.J.L., 2009, A frozen record of density-driven crustal overturn in lava lakes - The example of Kilauea Iki 1959: Bulletin of Volcanology, v. 71, p. 313-318, doi: 10.1007/s00445-008-0225-y.

Sutton, A.J., and Elias, T., 2014, One hundred volatile years of volcanic gas studies at the Hawaiian Volcano Observatory, chap. 7 of Poland, M.P., Takahashi, T.J., and Landowski, C.M., eds., Characteristics of Hawaiian volcanoes: U.S. Geological Survey Professional Paper 1801, p. 295-320.

Sutton, A.J., and Elias, T., 2016, Kîlauea's double eruption, 2008-2016 - Volatile budget and associated hazards [abs.]: American Geophysical Union, Fall meeting, abstract V53A-3074.

Sutton, A.J., Elias, T., Garbeil, H., Horton, K.A., Kern, C., Oppenheimer, C., Orr, T.R., Patrick, M.R., Poland, M.P., Thelen, W.A., and Werner, C.A., 2013, Techniques for constraining short term eruptive processes at Kilauea's Overlook Vent [abs.]: American Geophysical Union, Fall meeting, abstract V43B-2876. 
Sutton, A.J., Elias, T., and Kauahikaua, J., 2003, Lava effusion rates for the $\mathrm{Pu}^{\prime} \mathrm{u}$ ' $\overline{\mathrm{O}}^{‘} \overline{\mathrm{o}}-\mathrm{K}$ Kupaianaha eruption derived from $\mathrm{SO}_{2}$ emissions and very low frequency (VLF) measurements, in Heliker, C., Swanson, D.A., and Takahashi, T.J., The Pu'u 'Ō'o-Kupaianaha eruption of Kilauea Volcano, Hawai' ${ }^{\prime}$-The first 20 years: U.S. Geological Survey Professional Paper 1676, p. $137-148$.

Sutton, J., Elias, T., Hendley, J.W., and Stauffer, P.H., 1997, Volcanic air pollution-A hazard in Hawai'i: U.S. Geological Survey Fact Sheet 169-97, 2 p.

Swanson, D., Wooten, K., and Orr, T., 2009, Buckets of ash track tephra flux from Halema'uma'u Crater, Hawai'i: Eos, Transactions, American Geophysical Union, v. 90, p. 427-427, doi:10.1029/2009EO460003.

Swanson, D.A., 1973, Pāhoehoe flows from the 1969-1971 Mauna Ulu eruption, Kīlauea volcano, Hawaii: Geological Society of America Bulletin, v. 84, p. 615-626.

Swanson, D.A., Duffield, W.A., Jackson, D.B., and Peterson, D.W., 1979, Chronological narrative of the 1969-71 Mauna Ulu eruption of Kỉlauea volcano, Hawaii: U.S. Geological Survey Professional Paper 1056, 55 p.

Swanson, D.A., Orr, T., and Patrick, M.R., 2016, Changes in the mass flux of tephra from the lava lake in Overlook crater, Kilauea Volcano, Hawai i [abs.]: American Geophysical Union, Fall meeting, abstract V43A-3122.

Tam, E., Miike, R., Labrenz, S., Sutton, A.J., Elias, T., Davis, J., Chen, Y-L., Tantisira, K., Dockery, D., and Avol, E., 2016, Volcanic air pollution over the Island of Hawai i-Emissions, dispersal, and composition. Association with respiratory systems and lung function in Hawai' i Island school children: Environment International, v. 92-93, p. 543-552, doi: 10.1016/j.envint.2016.03.025.
Thelen, W., and Patrick, M.R., 2012, A conceptual model for recent seismicity on Kilauea's upper east rift zone [abs.]: American Geophysical Union Chapman Conference on Hawaiian Volcanoes - From Source to Surface, Waikoloa, HI, August 20-24, abstract TU-35.

Thornber, C.R., Orr, T.R., Heliker, C., and Hoblitt, R.P., 2015, Petrologic testament to changes in shallow magma storage and transport during $30+$ years of recharge and eruption at Kilauea Volcano, Hawai i, chap. 8 of Carey, R., Cayol, V., Poland, M., and Weis, D., eds., Hawaiian volcanoes-From source to surface: American Geophysical Union Monograph 208, p. 147-188.

Tilling, R.I., Kauahikaua, J.P., Brantley, S.R., and Neal, C.A., 2014, The Hawaiian Volcano Observatory-A natural laboratory for studying basaltic volcanism, chap. 1 of Poland, M.P., Takahashi, T.J., and Landowski, C.M., eds., Characteristics of Hawaiian volcanoes: U.S. Geological Survey Professional Paper 1801, p. 1-64.

van Manen, S.M., 2014a, Perception of a chronic volcanic hazard-Persistent degassing at Masaya volcano, Nicaragua: Journal of Applied Volcanology, v. 3, no. 9, doi: 10.1186/ s13617-014-0009-3.

van Manen, S.M., 2014b, Hazard and risk perception at Turrialba volcano (Costa Rica); implications for disaster risk management: Applied Geography, v. 50, p. 63-73, doi: 10.1016/j.apgeog.2014.02.004.

Wilson, D., Elias, T., Orr, T., Patrick, M., Sutton, A.J., and Swanson, D., 2008, Small explosion from new vent at Kīlauea's summit: Eos, v. 89, p. 203, doi:10.1029/2008EO220003.

Wooten, K.M., Thornber, C.R., Orr, T.R., Ellis, J.F., and Trusdell, F.A., 2009, Catalog of tephra samples from Kîlauea's summit eruption, March-December 2008: U.S. Geological Survey Open-File Report 2009-1134, 26 p. [Also available at https:// pubs.usgs.gov/of/2009/1134/.] 


\section{Glossary}

A4 An ash collection bucket near the rim of Halema'uma'u Crater about $200 \mathrm{~m}$ west of the lava lake (fig. 2). This spot is a common site for observing the lava lake, and is one of the few locations with reliable views of the SE sink.

Dl event Abbreviation of deflation-inflation event. DI events are cycles of magma reservoir pressure that commonly occur at the summit of Kîlauea Volcano, and are best observed in summit tiltmeters (such as at station UWE, see below). Increasing values of radial tilt (along an azimuth of $327^{\circ}$ ) at UWE correspond to inflation of the magma reservoir, and decreasing values correspond to deflation. DI events are relevant to the summit eruption because they are associated with cycles of lava level change. Deflation corresponds with a dropping lava level, and inflation with lava level rise.

Halema'uma'u Overlook Former public viewing platform, enclosed by wooden fencing, situated on the southeast rim of Halema'uma'u Crater (fig. 2). The Overlook crater formed in 2008 directly below this overlook. The Halema'uma'u Overlook has been struck by blocks and spatter in several explosive events since the current summit eruption began, and has been closed to the public since February 2008. The Halema'uma'u Overlook is the most common location on the Halema'uma'u Crater rim for Hawaiian Volcano Observatory geologists to make visual observations of the lava lake.

HMcam A camera situated at the Halema'uma'u Overlook that provides one of the best views of the lake (fig. 2). The camera acquires in a nearinfrared mode, which provides improved views through the volcanic fume. In the near-infrared mode the images are shown as grayscale.
HTcam A longwave thermal infrared camera situated about $80 \mathrm{~m}$ southwest of the Halema'uma'u Overlook (fig. 2).

Jaggar Museum/overlook Jaggar Museum is located on the northern rim of Killauea Caldera, and is attached to the Hawaiian Volcano Observatory buildings (fig. 1). In front of the museum is a public viewing area (Jaggar Museum overlook) that is currently the best location for the public to view the Overlook crater and lava lake.

Overlook crater The informal name given to the crater formed on March 19, 2008, at the opening of the current summit eruption. The Overlook crater is in the southeast portion of Halema'uma' $u$ Crater directly below the Halema 'uma'u Overlook (fig. 1). The active lava lake is contained within the Overlook crater. When the crater formed on March 19, 2008, it was $35 \mathrm{~m}$ wide. By late 2016 the crater had enlarged to $250 \times 190 \mathrm{~m}$.

SE (southeast) sink An area along the southeastern margin of the lava lake that is often spattering (fig. 2). This site is the most common spattering area in the lake. When spattering is present it is also an area of enhanced downwelling of surface crust. The spattering in this area often builds a grotto of solidified spatter.

Spattering/nonspattering regimes In 2016 the lake was spattering most of the time (spattering regime), with one or more spattering sites active. Occasionally, spattering would shut down and the lake would switch to a nonspattering regime. These nonspattering regimes could last for several hours, and normally corresponded with the lake level abruptly rising several meters in a process called "gas pistoning".

UWE A tiltmeter located near the Hawaiian Volcano Observatory on the north rim of Kîlauea Caldera (fig. 1). 
Back cover. Asymmetric spreading involves one plate moving rapidly away from a more slowly moving plate. Photograph taken November 26, 2016
Menlo Park Publishing Service Center, California

Manuscript approved for publication January 11, 2018 Edited by Katherine Jacques

Layout and design by Cory Hurd 


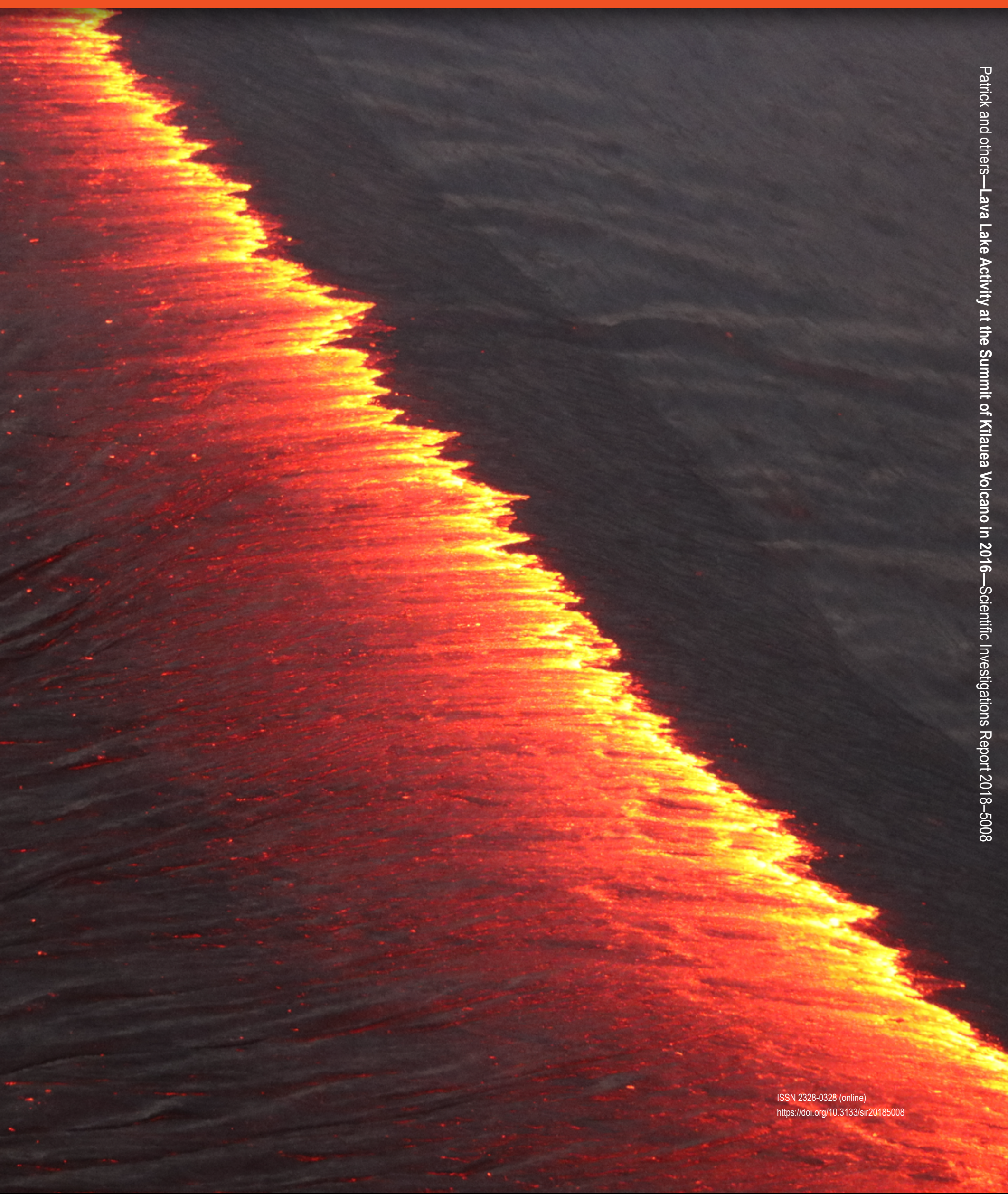

